Research Article

\title{
Comparison of Uplift Capacity and Nonlinear Failure Surfaces of Single-Belled Anchor in Homogeneous and Layered Sand Deposits
}

\author{
Tanaya Deb $\mathbb{1}^{1}$ and Sujit Kumar Pal ${ }^{2}$ \\ ${ }^{1}$ Research Scholar, Department of Civil Engineering, NIT Agartala, Agartala, Tripura, India \\ ${ }^{2}$ Associate Professor, Department of Civil Engineering, NIT Agartala, Agartala, Tripura, India \\ Correspondence should be addressed to Tanaya Deb; debtanaya88@gmail.com
}

Received 10 October 2018; Accepted 11 March 2019; Published 16 May 2019

Guest Editor: Michel Arrigoni

Copyright (C) 2019 Tanaya Deb and Sujit Kumar Pal. This is an open access article distributed under the Creative Commons Attribution License, which permits unrestricted use, distribution, and reproduction in any medium, provided the original work is properly cited.

This experimental study explains the contribution of embedment ratios, diameter ratios, and bell angles to uplift capacities of single-belled anchors and formation of nonlinear failure surfaces in homogeneous and layered sand deposits. Uplift capacities in both types of sand deposits are increased with higher embedment ratios, lesser diameter ratios, and bell angles. Uplift capacities are higher in layered sand deposit in comparison with homogeneous sand deposit for the same model. Analytical uplift capacities are predicted by the horizontal slice method based on observed failure surfaces. A comparative discussion is made on nonlinear failure surfaces as well as analytical uplift capacities in reference to aforementioned parameters for the variation in sand deposits. The $45^{\circ}$ and $63^{\circ}$ belled anchors are more effective as uplift-resistant structures than $72^{\circ}$ anchors in both types of sand deposits. Out of 36 analytical data on homogeneous sand and 33 analytical data on layered sand, $94.45 \%$ data are within the range of +08.51 to $-10.70 \%$ and $100 \%$ data are within the range of +10.47 to $-10.72 \%$, respectively, with respect to the experimental uplift capacities. Four numbers of multiple linear regression models have been developed by observed breakout factors to eliminate the size effect, so the newly developed models are suitable for actual engineering to compare with prototype tests within the suggested imitation of values of variable parameters.

\section{Introduction}

For radar tower, television line tower, power pole, roadside sign posts, and outdoor sign pools, imbalance horizontal forces mainly due to severe wind velocity and resultant uplift load are more than their self-weight. Peck et al. [1] reported that piles are often used specially to resist tensile forces beneath several common types of structures such as towers, gas storage tanks, and tall stacks; beneath such structures, the tensile forces are always caused by the moment due to wind. In such structures, the expected uplift load and overturning moments are basic design considerations to ascertain their types, shapes, and sizes. Belled anchor piles may be attractive and economy-friendly alternative to resist resultant pull-out forces in foundation design, but its uplift capacity has yet not been fully investigated. The uplift capacity is influenced by embedment depths, sizes of diameter, and bell angles as observed by Dickin et al. [2-8], but these studies are carried out on homogeneous sand only. Few field tests on belled anchors were reported by Adams and Radhakrishna [9] and Ismael and Kylm [10]. The experimental, numerical, and mathematical studies were also been conducted on embedment depth and different sizes of plate anchors by Meyerhof et al. [11-20].

The behaviour of anchors in layered sand was experimentally investigated by Bouazza and Finlay [21] on laboratory models. Kumar [22] conducted a numerical study on uplift resistance of circular and strip anchor where failure mechanism was explained by velocity hydrograph. Sakai and Tanaka [23] presented pictorial view of failure mechanism in two-layered sand, where medium dense and loose sands were overlying dense sand and vice versa. But these studies are performed on plate anchors only. Till the 
date, studies on the uplift behaviour as well as nonlinear failure behaviour on belled anchors in higher-dense sand overlying lesser-dense sand have yet been lacking.

In all the available studies conducted on plate anchors in homogeneous sand, it had been well documented that uplift capacity is derived by the combination of weight of breakout sand wedge and mobilized shear along failure surfaces $[12,24-28]$. The study on analytical net uplift capacity of belled anchor in layered sand is still lacking.

Linear failure surface having slip surface at angle $\phi / 2$ with vertical $[13,15,29], \phi$ with vertical [18], and $\psi$ with vertical [29] were documented. Meyerhof and Adams [11] suggested that slip surface was pyramidal shaped and initiates from circular anchor base, making angle within the range of $\phi / 2$ to $\phi / 4$ in dense sand and cylindrical shaped failure in loose sand. Ghaly et al. [30] in their analysis investigated that the failure wedge had the shape of truncated cone around shallow and transition anchor, and the cone angle made with vertical was up to $(2 / 3) \phi$. Balla [12] first introduced nonlinear failure surface initiated tangentially from edge of horizontal plate anchor which terminated at ground surface making angle of $\left(45^{\circ}-\phi / 2\right)$ in dense sand, and Chattopadhyay and Pise [26] used the same boundary condition as established by Balla [12]. Saran et al. [31] used hyperbolic stress-strain relationship of soil element and predicted that formation of breakout wedge was linear in shape. Ilamparuthi and Muthukrisnaiah [32] and Ilamparuthi et al. [33] experimentally reported that, around plate anchor (half-cut flat and curved circular models which were semicylindrical in shape), the failure surface originated making an angle of $(\phi / 2 \pm 2)^{\circ}$ with edge of anchor base. But these studies are performed on plate anchors in homogeneous sand media only, and studies on the nonlinear failure pattern around belled anchors have yet been very limited.

The existing literatures are having dearth of data on uplift capacity as well as predictive mathematical models are insufficient to provide a clear understanding on the comparison of uplift behaviour and actual pattern of failure surface around belled anchors due to changes in sand strata and different parameters.

\section{Failure Mechanism under Uplift Loading}

At the initial stage with the application of uplift loading, the total stress beneath the anchor base starts to gradually decrease and simultaneously there is gradual increase of total stress just above the anchor base with upward movement of anchor; this phenomenon continues and lasts long up to failure. In this present study, it is observed that, at the first stage of pulling, the sand at the most neighbouring zone of anchor base move along with the anchor and simultaneously there is initiation of cavity below the anchor base. Saeedy [27] explained that sand above the anchor started to be compressed with initial uplift and degree of compression of locked up sand above the anchor base was dependent on state of stress that helps in mobilization of shear strength and continues to be compressed up to the verge of failure. Within the compressed zone for locking up of sands, the significant factors are dilatancy of sand [14] and higher interlocking among the sand particles within the failure zone [32].

With continuous pulling, the shear stress level in sand near the anchor base increased gradually to reach shear strength and simultaneously the cavity is expanded. The slip surfaces have started from the anchor base and progressively migrate above the anchor base towards sand surface with more lateral spreading. Kumar [22] stated that failure wedge development occurred at that velocity as that of the upward velocity of anchor.

At the collapsed stage, it is noticed that, when the displaced sand around the base begin to flow downward to fill the cavity, simultaneously emerging failure surface reaches the sand surface following a nonlinear path, and it is due to the fact that (i) at plastic stage, shear strength is fully mobilized along failure surface and (ii) on the verge of failure, tension cracks are produced in disturbed soil around the base. In the present study, it has been observed that the failure wedge once generated remains unchanged even after further pulling and the domain outside of failure surface remains in rest position. The pulling is sustained after the failure indicated by the proving ring till the sand particles around the base of models move downward to fill up the cavity which is a fully collapsed stage. Matsuo [24] reported that, due to uplift of anchor, earth pressure within the wedge altered from semiactive condition to passive condition. Failure surface mechanism in homogeneous sand deposit was reported by Dickin et al. $[3,8]$ by using semicylindrical modelling. Sakai and Tanaka [23] explained that development of shear band indicated the localized deformation in layered sand. In this study, similar type of failure mechanism is observed for both the types of sand deposits.

\section{Objectives of the Present Study}

The present study aims to explore the comparison in the uplift behaviour of 3D belled anchor models and formation of respective failure surfaces on both the sides of $2 \mathrm{D}$ panels in homogeneous and layered buried sand with variation in several embedment ratios and anchor characteristics on the basis of experimental study. The present study has anticipated analytical uplift capacity, i.e., combination of dead weight of breakout wedge and mobilized shear based on horizontal slice method using observed failure surfaces. The comparison in nonlinear failure surfaces as well as analytical uplift capacities are correlated with comparison of experimental uplift capacity values in same model based on sand types. The analytical uplift capacities are compared with the experimental values, and predicted errors are reported based on experimental data. To predict breakout factors in both homogeneous and layered sand deposits, multiple linear regression models are developed and these are compared with breakout factor of present study and very few previous data.

\section{Materials, Models, and Testing Procedure}

4.1. Sand, Model Anchors, and Testing Tank. Two different types of dry sands collected from the local market are used to 
represent the layered foundation media in the present study, and these are designated as sand I $\left(S_{\mathrm{I}}\right)$ and sand II $\left(S_{\mathrm{II}}\right)$. In layered sand deposit, $S_{\text {II }}$ is overlying $S_{\text {I }}$, hence it is designated as $S_{\mathrm{II}} / S_{\mathrm{I}}$. Figure 1 shows the grain size distribution curve of sand samples. The physical and engineering properties are presented in Table 1. In Table 1, it is observed that $\gamma$ and $\phi$ values of $S_{\text {II }}$ are higher than those of $S_{\text {I }}$, so $S_{\text {II }}$ is stronger than $S_{\mathrm{I}}$ in the present test condition.

The shaft and bell portion of the bell anchor is fabricated from solid rounded bar, and these two parts are welded internally. The diameter of shaft is kept constant at $26 \mathrm{~mm}$. The hollow 2D panel anchors are fabricated from $1 \mathrm{~mm}$ thick steel plates, and shaft and bell thickness are same as shaft and bell diameter of 3D models. The heights of both types of models are fixed at $650 \mathrm{~mm}$. The 2D panels are $590 \pm 2.5 \mathrm{~mm}$ in length. The identifications of 3D model and 2D panel along with their detail geometric dimensions are presented in Table 2 (column (i) to (vi)). At the top of all 3D models and the centre of the length of $2 \mathrm{D}$ panels, a small hollow cylindrical arrangement is welded with internal grooving to hold the proving ring gently. Near to the top of cylindrical arrangement, two numbers of horizontally projected short steel strips are welded at $180^{\circ}$ to each other to hold the couple of dial gauges gently.

The inner dimensions of testing tank is $700 \mathrm{~mm}(\mathrm{l}) \times 600$ (w) $\mathrm{mm}$ in plan area and $700 \mathrm{~mm}$ in height and supported by steel frame. Its four sides are enclosed by pieces of plaxi-glass of $12 \mathrm{~mm}$ thick, and these are frictionless. Vertical steel stiffeners are joined with frame by welding, and sheets of plaxi-glass are bolted with stiffeners and a frame to prevent outward deflection. The testing tank size is sufficient to be free from boundary effects.

4.2. Sand Bed Preparation for $3 D$ Models and $2 D$ Panels. Prior to the preparation of foundation media $S_{\mathrm{I}}$ and $S_{\mathrm{II}} / S_{\mathrm{I}}$, first a $10 \mathrm{~mm}$ thick compacted sand bed is properly finished with horizontal surface to avoid eccentricity prior to install 3D model and 2D panel over the bed. The values of $L$ and $L /$ $D_{\mathrm{b}}$ are explained in details in Table 2 (column (vii) and (viii)) for models installed in homogeneous sand deposit $\left(S_{\mathrm{I}}\right)$. In layered sand deposit, $S_{\mathrm{I}}$ of constant thickness $\left(L_{\mathrm{I}}\right)$ of $168 \mathrm{~mm}$ is underlying $S_{\text {II }}$. Over $S_{\mathrm{I}}, S_{\text {II }}$ is poured for rest of the predetermined height $\left(L_{\mathrm{II}}\right)$ to attain desired embedment ratio. The ratios of $L_{\mathrm{II}} / L$ and $L_{\mathrm{I}} / L$ are presented in Table 3 (column (v) and (vi)). The placement density of $S_{\mathrm{I}}$ and $S_{\mathrm{II}}$ is achieved by raining technique $[2,21]$, and height of free fall is fixed to be $700 \mathrm{~mm}$ in both the cases, and a soil tray is used manually to fill the testing tank. The plot of reproduced density vs. calibrated height of fall is presented in Figure 2. The regularity of sand density is checked by placing few wooden cubes of $80 \mathrm{cc}$ in the corners of model tank within both deposits and deviation in density observed to be $\pm 1 \%$ only.

To study the failure surfaces on both the sides of $2 \mathrm{D}$ panels in $S_{\text {II }} / S_{\text {I }}$ media, successive layers of $3 \mathrm{~mm}$ thick dyed (i.e., red colour) and $18 \mathrm{~mm}$ thick nondyed (i.e., natural colour) sand $S_{\mathrm{I}}$ is poured up to height of $168 \mathrm{~mm}$, and overlying deposit of $S_{\text {II }}$ is similarly prepared by using dyed (i.e., green colour) and non-dyed sand (i.e., natural colour) maintaining the same thickness. The homogeneous sand bed on both the sides of $2 \mathrm{D}$

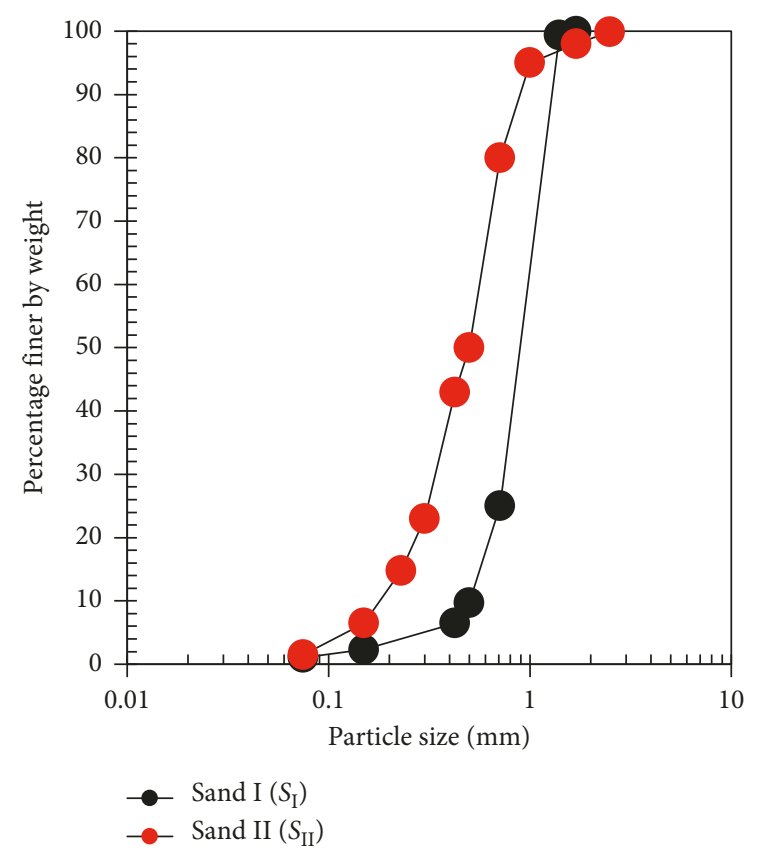

FIGURE 1: Grain size distribution for sand I $\left(S_{\mathrm{I}}\right)$ and sand II $\left(S_{\text {II }}\right)$.

Table 1: Properties of sand I $\left(S_{\mathrm{I}}\right)$ and sand II $\left(S_{\mathrm{II}}\right)$.

\begin{tabular}{|c|c|c|}
\hline \multirow{2}{*}{ Physical properties } & \multicolumn{2}{|c|}{ Test results } \\
\hline & $S_{\text {I }}$ & $S_{\text {II }}$ \\
\hline Medium sand, 2 to $0.425 \mathrm{~mm}(\%)$ & 93.50 & 77.50 \\
\hline Fine sand, 0.425 to $0.075 \mathrm{~mm}(\%)$ & 6.50 & 23.00 \\
\hline Silt and clay, 0.075 to $0.002 \mathrm{~mm}(\%)$ & 1.05 & 1.50 \\
\hline Effective grain size, $D_{10}(\mathrm{~mm})$ & 0.71 & 0.23 \\
\hline Average grain size, $D_{50}(\mathrm{~mm})$ & 0.93 & 0.65 \\
\hline Coefficient of curvature, $C_{\mathrm{c}}$ & 0.91 & 1.33 \\
\hline Coefficient of uniformity, $C_{\mathrm{u}}$ & 1.00 & 3.26 \\
\hline Sand classification as per USCS & SP & SW \\
\hline Specific gravity, $G_{s}$ & 2.67 & 2.69 \\
\hline Minimum void ratio, $e_{\min }$ & 0.63 & 0.49 \\
\hline Maximum void ratio, $e_{\max }$ & 0.88 & 0.79 \\
\hline Void ratio at placement density, $e_{\text {exptl. }}$ & 0.71 & 0.58 \\
\hline Minimum dry density, $\gamma_{\min }\left(\mathrm{kN} / \mathrm{m}^{3}\right)$ & 14.20 & 15.00 \\
\hline Maximum dry density, $\gamma_{\max }\left(\mathrm{kN} / \mathrm{m}^{3}\right)$ & 16.50 & 18.20 \\
\hline Placement dry density, $\gamma\left(\mathrm{kN} / \mathrm{m}^{3}\right)$ & 15.60 & 16.90 \\
\hline Relative density, $D_{\mathrm{r}}(\%)$ & 64.38 & 63.94 \\
\hline \multicolumn{3}{|l|}{ Engineering properties } \\
\hline Undrained cohesion, $c\left(\mathrm{kN} / \mathrm{m}^{2}\right)$ & 0.00 & 0.00 \\
\hline Soil internal friction angle, $\phi\left(^{\circ}\right)$ & 33.50 & 39.00 \\
\hline $\begin{array}{l}\text { Coefficient of hydraulic conductivity, } k \\
(\mathrm{~m} / \mathrm{sec})\end{array}$ & $1.83 \times 10^{-4}$ & $7.83 \times 10^{-5}$ \\
\hline Modulus of elasticity, $E_{\mathrm{s}}(\mathrm{kPa})$ & 31,600 & 46,000 \\
\hline Dilatancy angle, $\psi\left({ }^{\circ}\right)$ & 3.50 & 9.00 \\
\hline
\end{tabular}

panel is prepared by successive layers of $3 \mathrm{~mm}$ thick dyed (i.e., red colour) and $18 \mathrm{~mm}$ thick nondyed sand $S_{\text {I }}$. The number of layers is dependent on the height above the anchor base, and the thickness of top most layer which is less than $3 \mathrm{~mm}$ is finished with continuing colour of sand. The thickness of dyed and nondyed layers is conveniently determined to maintain the placement densities of sand. 
TABLE 2: Detail geometry of the 3D model and 2D panel and their designations in homogeneous sand deposit $\left(S_{\mathrm{I}}\right)$.

\begin{tabular}{|c|c|c|c|c|c|c|c|c|c|}
\hline $\begin{array}{l}\alpha \\
\left({ }^{\circ}\right) \\
(\mathrm{i}) \\
\end{array}$ & $\begin{array}{c}D_{\mathrm{s}} \text { or } \\
T_{\mathrm{s}} \\
\text { (ii) } \\
\end{array}$ & $\begin{array}{c}D_{\mathrm{b}} \text { or } \\
T_{\mathrm{b}} \\
\text { (iii) } \\
\end{array}$ & $\begin{array}{c}D_{\mathrm{b}} / D_{\mathrm{s}} \text { or } \\
T_{\mathrm{b}} / T_{\mathrm{s}} \\
\quad \text { (iv) } \\
\end{array}$ & $\begin{array}{c}\text { 3D model } \\
\text { identifications } \\
(\mathrm{v})\end{array}$ & $\begin{array}{c}\text { 2D panel } \\
\text { identifications } \\
\text { (vi) }\end{array}$ & $\begin{array}{c}L / D_{\mathrm{b}} \text { or } \\
L / T_{\mathrm{s}} \\
\text { (vii) }\end{array}$ & $\begin{array}{c}L \\
(\mathrm{~mm}) \\
(\mathrm{viii})\end{array}$ & $\begin{array}{c}\text { 3D model } \\
\text { designations in } S_{\mathrm{I}} \\
(\mathrm{ix})\end{array}$ & $\begin{array}{c}\text { 2D panel designations } \\
\text { in } S_{\mathrm{II}} / S_{\mathrm{I}} \\
(\mathrm{x})\end{array}$ \\
\hline 45 & 26 & 92 & 0.28 & $3 \mathrm{D}: 45-0.28$ & 2D:45-0.28 & $\begin{array}{l}276 \\
368 \\
460 \\
\end{array}$ & $\begin{array}{l}3 \\
4 \\
5 \\
\end{array}$ & $\begin{array}{l}\text { 3D:45-0.28-3- }\left(S_{\mathrm{I}}\right) \\
\text { 3D:45-0.28-4- }\left(S_{\mathrm{I}}\right) \\
\text { 3D:45-0.28-5- }\left(S_{\mathrm{I}}\right)\end{array}$ & $\begin{array}{l}2 \mathrm{D}: 45-0.28-3-\left(S_{\mathrm{I}}\right) \\
2 \mathrm{D}: 45-0.28-4-\left(S_{\mathrm{I}}\right) \\
2 \mathrm{D}: 45-0.28-5-\left(S_{\mathrm{I}}\right)\end{array}$ \\
\hline 45 & 26 & 80 & 0.33 & $3 \mathrm{D}: 45-0.33$ & $2 \mathrm{D}: 45-0.33$ & $\begin{array}{l}240 \\
320 \\
400 \\
\end{array}$ & $\begin{array}{l}3 \\
4 \\
5 \\
\end{array}$ & $\begin{array}{l}\text { 3D:45-0.33-3- }\left(S_{\mathrm{I}}\right) \\
\text { 3D:45-0.33-4- }\left(S_{\mathrm{I}}\right) \\
\text { 3D:45-0.33-5- }\left(S_{\mathrm{I}}\right)\end{array}$ & $\begin{array}{l}2 \mathrm{D}: 45-0.33-3-\left(S_{\mathrm{I}}\right) \\
2 \mathrm{D}: 45-0.33-4-\left(S_{\mathrm{I}}\right) \\
2 \mathrm{D}: 45-0.33-5-\left(S_{\mathrm{I}}\right)\end{array}$ \\
\hline 45 & 26 & 68 & 0.38 & $3 \mathrm{D}: 45-0.38$ & $2 \mathrm{D}: 45-0.38$ & $\begin{array}{l}204 \\
272 \\
340 \\
\end{array}$ & $\begin{array}{l}3 \\
4 \\
5 \\
\end{array}$ & $\begin{array}{l}\text { 3D:45-0.38-3- }\left(S_{\mathrm{I}}\right) \\
\text { 3D:45-0.38-4- }\left(S_{\mathrm{I}}\right) \\
\text { 3D:45-0.38-5- }\left(S_{\mathrm{I}}\right)\end{array}$ & $\begin{array}{l}2 \mathrm{D}: 45-0.38-3-\left(S_{\mathrm{I}}\right) \\
2 \mathrm{D}: 45-0.38-4-\left(S_{\mathrm{I}}\right) \\
2 \mathrm{D}: 45-0.38-5-\left(S_{\mathrm{I}}\right)\end{array}$ \\
\hline 45 & 26 & 56 & 0.46 & $3 \mathrm{D}: 45-0.46$ & $2 \mathrm{D}: 45-0.46$ & $\begin{array}{l}168 \\
224 \\
280 \\
\end{array}$ & $\begin{array}{l}3 \\
4 \\
5\end{array}$ & $\begin{array}{l}\text { 3D:45-0.46-3- }\left(S_{\mathrm{I}}\right) \\
\text { 3D:45-0.46-4- }\left(S_{\mathrm{I}}\right) \\
\text { 3D:45-0.46-5- }\left(S_{\mathrm{I}}\right)\end{array}$ & $\begin{array}{l}2 \mathrm{D}: 45-0.46-3-\left(S_{\mathrm{I}}\right) \\
2 \mathrm{D}: 45-0.46-4-\left(S_{\mathrm{I}}\right) \\
2 \mathrm{D}: 45-0.46-5-\left(S_{\mathrm{I}}\right)\end{array}$ \\
\hline 63 & 26 & 92 & 0.28 & $3 \mathrm{D}: 63-0.28$ & 2D:63-0.28 & $\begin{array}{l}276 \\
368 \\
460 \\
\end{array}$ & $\begin{array}{l}3 \\
4 \\
5 \\
\end{array}$ & $\begin{array}{l}\text { 3D:63-0.28-3- }\left(S_{\mathrm{I}}\right) \\
\text { 3D:63-0.28-4- }\left(S_{\mathrm{I}}\right) \\
\text { 3D:63-0.28-5- }\left(S_{\mathrm{I}}\right)\end{array}$ & $\begin{array}{l}2 \mathrm{D}: 63-0.28-3-\left(S_{\mathrm{I}}\right) \\
2 \mathrm{D}: 63-0.28-4-\left(S_{\mathrm{I}}\right) \\
2 \mathrm{D}: 63-0.28-5-\left(S_{\mathrm{I}}\right)\end{array}$ \\
\hline 63 & 26 & 80 & 0.33 & $3 \mathrm{D}: 63-0.33$ & 2D:63-0.33 & $\begin{array}{l}240 \\
320 \\
400 \\
\end{array}$ & $\begin{array}{l}3 \\
4 \\
5\end{array}$ & $\begin{array}{l}\text { 3D:63-0.33-3- }\left(S_{\mathrm{I}}\right) \\
\text { 3D:63-0.33-4- }\left(S_{\mathrm{I}}\right) \\
\text { 3D:63-0.33-5- }\left(S_{\mathrm{I}}\right)\end{array}$ & $\begin{array}{l}2 \mathrm{D}: 63-0.33-3-\left(S_{\mathrm{I}}\right) \\
2 \mathrm{D}: 63-0.33-4-\left(S_{\mathrm{I}}\right) \\
2 \mathrm{D}: 63-0.33-5-\left(S_{\mathrm{I}}\right)\end{array}$ \\
\hline 63 & 26 & 68 & 0.38 & 3D:63-0.38 & 2D:63-0.38 & $\begin{array}{l}204 \\
272 \\
340 \\
\end{array}$ & $\begin{array}{l}3 \\
4 \\
5 \\
\end{array}$ & $\begin{array}{l}\text { 3D:63-0.38-3- }\left(S_{\mathrm{I}}\right) \\
\text { 3D:63-0.38-4- }\left(S_{\mathrm{I}}\right) \\
\text { 3D:63-0.38-5- }\left(S_{\mathrm{I}}\right)\end{array}$ & $\begin{array}{l}2 \mathrm{D}: 63-0.38-3-\left(S_{\mathrm{I}}\right) \\
2 \mathrm{D}: 63-0.38-4-\left(S_{\mathrm{I}}\right) \\
2 \mathrm{D}: 63-0.38-5-\left(S_{\mathrm{I}}\right)\end{array}$ \\
\hline 63 & 26 & 56 & 0.46 & $3 \mathrm{D}: 63-0.46$ & 2D:63-0.46 & $\begin{array}{l}168 \\
224 \\
280 \\
\end{array}$ & $\begin{array}{l}3 \\
4 \\
5 \\
\end{array}$ & $\begin{array}{l}\text { 3D:63-0.46-3- }\left(S_{\mathrm{I}}\right) \\
\text { 3D:63-0.46-4- }\left(S_{\mathrm{I}}\right) \\
\text { 3D:63-0.46-5- }\left(S_{\mathrm{I}}\right)\end{array}$ & $\begin{array}{l}2 \mathrm{D}: 63-0.46-3-\left(S_{\mathrm{I}}\right) \\
2 \mathrm{D}: 63-0.46-4-\left(S_{\mathrm{I}}\right) \\
2 \mathrm{D}: 63-0.46-5-\left(S_{\mathrm{I}}\right)\end{array}$ \\
\hline 72 & 26 & 92 & 0.28 & $3 \mathrm{D}: 72-0.28$ & $2 \mathrm{D}: 72-0.28$ & $\begin{array}{l}276 \\
368 \\
460 \\
\end{array}$ & $\begin{array}{l}3 \\
4 \\
5 \\
\end{array}$ & $\begin{array}{l}\text { 3D:72-0.28-3- }\left(S_{\mathrm{I}}\right) \\
\text { 3D:72-0.28-4- }\left(S_{\mathrm{I}}\right) \\
\text { 3D:72-0.28-5- }\left(S_{\mathrm{I}}\right)\end{array}$ & $\begin{array}{l}\text { 2D:72-0.28-3- }\left(S_{\mathrm{I}}\right) \\
\text { 2D:72-0.28-4- }\left(S_{\mathrm{I}}\right) \\
\text { 2D:72-0.28-5- }\left(S_{\mathrm{I}}\right)\end{array}$ \\
\hline 72 & 26 & 80 & 0.33 & $3 \mathrm{D}: 72-0.33$ & $2 \mathrm{D}: 72-0.3$ & $\begin{array}{l}240 \\
320 \\
400 \\
\end{array}$ & $\begin{array}{l}3 \\
4 \\
5 \\
\end{array}$ & $\begin{array}{l}\text { 3D:72-0.33-3- }\left(S_{\mathrm{I}}\right) \\
\text { 3D:72-0.33-4- }\left(S_{\mathrm{I}}\right) \\
\text { 3D:72-0.33-5- }\left(S_{\mathrm{I}}\right)\end{array}$ & $\begin{array}{l}2 \mathrm{D}: 72-0.33-3-\left(S_{\mathrm{I}}\right) \\
2 \mathrm{D}: 72-0.33-4-\left(S_{\mathrm{I}}\right) \\
2 \mathrm{D}: 72-0.33-5-\left(S_{\mathrm{I}}\right)\end{array}$ \\
\hline 72 & 26 & 68 & 0.38 & 3D:72-0.38 & 2D:72-0.38 & $\begin{array}{l}204 \\
272 \\
340 \\
\end{array}$ & $\begin{array}{l}3 \\
4 \\
5\end{array}$ & $\begin{array}{l}\text { 3D:72-0.38-3- }\left(S_{\mathrm{I}}\right) \\
\text { 3D:72-0.38-4- }\left(S_{\mathrm{I}}\right) \\
\text { 3D:72-0.38-5- }\left(S_{\mathrm{I}}\right)\end{array}$ & $\begin{array}{l}2 \mathrm{D}: 72-0.38-3-\left(S_{\mathrm{I}}\right) \\
2 \mathrm{D}: 72-0.38-4-\left(S_{\mathrm{I}}\right) \\
2 \mathrm{D}: 72-0.38-5-\left(S_{\mathrm{I}}\right)\end{array}$ \\
\hline 72 & 26 & 56 & 0.46 & $3 \mathrm{D}: 72-0.46$ & 2D:72-0.46 & $\begin{array}{l}168 \\
224 \\
280\end{array}$ & $\begin{array}{l}3 \\
4 \\
5\end{array}$ & $\begin{array}{l}\text { 3D:72-0.46-3- }\left(S_{\mathrm{I}}\right) \\
\text { 3D:72-0.46-4- }\left(S_{\mathrm{I}}\right) \\
\text { 3D:72-0.46-5- }\left(S_{\mathrm{I}}\right)\end{array}$ & $\begin{array}{l}2 \mathrm{D}: 72-0.46-3-\left(S_{\mathrm{I}}\right) \\
2 \mathrm{D}: 72-0.46-4-\left(S_{\mathrm{I}}\right) \\
2 \mathrm{D}: 72-0.46-5-\left(S_{\mathrm{I}}\right)\end{array}$ \\
\hline
\end{tabular}

4.3. Experimental Programme. To carry out experimental investigations on the uplift behaviour of single-belled anchors and failure surfaces in buried sand, conditions are explained below:

4.3.1. Series A (Experimental Investigation on Uplift Capacity of $3 D$ Models). Each model is installed at $L / D_{\mathrm{b}}$ of 3,4 , and 5 , having $D_{\mathrm{s}} / D_{\mathrm{b}}=0.28,0.33,0.38$, and 0.46 and $\beta$ of 45,63 , and $72^{\circ}$ in $S_{\text {I }}$ and $S_{\text {II }} / S_{\text {I }}$ deposits. In this series, total 69 tests are performed.

4.3.2. Series B (Failure Mechanism Study on Both the Sides of $2 D$ Panels). Each model is installed at $L / T_{\mathrm{b}}=3,4$, and $5, T_{\mathrm{s}} /$ $T_{\mathrm{b}}=0.28,0.33,0.38$, and 0.46 , and $a=45,63$, and $72^{\circ}$ in $S_{\mathrm{I}}$ and $S_{\mathrm{II}} / S_{\mathrm{I}}$ deposits. In this series also, total 69 tests are performed.

4.4. Experimental Setup, Test Procedures, and Observations. Figure 3 shows the schematic diagram of the experimental setup consisting of a loading frame, anchor installed inside the model tank, connected proving ring, position of dial gauges, and other accessories. The loading frame of steel channels having horizontal beam (reaction frame) consisting of ball-bearing arrangement and the base is bolted in concrete for stability. A pulling shaft as screw jack passes through ball-bearing system by nut and screw motion. The bottom of pulling shaft is connected with top of the model along with the proving ring. Vertical movement of shaft is controlled by a manually operated 
TABLE 3: Detail thickness of sand I $\left(S_{\mathrm{I}}\right)$ and sand II $\left(S_{\mathrm{II}}\right)$ in layered sand deposit $\left(S_{\mathrm{II}} / S_{\mathrm{I}}\right)$ and $3 \mathrm{D}$ model and $2 \mathrm{D}$ panel and their designations in $S_{\text {II }} / S_{\text {I }}$.

\begin{tabular}{|c|c|c|c|c|c|c|c|}
\hline $\begin{array}{l}\text { 3D model } \\
\text { identifications } \\
\text { (i) }\end{array}$ & $\begin{array}{l}\text { 2D panel } \\
\text { identifications } \\
\text { (ii) }\end{array}$ & $\begin{array}{c}L \\
\text { (iii) }\end{array}$ & $\begin{array}{c}L / D_{\mathrm{b}} \text { or } L / \\
T_{\mathrm{s}} \\
\text { (iv) } \\
\end{array}$ & $\begin{array}{c}L_{\mathrm{II}} / \\
L \\
(\mathrm{v})\end{array}$ & $\begin{array}{l}L_{\mathrm{I}} / L \\
(\mathrm{vi})\end{array}$ & $\begin{array}{c}\text { 3D anchor designations in } \\
S_{\mathrm{I}} \\
\text { (vii) }\end{array}$ & $\begin{array}{c}\text { 2D panel designations in } S_{\text {II }} / \\
S_{\text {I }} \\
\text { (viii) }\end{array}$ \\
\hline \multirow{3}{*}{$3 \mathrm{D}: 45-0.28$} & \multirow{3}{*}{$2 \mathrm{D}: 45-0.28$} & 276 & 3 & 0.39 & 0.61 & $\begin{array}{c}3 \mathrm{D}: 45-0.28-3-\left(0.39 S_{\mathrm{II}} /\right. \\
\left.0.61 S_{\mathrm{I}}\right)\end{array}$ & $\begin{array}{c}2 \mathrm{D}: 45-0.28-3-\left(0.39 S_{\mathrm{II}} /\right. \\
\left.0.61 S_{\mathrm{I}}\right)\end{array}$ \\
\hline & & 368 & 4 & 0.54 & 0.46 & $\begin{array}{c}3 \mathrm{D}: 45-0.28-4-\left(0.54 S_{\mathrm{II}} /\right. \\
\left.0.46 S_{\mathrm{I}}\right)\end{array}$ & $\begin{array}{c}2 \mathrm{D}: 45-0.28-4-\left(0.54 S_{\mathrm{II}} /\right. \\
\left.0.46 S_{\mathrm{I}}\right)\end{array}$ \\
\hline & & 460 & 5 & 0.63 & 0.37 & $\begin{array}{c}3 \mathrm{D}: 45-0.28-5-\left(0.63 S_{\mathrm{II}} /\right. \\
\left.0.37 S_{\mathrm{I}}\right)\end{array}$ & $\begin{array}{c}2 \mathrm{D}: 45-0.28-5-\left(0.63 S_{\mathrm{II}} /\right. \\
\left.0.37 S_{\mathrm{I}}\right)\end{array}$ \\
\hline \multirow{3}{*}{ 3D:45-0.33 } & \multirow{3}{*}{$2 \mathrm{D}: 45-0.33$} & 240 & 3 & 0.30 & 0.70 & $\begin{array}{c}3 \mathrm{D}: 45-0.33-3-\left(0.30 S_{\mathrm{II}} /\right. \\
\left.0.70 S_{\mathrm{I}}\right)\end{array}$ & $\begin{array}{c}2 \mathrm{D}: 45-0.33-3-\left(0.30 S_{\mathrm{II}} /\right. \\
\left.0.70 S_{\mathrm{I}}\right)\end{array}$ \\
\hline & & 320 & 4 & 0.47 & 0.53 & $\begin{array}{c}3 \mathrm{D}: 45-0.33-4-\left(0.47 S_{\mathrm{II}} /\right. \\
\left.0.53 S_{\mathrm{I}}\right)\end{array}$ & $\begin{array}{c}2 \mathrm{D}: 45-0.33-4-\left(0.47 S_{\mathrm{II}} /\right. \\
\left.0.53 S_{\mathrm{I}}\right)\end{array}$ \\
\hline & & 400 & 5 & 0.58 & 0.42 & $\begin{array}{c}3 \mathrm{D}: 45-0.33-5-\left(0.58 S_{\mathrm{II}} /\right. \\
\left.0.42 S_{\mathrm{I}}\right)\end{array}$ & $\begin{array}{c}2 \mathrm{D}: 45-0.33-5-\left(0.58 S_{\mathrm{II}} /\right. \\
\left.0.42 S_{\mathrm{I}}\right)\end{array}$ \\
\hline \multirow{3}{*}{ 3D:45-0.38 } & \multirow{3}{*}{$2 \mathrm{D}: 45-0.38$} & 204 & 3 & 0.18 & 0.82 & $\begin{array}{c}3 \mathrm{D}: 45-0.38-3-\left(0.18 S_{\mathrm{II}} /\right. \\
\left.0.82 S_{\mathrm{I}}\right)\end{array}$ & $\begin{array}{c}2 \mathrm{D}: 45-0.38-3-\left(0.18 S_{\mathrm{II}} /\right. \\
\left.0.82 S_{\mathrm{I}}\right)\end{array}$ \\
\hline & & 272 & 4 & 0.38 & 0.62 & $\begin{array}{c}3 \mathrm{D}: 45-0.38-4-\left(0.38 S_{\mathrm{II}} /\right. \\
\left.0.62 S_{\mathrm{I}}\right)\end{array}$ & $\begin{array}{c}2 \mathrm{D}: 45-0.38-4-\left(0.38 S_{\mathrm{II}} /\right. \\
\left.0.62 S_{\mathrm{I}}\right)\end{array}$ \\
\hline & & 340 & 5 & 0.51 & 0.49 & $\begin{array}{c}3 \mathrm{D}: 45-0.38-5-\left(0.51 S_{\mathrm{II}} /\right. \\
\left.0.49 S_{\mathrm{I}}\right)\end{array}$ & $\begin{array}{c}2 \mathrm{D}: 45-0.38-5-\left(0.51 S_{\mathrm{II}} /\right. \\
\left.0.49 S_{\mathrm{I}}\right)\end{array}$ \\
\hline \multirow{3}{*}{ 3D:45-0.46 } & \multirow{3}{*}{$2 \mathrm{D}: 45-0.46$} & 168 & 3 & 1.00 & 1.00 & 3D:45-0.46-3- $\left(S_{\mathrm{I}}\right)$ & 2D:45-0.46-3-(S $)$ \\
\hline & & 224 & 4 & 0.25 & 0.75 & $\begin{array}{c}3 \mathrm{D}: 45-0.46-4-\left(0.25 S_{\mathrm{II}} /\right. \\
\left.0.75 S_{\mathrm{I}}\right)\end{array}$ & $\begin{array}{c}2 \mathrm{D}: 45-0.46-4-\left(0.25 S_{\mathrm{II}} /\right. \\
\left.0.75 S_{\mathrm{I}}\right)\end{array}$ \\
\hline & & 280 & 5 & 0.40 & 0.60 & $\begin{array}{c}3 \mathrm{D}: 45-0.46-5-\left(0.40 S_{\mathrm{II}} /\right. \\
\left.0.60 S_{\mathrm{I}}\right)\end{array}$ & $\begin{array}{c}2 \mathrm{D}: 45-0.46-5-\left(0.40 S_{\mathrm{II}} /\right. \\
\left.0.60 S_{\mathrm{I}}\right)\end{array}$ \\
\hline \multirow{3}{*}{ 3D:63-0.28 } & \multirow{3}{*}{$2 \mathrm{D}: 63-0.28$} & 276 & 3 & 0.39 & 0.61 & $\begin{array}{c}3 \mathrm{D}: 63-0.28-3-\left(0.39 S_{\mathrm{II}} /\right. \\
\left.0.61 S_{\mathrm{I}}\right)\end{array}$ & $\begin{array}{c}2 \mathrm{D}: 63-0.28-3-\left(0.39 S_{\mathrm{II}} /\right. \\
\left.0.61 S_{\mathrm{I}}\right)\end{array}$ \\
\hline & & 368 & 4 & 0.54 & 0.46 & $\begin{array}{c}3 \mathrm{D}: 63-0.28-4-\left(0.54 S_{\mathrm{II}} /\right. \\
\left.0.46 S_{\mathrm{I}}\right)\end{array}$ & $\begin{array}{c}2 \mathrm{D}: 63-0.28-4-\left(0.54 S_{\mathrm{II}} /\right. \\
\left.0.46 S_{\mathrm{I}}\right)\end{array}$ \\
\hline & & 460 & 5 & 0.63 & 0.37 & $\begin{array}{c}3 \mathrm{D}: 63-0.28-5-\left(0.63 S_{\mathrm{II}} /\right. \\
\left.0.37 S_{\mathrm{I}}\right)\end{array}$ & $\begin{array}{c}2 \mathrm{D}: 63-0.28-5-\left(0.63 S_{\mathrm{II}} /\right. \\
\left.0.37 S_{\mathrm{I}}\right)\end{array}$ \\
\hline \multirow{3}{*}{$3 \mathrm{D}: 63-0.33$} & \multirow{3}{*}{ 2D:63-0.33 } & 240 & 3 & 0.30 & 0.70 & $\begin{array}{c}3 \mathrm{D}: 63-0.33-3-\left(0.30 S_{\mathrm{II}} /\right. \\
\left.0.70 S_{\mathrm{I}}\right)\end{array}$ & $\begin{array}{c}2 \mathrm{D}: 63-0.33-3-\left(0.30 S_{\mathrm{II}} /\right. \\
\left.0.70 S_{\mathrm{I}}\right)\end{array}$ \\
\hline & & 320 & 4 & 0.47 & 0.53 & $\begin{array}{c}3 \mathrm{D}: 63-0.33-4-\left(0.47 S_{\mathrm{II}} /\right. \\
\left.0.53 S_{\mathrm{I}}\right)\end{array}$ & $\begin{array}{c}2 \mathrm{D}: 63-0.33-4-\left(0.47 S_{\mathrm{II}} /\right. \\
\left.0.53 S_{\mathrm{I}}\right)\end{array}$ \\
\hline & & 400 & 5 & 0.58 & 0.42 & $\begin{array}{c}3 \mathrm{D}: 63-0.33-5-\left(0.58 S_{\mathrm{II}} /\right. \\
\left.0.42 S_{\mathrm{I}}\right)\end{array}$ & $\begin{array}{c}2 \mathrm{D}: 63-0.33-5-\left(0.58 S_{\mathrm{II}} /\right. \\
\left.0.42 S_{\mathrm{I}}\right)\end{array}$ \\
\hline \multirow{3}{*}{ 3D:63-0.38 } & \multirow{3}{*}{$2 \mathrm{D}: 63-0.38$} & 204 & 3 & 0.18 & 0.82 & $\begin{array}{c}3 \mathrm{D}: 63-0.38-3-\left(0.18 S_{\mathrm{II}} /\right. \\
\left.0.82 S_{\mathrm{I}}\right)\end{array}$ & $\begin{array}{c}2 \mathrm{D}: 63-0.38-3-\left(0.18 S_{\mathrm{II}} /\right. \\
\left.0.82 S_{\mathrm{I}}\right)\end{array}$ \\
\hline & & 272 & 4 & 0.38 & 0.62 & $\begin{array}{c}3 \mathrm{D}: 63-0.38-4-\left(0.38 S_{\mathrm{II}} /\right. \\
\left.0.62 S_{\mathrm{I}}\right)\end{array}$ & $\begin{array}{c}2 \mathrm{D}: 63-0.38-4-\left(0.38 S_{\mathrm{II}} /\right. \\
\left.0.62 S_{\mathrm{I}}\right)\end{array}$ \\
\hline & & 340 & 5 & 0.51 & 0.49 & $\begin{array}{c}3 \mathrm{D}: 63-0.38-5-\left(0.51 S_{\mathrm{II}} /\right. \\
\left.0.49 S_{\mathrm{I}}\right)\end{array}$ & $\begin{array}{c}2 \mathrm{D}: 63-0.38-5-\left(0.51 S_{\mathrm{II}} /\right. \\
\left.0.49 S_{\mathrm{I}}\right)\end{array}$ \\
\hline \multirow{3}{*}{$3 \mathrm{D}: 63-0.46$} & \multirow{3}{*}{ 2D:63-0.46 } & 168 & 3 & 1.00 & 1.00 & 3D:63-0.46-3-( $\left(S_{\mathrm{I}}\right)$ & 2D:63-0.46-3-(S $)$ \\
\hline & & 224 & 4 & 0.25 & 0.75 & $\begin{array}{c}3 \mathrm{D}: 63-0.46-4-\left(0.25 S_{\mathrm{II}} /\right. \\
\left.0.75 S_{\mathrm{I}}\right)\end{array}$ & $\begin{array}{c}2 \mathrm{D}: 63-0.46-4-\left(0.25 S_{\mathrm{II}} /\right. \\
\left.0.75 S_{\mathrm{I}}\right)\end{array}$ \\
\hline & & 280 & 5 & 0.40 & 0.60 & $\begin{array}{c}3 \mathrm{D}: 63-0.46-5-\left(0.40 S_{\mathrm{II}} /\right. \\
\left.0.60 S_{\mathrm{I}}\right)\end{array}$ & $\begin{array}{c}2 \mathrm{D}: 63-0.46-5-\left(0.40 S_{\mathrm{II}} /\right. \\
\left.0.60 S_{\mathrm{I}}\right)\end{array}$ \\
\hline \multirow{3}{*}{ 3D:72-0.28 } & \multirow{3}{*}{$2 \mathrm{D}: 72-0.28$} & 276 & 3 & 0.39 & 0.61 & $\begin{array}{c}3 \mathrm{D}: 72-0.28-3-\left(0.39 S_{\mathrm{II}} /\right. \\
\left.0.61 S_{\mathrm{I}}\right)\end{array}$ & $\begin{array}{c}2 \mathrm{D}: 72-0.28-3-\left(0.39 S_{\mathrm{II}} /\right. \\
\left.0.61 S_{\mathrm{I}}\right)\end{array}$ \\
\hline & & 368 & 4 & 0.54 & 0.46 & $\begin{array}{c}3 \mathrm{D}: 72-0.28-4-\left(0.54 S_{\mathrm{II}} /\right. \\
\left.0.46 S_{\mathrm{I}}\right)\end{array}$ & $\begin{array}{c}2 \mathrm{D}: 72-0.28-4-\left(0.54 S_{\mathrm{II}} /\right. \\
\left.0.46 S_{\mathrm{I}}\right)\end{array}$ \\
\hline & & 460 & 5 & 0.63 & 0.37 & $\begin{array}{c}3 \mathrm{D}: 72-0.28-5-\left(0.63 S_{\mathrm{II}} /\right. \\
\left.0.37 S_{\mathrm{I}}\right)\end{array}$ & $\begin{array}{c}2 \mathrm{D}: 72-0.28-5-\left(0.63 S_{\mathrm{II}} /\right. \\
\left.0.37 S_{\mathrm{I}}\right)\end{array}$ \\
\hline
\end{tabular}


TABLE 3: Continued.

\begin{tabular}{|c|c|c|c|c|c|c|c|}
\hline $\begin{array}{l}3 \mathrm{D} \text { model } \\
\text { identifications } \\
\text { (i) }\end{array}$ & $\begin{array}{c}\text { 2D panel } \\
\text { identifications } \\
\text { (ii) }\end{array}$ & $\begin{array}{c}L \\
\text { (iii) }\end{array}$ & $\begin{array}{c}L / D_{\mathrm{b}} \text { or } L / \\
T_{\mathrm{s}} \\
\text { (iv) } \\
\end{array}$ & $\begin{array}{c}L_{\mathrm{II}} / \\
L \\
(\mathrm{v})\end{array}$ & $\begin{array}{l}L_{\mathrm{I}} / L \\
(\mathrm{vi})\end{array}$ & $\begin{array}{c}\text { 3D anchor designations in } \\
S_{\mathrm{I}} \\
\text { (vii) }\end{array}$ & $\begin{array}{c}\text { 2D panel designations in } S_{\text {II }} / \\
S_{\text {I }} \\
\text { (viii) }\end{array}$ \\
\hline \multirow{3}{*}{ 3D:72-0.33 } & \multirow{3}{*}{$2 \mathrm{D}: 72-0.33$} & 240 & 3 & 0.30 & 0.70 & $\begin{array}{c}3 \mathrm{D}: 72-0.33-3-\left(0.30 S_{\mathrm{II}} /\right. \\
\left.0.70 S_{\mathrm{I}}\right)\end{array}$ & $\begin{array}{c}2 \mathrm{D}: 72-0.33-3-\left(0.30 S_{\mathrm{II}} /\right. \\
\left.0.70 S_{\mathrm{I}}\right)\end{array}$ \\
\hline & & 320 & 4 & 0.47 & 0.53 & $\begin{array}{c}3 \mathrm{D}: 72-0.33-4-\left(0.47 S_{\mathrm{II}} /\right. \\
\left.0.53 S_{\mathrm{I}}\right)\end{array}$ & $\begin{array}{c}2 \mathrm{D}: 72-0.33-4-\left(0.47 S_{\mathrm{II}} /\right. \\
\left.0.53 S_{\mathrm{I}}\right)\end{array}$ \\
\hline & & 400 & 5 & 0.58 & 0.42 & $\begin{array}{c}3 \mathrm{D}: 72-0.33-5-\left(0.58 S_{\mathrm{II}} /\right. \\
\left.0.42 S_{\mathrm{I}}\right) \\
\end{array}$ & $\begin{array}{c}2 \mathrm{D}: 72-0.33-5-\left(0.58 S_{\mathrm{II}} /\right. \\
\left.0.42 S_{\mathrm{I}}\right) \\
\end{array}$ \\
\hline \multirow{3}{*}{ 3D:72-0.38 } & \multirow{3}{*}{ 2D:72-0.38 } & 204 & 3 & 0.18 & 0.82 & $\begin{array}{c}3 \mathrm{D}: 72-0.38-3-\left(0.18 S_{\mathrm{II}} /\right. \\
\left.0.82 S_{\mathrm{I}}\right)\end{array}$ & $\begin{array}{c}2 \mathrm{D}: 72-0.38-3-\left(0.18 S_{\mathrm{II}} /\right. \\
\left.0.82 S_{\mathrm{I}}\right)\end{array}$ \\
\hline & & 272 & 4 & 0.38 & 0.62 & $\begin{array}{c}3 \mathrm{D}: 72-0.38-4-\left(0.38 S_{\mathrm{II}} /\right. \\
\left.0.62 S_{\mathrm{I}}\right)\end{array}$ & $\begin{array}{c}2 \mathrm{D}: 72-0.38-4-\left(0.38 S_{\mathrm{II}} /\right. \\
\left.0.62 S_{\mathrm{I}}\right)\end{array}$ \\
\hline & & 340 & 5 & 0.51 & 0.49 & $\begin{array}{c}3 \mathrm{D}: 72-0.38-5-\left(0.51 S_{\mathrm{II}} /\right. \\
\left.0.49 S_{\mathrm{I}}\right)\end{array}$ & $\begin{array}{c}2 \mathrm{D}: 72-0.38-5-\left(0.51 S_{\mathrm{II}} /\right. \\
\left.0.49 S_{\mathrm{I}}\right)\end{array}$ \\
\hline \multirow{3}{*}{ 3D:72-0.46 } & \multirow{3}{*}{ 2D:72-0.46 } & 168 & 3 & 1.00 & 1.00 & 3D:72-0.46-3- $\left(S_{\mathrm{I}}\right)$ & $2 \mathrm{D}: 72-0.46-3-\left(S_{\mathrm{I}}\right)$ \\
\hline & & 224 & 4 & 0.25 & 0.75 & $\begin{array}{c}3 \mathrm{D}: 72-0.46-4-\left(0.25 S_{\mathrm{II}} /\right. \\
\left.0.75 S_{\mathrm{I}}\right)\end{array}$ & $\begin{array}{c}2 \mathrm{D}: 72-0.46-4-\left(0.25 S_{\mathrm{II}} /\right. \\
\left.0.75 S_{\mathrm{I}}\right)\end{array}$ \\
\hline & & 280 & 5 & 0.40 & 0.60 & $\begin{array}{c}3 \mathrm{D}: 72-0.46-5-\left(0.40 S_{\mathrm{II}} /\right. \\
\left.0.60 S_{\mathrm{I}}\right)\end{array}$ & $\begin{array}{c}2 \mathrm{D}: 72-0.46-5-\left(0.40 S_{\mathrm{II}} /\right. \\
\left.0.60 S_{\mathrm{I}}\right)\end{array}$ \\
\hline
\end{tabular}

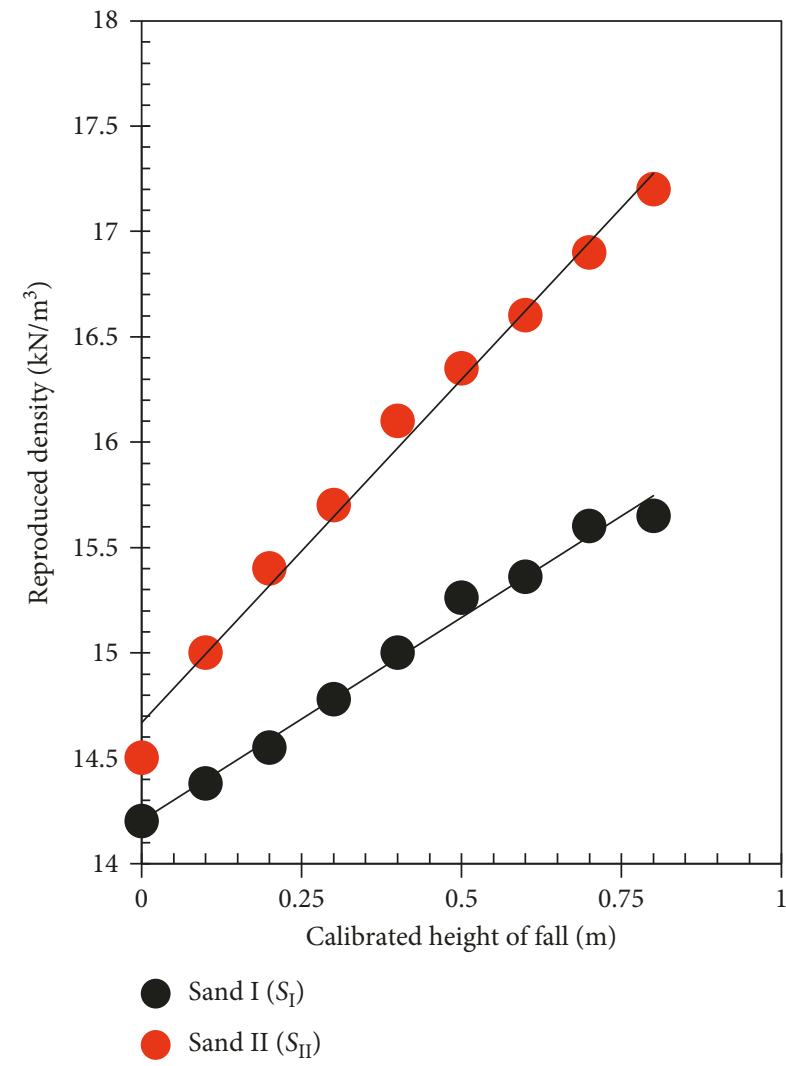

FIGURE 2: Reproduced density vs. calibrated height of fall relation of sand I $\left(S_{\mathrm{I}}\right)$ and sand II $\left(S_{\mathrm{II}}\right)$.

rotating circular wheel fixed with nut arrangement supported on the ball-bearing system. The clockwise motion of wheel helps the model anchors to move upward. The dial gauges of $0.01 \mathrm{~mm}$ accuracy are attached properly with magnetic bases which are fitted on steel bars running over the top of model tank. The proving ring of $1.0 \mathrm{kN}$

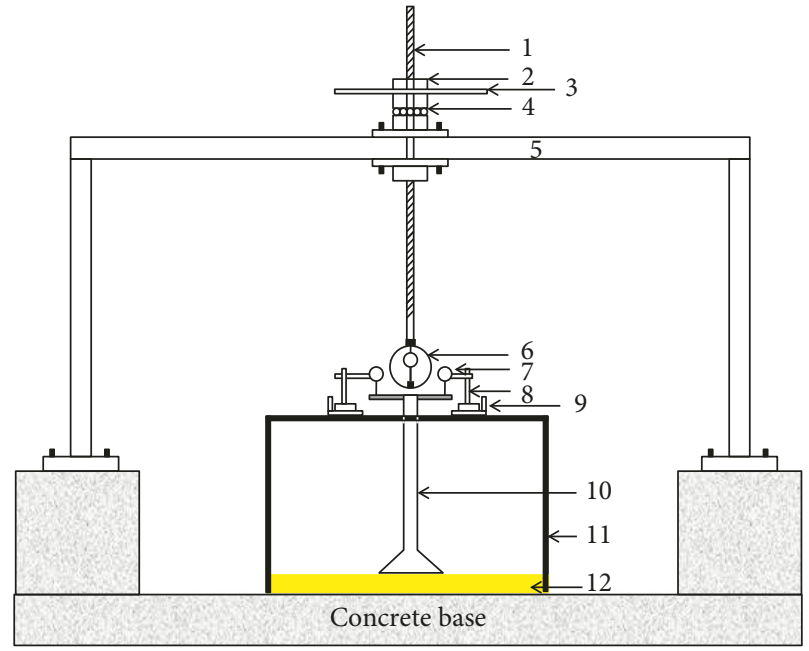

FIgURE 3: Schematic diagram of the experimental setup (front view): (1) long screw, (2) nut, (3) rotating wheel, (4) ball-bearing arrangement, (5) reaction frame, (6) proving ring, (7) dial gauge, (8) magnetic base, (9) magnetic base fixture, (10) model anchor, (11) model tank, and (12) sand bed.

capacity records the gross uplift capacity of model anchors, and corresponding displacement of the anchors are recorded from deflection in dial gauges.

\section{Model Designations}

In Table 2 (column (ix) and (x)), the detail designation of $3 \mathrm{D}$ models and $2 \mathrm{D}$ panels is represented as they are installed in $S_{\text {I }}$ deposit. In Table 3, (column (vii) and (viii)), the detail designation of 3D models and 2D panels is presented as they are installed in $S_{\mathrm{II}} / S_{\mathrm{I}}$ deposit. In order to represent any model, a common coding system is maintained, consisting of five sections. The first, second, third, fourth, and fifth sections specify the size (either $3 \mathrm{D}$ or $2 \mathrm{D}$ ), $\beta, D_{\mathrm{s}} /$ $D_{\mathrm{b}}$ (in case of $3 \mathrm{D}$ model) or $T_{\mathrm{s}} / T_{\mathrm{b}}$ (in case of $2 \mathrm{D}$ panel), $L /$ 
$D_{\mathrm{b}}$, and type of sand deposit (either $S_{\mathrm{I}}$ or $S_{\mathrm{II}} / S_{\mathrm{I}}$ ), respectively. When a $3 \mathrm{D}$ model is having $\beta=45^{\circ}, D_{\mathrm{s}} / D_{\mathrm{b}}=0.28$ at $L / D_{\mathrm{b}}=5$, and its $37 \%$ and $63 \%$ of total embedment depth are in $S_{\text {I }}$ (bottom layer) and $S_{\text {II }}$ (top layer), respectively, then it is designated as $3 \mathrm{D}: 45-0.28-5-\left(0.63 S_{\mathrm{II}} / 0.37 S_{\mathrm{I}}\right)$; and the identical panel is represented as $2 \mathrm{D}: 45-0.28-5-\left(0.63 S_{\mathrm{II}} /\right.$ $\left.0.37 S_{\mathrm{I}}\right)$. The symbol $3 \mathrm{D}: 63-0.33-4-\left(S_{\mathrm{I}}\right)$ implies that a $3 \mathrm{D}$ model has $\beta=63^{\circ}, D_{\mathrm{s}} / D_{\mathrm{b}}=0.33$, and $L / D_{\mathrm{b}}=4$ and it is embedded fully in $S_{\mathrm{I}}$ and identical $2 \mathrm{D}$ panel is represented as $2 \mathrm{D}: 63-0.28-4-\left(S_{\mathrm{I}}\right)$.

\section{Test Results of 3D Models and Discussions}

All the experimental data of $Q_{\mathrm{u}}\left(S_{\mathrm{I}}\right)$ and $Q_{\mathrm{u}}\left(S_{\mathrm{II}} / S_{\mathrm{I}}\right)$ for each 3D models are shown in Table 4 (column (ii) and (vi), respectively) facilitate to compare uplift behaviour of belled anchors in $S_{\mathrm{I}}$ and $S_{\mathrm{II}} / S_{\mathrm{I}}$ deposits in reference to variation in $L / D_{\mathrm{b}}, L / D_{\mathrm{b}}$, and $\beta$. On the basis of experimental data, the effect of embedment ratios, diameter ratios, and bell angles on different uplift capacities of belled anchors in homogeneous and layered sand deposits is discussed herein.

6.1. Comparison of Uplift Capacities of 3D Belled Anchor in Homogeneous $\left(S_{I}\right)$ and Layered $\left(S_{I I} / S_{I}\right)$ Sand Deposits in reference to Embedment Ratios, Diameter Ratios, and Bell Angles. Figures 4(a) and 4(b) represent the comparison of net uplift capacity vs. model displacement for models 3D:45-0.46 and 3D:72-0.28, respectively, both in $S_{\mathrm{I}}$ and $S_{\mathrm{II}} / S_{\mathrm{I}}$ deposits, installed at $L / D_{\mathrm{b}}=3,4$, and 5 . The patterns of net uplift capacity vs. model displacement curves are not similar for both $S_{\text {I }}$ as well as $S_{\text {II }} / S_{\text {I }}$ deposits. In $S_{\text {I }}$, initially, the curve is linear representing true elastic response in very early stage and at that stage rate of increment in uplift, resistance is higher than the vertical displacement. Thereafter, the curve takes the shape of pseudoelastic pattern resembling curvilinear and finally produces elastoplastic response with rapid growth of plastic region as well as highest rate of deformation. The behaviour of curves is similar in nature as demonstrated by Rowe and Davis [14] and Deb and Pal [34].

In general, in $S_{\text {II }} / S_{\text {I }}$, more or less curvilinear shape is noticed in net uplift capacity vs. anchor displacement curve up to bottom layer of sand $\left(S_{\mathrm{I}}\right)$. After that, in all curves, there is a sudden higher rate of increment in uplift capacity at very lower rate of upward displacement. This type of net uplift capacity vs. anchor displacement behaviour is dominated by the strength differences in top and bottom layers of sand. A similar pattern of relationship in net uplift capacity vs. anchor displacement curves was reported by Stewart [35] for plate anchors installed in soft clay underlying comparatively dense sand. In layered sand, for same model, the net uplift capacity vs. anchor displacement curves show more upward movement than that of homogeneous sand as the thickness of $S_{\text {II }}$ gradually increases with higher value of embedment ratio. In both cases, at collapsed stage strength mobilization is lower than the rate of increment in vertical displacement. Net ultimate uplift capacity $\left(Q_{\mathrm{u}}\left(S_{\mathrm{I}}\right)\right.$ and $\left.Q_{\mathrm{u}}\left(S_{\mathrm{II}} / S_{\mathrm{I}}\right)\right)$ from experimental observation is presented as

$$
\begin{gathered}
Q_{\mathrm{u}}\left(S_{\mathrm{I}}\right)=Q_{\mathrm{g}}\left(S_{\mathrm{I}}\right)-W_{\mathrm{M}}, \\
Q_{\mathrm{u}}\left(\frac{S_{\mathrm{II}}}{S_{\mathrm{I}}}\right)=Q_{\mathrm{g}}\left(\frac{S_{\mathrm{II}}}{S_{\mathrm{I}}}\right)-W_{\mathrm{M}} .
\end{gathered}
$$

In case of $S_{\mathrm{II}} / S_{\mathrm{I}}$ deposit, $\left.Q_{\mathrm{u}}\left(S_{\mathrm{II}} / S_{\mathrm{I}}\right)\right)$ values for $3 \mathrm{D}: 45$ 0.33-3- $\left(0.30 S_{\text {II }} / 0.70 S_{\text {I }}\right), \quad 3 \mathrm{D}: 45-0.38-3-\left(0.18 S_{\text {II }} / 0.82 S_{\mathrm{I}}\right), \quad 3 \mathrm{D}$ : 45-0.46-4- $\left(0.25 S_{\text {II }} / 0.75 S_{\mathrm{I}}\right), \quad 3 \mathrm{D}: 63-0.33-3-\left(0.30 S_{\mathrm{II}} / 0.70 S_{\mathrm{I}}\right)$, $3 \mathrm{D}: 63-0.38-3-\left(0.18 S_{\text {II }} / 0.82 S_{\mathrm{I}}\right), 3 \mathrm{D}: 63-0.46-4-\left(0.25 S_{\mathrm{II}} / 0.75 S_{\mathrm{I}}\right)$, $3 \mathrm{D}: 72-0.33-3-\left(0.30 S_{\mathrm{II}} / 0.70 S_{\mathrm{I}}\right), 3 \mathrm{D}: 72-0.38-3-\left(0.18 S_{\mathrm{II}} / 0.82 S_{\mathrm{I}}\right)$, and 3D:672-0.46-4- $\left(0.25 S_{\text {II }} / 0.75 S_{\text {I }}\right)$ are found to be higher than $Q_{\mathrm{u}}\left(S_{\mathrm{I}}\right)$ by maximum $10 \%$. For other models of the present study, the values of $Q_{\mathrm{u}}\left(S_{\mathrm{II}} / S_{\mathrm{I}}\right)$ are within 20 to $50 \%$ higher than $Q_{\mathrm{u}}\left(S_{\mathrm{I}}\right)$.

It has been explored from the experimental data presented in Table 4 (column (ii) and (vi)) that, due to increase in the values of $L / D_{\mathrm{b}}$, both the values of $Q_{\mathrm{u}}\left(S_{\mathrm{I}}\right)$ an $Q_{\mathrm{u}}\left(S_{\mathrm{II}} / S_{\mathrm{I}}\right)$ are gradually increased irrespective of $D_{\mathrm{s}} / D_{\mathrm{b}}$ and $\beta$. For example, $Q_{\mathrm{u}}\left(S_{\mathrm{I}}\right)$ values in 3D:63-0.38-3- $\left(S_{\mathrm{I}}\right), 3 \mathrm{D}: 63-0.38-4-\left(S_{\mathrm{I}}\right)$, and 3D: 63-0.38-5- $\left(S_{\mathrm{I}}\right)$ are $43.83,85.20$, and $121.18 \mathrm{~N}$, respectively, and $\mathrm{Q}_{\mathrm{u}}\left(S_{\mathrm{II}} / S_{\mathrm{I}}\right)$ values in 3D:63-0.38-3- $\left(0.18 S_{\mathrm{II}} / 0.82 S_{\mathrm{I}}\right), 3 \mathrm{D}: 63-0.38-$ $4-\left(0.38 S_{\text {II }} / 0.62 S_{\mathrm{I}}\right)$, and $3 \mathrm{D}: 63-0.38-5-\left(0.51 S_{\text {II }} / 0.49 S_{\text {I }}\right)$ are 47.04 , 103.81 , and $166.85 \mathrm{~N}$, respectively. Dickin et al. $[2,29,36]$ in case of plate anchors $[7,8,34]$ for belled anchors had noticed that uplift capacity was significantly increased by higher embedment ratios in homogeneous sand deposit. Higher embedment ratio involves larger overburden pressure on same anchor base irrespective of the type of sand deposit. The overburden pressure becomes significantly larger when stronger sand of increasing thickness is overlying comparatively weaker sand of fixed thickness, so $Q_{\mathrm{u}}\left(S_{\mathrm{II}} / S_{\mathrm{I}}\right)$ is higher than $Q_{\mathrm{u}}\left(S_{\mathrm{I}}\right)$ for the same model.

There has been a general trend to gradually decrease in both $Q_{\mathrm{u}}\left(S_{\mathrm{I}}\right)$ and $Q_{\mathrm{u}}\left(S_{\mathrm{II}} / S_{\mathrm{I}}\right)$ with increase in values of $D_{\mathrm{s}} / D_{\mathrm{b}}$ irrespective of $L / D_{\mathrm{b}}, \beta, S_{\mathrm{I}}$ and $S_{\mathrm{II}} / S_{\mathrm{I}}$. It has been revealed from the data reported in Table 4 (column (ii) and (vi)) that $Q_{\mathrm{u}}\left(S_{\mathrm{I}}\right)$ values in 3D:45-0.28-5- $\left(S_{\mathrm{I}}\right), 3 \mathrm{D}: 45-0.33-5-\left(S_{\mathrm{I}}\right), 3 \mathrm{D}: 45-0.38-5-\left(S_{\mathrm{I}}\right)$, and 3D:45-0.46-5- $\left(S_{\mathrm{I}}\right)$ are $347.56,235.75,134.35$, and $71.56 \mathrm{~N}$, re-

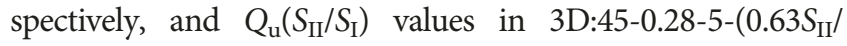
$\left.0.37 S_{\mathrm{I}}\right)$, 3D:45-0.33-5-(0.58S $\left.\mathrm{II} / 0.42 S_{\mathrm{I}}\right), \quad 3 \mathrm{D}: 45-0.38-5-\left(0.51 S_{\mathrm{II}} /\right.$ $\left.0.49 S_{\mathrm{I}}\right)$, and $3 \mathrm{D}: 45-0.46-5-\left(0.40 S_{\mathrm{II}} / 0.60 \mathrm{~S}_{\mathrm{I}}\right)$ are $523.51,294.28$, 179.73 , and $85.16 \mathrm{~N}$, respectively. Dickin et al. $[2,4,7,8,34,36]$ in dry sand observed that uplift capacity was considerably decreased by higher diameter ratios in homogeneous sand deposit. In the present study, increasing thickness of overlying stronger sand in layered sand deposit is responsible for higher value of $Q_{\mathrm{u}}\left(S_{\mathrm{II}} / S_{\mathrm{I}}\right)$ than $Q_{\mathrm{u}}\left(S_{\mathrm{I}}\right)$ in the same model.

It has been noticed from the experimental data reported in Table 4 (column (ii) and (vi)) that there has been a general trend for gradually decrease in $Q_{\mathrm{u}}\left(S_{\mathrm{I}}\right)$ and $Q_{\mathrm{u}}\left(S_{\mathrm{II}} / S_{\mathrm{I}}\right)$ with increase in $\beta$, regardless $L / D_{\mathrm{b}}, D_{\mathrm{s}} / D_{\mathrm{b}}, S_{\mathrm{I}}$, and $S_{\mathrm{II}} / S_{\mathrm{I}}$. In the present study, it is observed that, when $\beta$ increased from 45 to $63^{\circ}$ and from 63 to $72^{\circ}$, almost all the values of uplift capacities decreased by maximum $10 \%$ and by 17 to $22 \%$, respectively, in both the types of sand deposits. The similar pattern in behaviour of uplift capacity was noticed by Nazir et al. $[8,34]$ for small bell angles up to $60^{\circ}$ installed in homogeneous dry cohesionless soil in conventional test by 
TABLE 4: Values of experimental uplift capacities in $S_{\mathrm{I}}$ and $S_{\mathrm{II}} / S_{\mathrm{I}}\left(Q_{\mathrm{u}}\left(S_{\mathrm{I}}\right)\right.$ and $\left.Q_{\mathrm{u}}\left(S_{\mathrm{II}} / S_{\mathrm{I}}\right)\right)$, analytical uplift capacities in $S_{\mathrm{I}}$ and $S_{\mathrm{II}} / S_{\mathrm{I}}\left(Q_{\mathrm{u} . a n l y l}\left(S_{\mathrm{I}}\right)\right.$ and $\left.Q_{\mathrm{u} \text {.anlyl. }}\left(S_{\mathrm{II}} / S_{\mathrm{I}}\right)\right)$, error $(\%)$ on $Q_{\mathrm{u} \text {.anlyl. }}\left(S_{\mathrm{I}}\right)$ based on $Q_{\mathrm{u}}\left(S_{\mathrm{I}}\right)$, and error (\%) on $Q_{\mathrm{u} . \text { anlyl. }}\left(S_{\mathrm{II}} / S_{\mathrm{I}}\right)$ based on $Q_{\mathrm{u}}\left(S_{\mathrm{II}} / S_{\mathrm{I}}\right)$.

\begin{tabular}{|c|c|c|c|c|c|c|c|}
\hline $\begin{array}{l}\text { 3D model } \\
\text { designations in } S_{\mathrm{I}} \\
\text { (i) }\end{array}$ & $\begin{array}{l}Q_{\mathrm{u}}\left(S_{\mathrm{I}}\right) \\
(\mathrm{N}) \\
(\mathrm{ii}) \\
\end{array}$ & $\begin{array}{l}Q_{\text {u.anlyl. }}\left(S_{\mathrm{I}}\right) \\
\text { (N) } \\
\text { (iii) }\end{array}$ & $\begin{array}{c}\text { Error (\%) in (iii) } \\
\text { based on (ii) } \\
\text { (iv) }\end{array}$ & $\begin{array}{c}\text { 3D model } \\
\text { designations in } S_{\mathrm{II}} / S_{\mathrm{I}} \\
(\mathrm{v})\end{array}$ & $\begin{array}{l}Q_{\mathrm{u} .}\left(S_{\mathrm{II}} /\right. \\
\left.S_{\mathrm{I}}\right)(\mathrm{N}) \\
\quad(\mathrm{vi})\end{array}$ & $\begin{array}{l}Q_{\text {u.anlyl. }}\left(S_{\text {II }} /\right. \\
\left.S_{\mathrm{I}}\right)(\mathrm{N}) \\
\text { (vii) }\end{array}$ & $\begin{array}{c}\text { Error (\%) in (vii) } \\
\text { based on (vi) } \\
\text { (viii) }\end{array}$ \\
\hline $3 \mathrm{D}: 45-0.28-3-\left(S_{\mathrm{I}}\right)$ & 123.98 & 125.28 & -01.05 & $\begin{array}{l}3 \mathrm{D}: 45-0.28-3- \\
\left(0.39 S_{\mathrm{II}} / 0.61 S_{\mathrm{I}}\right)\end{array}$ & 151.15 & 149.60 & +01.03 \\
\hline $3 \mathrm{D}: 45-0.28-4-\left(S_{\mathrm{I}}\right)$ & 234.84 & 226.65 & +03.50 & $\begin{array}{l}\text { 3D:45-0.28-4- } \\
\left(0.54 S_{\text {II }} / 0.46 S_{\mathrm{I}}\right)\end{array}$ & 297.90 & 276.30 & +07.25 \\
\hline 3D:45-0.28-5-( $\left.S_{\mathrm{I}}\right)$ & 347.56 & 383.70 & -10.40 & $\begin{array}{l}3 \mathrm{D}: 45-0.28-5- \\
\left(0.63 S_{\mathrm{II}} / 0.37 S_{\mathrm{I}}\right)\end{array}$ & 523.51 & 481.68 & +08.00 \\
\hline $3 \mathrm{D}: 45-0.33-3-\left(S_{\mathrm{I}}\right)$ & 82.30 & 80.85 & +01.76 & $\begin{array}{l}3 \mathrm{D}: 45-0.33-3- \\
\left(0.30 S_{\mathrm{II}} / 0.70 S_{\mathrm{I}}\right)\end{array}$ & 89.76 & 95.97 & -06.92 \\
\hline 3D:45-0.33-4- $\left(S_{\mathrm{I}}\right)$ & 154.75 & 154.75 & -00.00 & $\begin{array}{l}3 \mathrm{D}: 45-0.33-4- \\
\left(0.47 S_{\mathrm{II}} / 0.53 S_{\mathrm{I}}\right)\end{array}$ & 189.53 & 187.57 & +01.03 \\
\hline 3D:45-0.33-5- $\left(S_{\mathrm{I}}\right)$ & 235.75 & 251.07 & -06.50 & $\begin{array}{l}3 \mathrm{D}: 45-0.33-5- \\
\left(0.58 S_{\mathrm{II}} / 0.42 S_{\mathrm{I}}\right)\end{array}$ & 294.28 & 325.84 & -10.72 \\
\hline 3D:45-0.38-3- $\left(S_{\mathrm{I}}\right)$ & 48.10 & 50.63 & -05.30 & $\begin{array}{l}3 \mathrm{D}: 45-0.38-3- \\
\left(0.18 S_{\mathrm{II}} / 0.82 S_{\mathrm{I}}\right)\end{array}$ & 50.71 & 52.34 & -03.22 \\
\hline 3D:45-0.38-4- $\left(S_{\mathrm{I}}\right)$ & 93.38 & 95.23 & -01.98 & $\begin{array}{l}\text { 3D:45-0.38-4- } \\
\left(0.38 S_{\mathrm{II}} / 0.62 S_{\mathrm{I}}\right)\end{array}$ & 112.92 & 115.80 & -02.54 \\
\hline 3D:45-0.38-5- $\left(S_{\mathrm{I}}\right)$ & 134.35 & 147.90 & -10.08 & $\begin{array}{l}3 \mathrm{D}: 45-0.38-5- \\
\left(0.51 S_{\mathrm{II}} / 0.49 S_{\mathrm{I}}\right)\end{array}$ & 179.73 & 188.64 & -04.96 \\
\hline $3 \mathrm{D}: 45-0.46-3-\left(S_{\mathrm{I}}\right)$ & 25.70 & 28.45 & -10.70 & $3 \mathrm{D}: 45-0.46-3-\left(S_{\mathrm{I}}\right)$ & 25.70 & 28.45 & -10.70 \\
\hline $3 \mathrm{D}: 45-0.46-4-\left(S_{\mathrm{I}}\right)$ & 47.11 & 47.24 & -00.28 & $\begin{array}{c}3 \mathrm{D}: 45-0.46-4- \\
\left(0.25 S_{\mathrm{II}} / 0.75 S_{\mathrm{I}}\right)\end{array}$ & 50.54 & 54.50 & -07.82 \\
\hline $3 \mathrm{D}: 45-0.46-5-\left(S_{\mathrm{I}}\right)$ & 71.56 & 71.77 & -00.30 & $\begin{array}{l}3 \mathrm{D}: 45-0.46-5- \\
\left(0.40 S_{\mathrm{II}} / 0.60 S_{\mathrm{I}}\right)\end{array}$ & 85.16 & 84.44 & +00.85 \\
\hline $3 \mathrm{D}: 63-0.28-3-\left(S_{\mathrm{I}}\right)$ & 115.17 & 106.51 & +07.52 & $\begin{array}{c}Q_{\mathrm{u}}: 63-0.28-3- \\
\left(0.39 S_{\mathrm{II}} / 0.61 S_{\mathrm{I}}\right)\end{array}$ & 138.05 & 128.56 & +06.88 \\
\hline 3D:63-0.28-4- $\left(S_{\mathrm{I}}\right)$ & 204.65 & 199.90 & +02.33 & $\begin{array}{l}Q_{\mathrm{u}}: 63-0.28-4- \\
\left(0.54 S_{\mathrm{II}} / 0.46 S_{\mathrm{I}}\right)\end{array}$ & 271.30 & 247.51 & +08.77 \\
\hline 3D:63-0.28-5- $\left(S_{\mathrm{I}}\right)$ & 313.90 & 321.46 & -02.41 & $\begin{array}{l}3 \mathrm{D}: 63-0.28-5- \\
\left(0.63 S_{\mathrm{II}} / 0.37 S_{\mathrm{I}}\right)\end{array}$ & 480.16 & 447.44 & +06.82 \\
\hline 3D:63-0.33-3- $\left(S_{\mathrm{I}}\right)$ & 74.54 & 73.83 & +00.95 & $\begin{array}{l}\text { 3D:63-0.33-3- } \\
\left(0.30 S_{\mathrm{II}} / 0.70 S_{\mathrm{I}}\right)\end{array}$ & 81.30 & 84.66 & -04.13 \\
\hline 3D:63-0.33-4- $\left(S_{\mathrm{I}}\right)$ & 142.40 & 136.42 & +04.20 & $\begin{array}{l}3 \mathrm{D}: 63-0.33-4- \\
\left(0.47 S_{\mathrm{II}} / 0.53 S_{\mathrm{I}}\right)\end{array}$ & 170.71 & 167.42 & +01.93 \\
\hline 3D:63-0.33-5- $\left(S_{\mathrm{I}}\right)$ & 218.68 & 213.21 & +02.50 & $\begin{array}{l}\text { 3D:63-0.33-5- } \\
\left(0.58 S_{\text {II }} / 0.42 S_{\text {I }}\right)\end{array}$ & 273.15 & 269.43 & +01.36 \\
\hline 3D:63-0.38-3- $\left(S_{\mathrm{I}}\right)$ & 43.83 & 43.82 & +00.02 & $\begin{array}{l}\text { 3D:63-0.38-3- } \\
\left(0.18 S_{\text {II }} / 0.82 S_{\text {I }}\right)\end{array}$ & 47.04 & 48.21 & -02.48 \\
\hline 3D:63-0.38-4- $\left(S_{\mathrm{I}}\right)$ & 85.20 & 79.26 & +06.96 & $\begin{array}{l}3 \mathrm{D}: 63-0.38-4- \\
\left(0.38 S_{\mathrm{II}} / 0.62 S_{\mathrm{I}}\right)\end{array}$ & 103.81 & 100.80 & +02.91 \\
\hline $3 \mathrm{D}: 63-0.38-5-\left(S_{\mathrm{I}}\right)$ & 121.18 & 117.97 & +02.65 & $\begin{array}{l}3 \mathrm{D}: 63-0.38-5- \\
\left(0.51 S_{\mathrm{II}} / 0.49 S_{\mathrm{I}}\right)\end{array}$ & 166.48 & 166.85 & -00.22 \\
\hline $3 \mathrm{D}: 63-0.46-3-\left(S_{\mathrm{I}}\right)$ & 21.71 & 25.77 & -18.72 & $3 \mathrm{D}: 63-0.46-3-\left(S_{\mathrm{I}}\right)$ & 21.71 & 25.77 & -18.72 \\
\hline 3D:63-0.46-4- $\left(S_{\mathrm{I}}\right)$ & 42.53 & 41.42 & +02.60 & $\begin{array}{l}\text { 3D:63-0.46-4- } \\
\left(0.25 S_{\mathrm{II}} / 0.75 S_{\mathrm{I}}\right)\end{array}$ & 45.77 & 48.71 & -06.43 \\
\hline 3D:63-0.46-5- $\left(S_{\mathrm{I}}\right)$ & 64.33 & 63.38 & +01.48 & $\begin{array}{l}3 \mathrm{D}: 63-0.46-5- \\
\left(0.40 S_{\mathrm{II}} / 0.60 S_{\mathrm{I}}\right)\end{array}$ & 78.02 & 74.10 & +05.02 \\
\hline $3 \mathrm{D}: 72-0.28-3-\left(S_{\mathrm{I}}\right)$ & 95.14 & 89.81 & +05.61 & $\begin{array}{c}\text { 3D:72-0.28-3- } \\
\left(0.39 S_{\mathrm{II}} / 0.61 S_{\mathrm{I}}\right)\end{array}$ & 112.38 & 104.71 & +06.82 \\
\hline 3D:72-0.28-4- $\left(S_{\mathrm{I}}\right)$ & 177.06 & 166.48 & +05.98 & $\begin{array}{l}3 \mathrm{D}: 72-0.28-4- \\
\left(0.54 S_{\mathrm{II}} / 0.46 S_{\mathrm{I}}\right)\end{array}$ & 221.14 & 191.08 & +13.60 \\
\hline 3D:72-0.28-5- $\left(S_{\mathrm{I}}\right)$ & 257.56 & 251.10 & +02.51 & $\begin{array}{l}Q_{\mathrm{u}}: 72-0.28-5- \\
\left(0.63 S_{\mathrm{II}} / 0.37 S_{\mathrm{I}}\right)\end{array}$ & 370.34 & 347.20 & +06.25 \\
\hline 3D:72-0.33-3- $\left(S_{\mathrm{I}}\right)$ & 60.86 & 63.00 & -03.52 & $\begin{array}{l}3 \mathrm{D}: 72-0.33-3- \\
\left(0.30 S_{\mathrm{II}} / 0.70 S_{\mathrm{I}}\right)\end{array}$ & 66.61 & 68.52 & -02.87 \\
\hline 3D:72-0.33-4- $\left(S_{\mathrm{I}}\right)$ & 112.20 & 105.46 & +06.00 & $\begin{array}{l}3 \mathrm{D}: 72-0.33-4- \\
\left(0.47 S_{\mathrm{II}} / 0.53 S_{\mathrm{I}}\right)\end{array}$ & 136.13 & 122.74 & +09.83 \\
\hline
\end{tabular}


TABLE 4: Continued.

\begin{tabular}{|c|c|c|c|c|c|c|c|}
\hline $\begin{array}{l}3 \mathrm{D} \text { model } \\
\text { designations in } S_{\mathrm{I}} \\
\text { (i) }\end{array}$ & $\begin{array}{l}Q_{\mathrm{u}}\left(S_{\mathrm{I}}\right) \\
(\mathrm{N}) \\
(\mathrm{ii})\end{array}$ & $\begin{array}{l}\text { Qu.anlyl. }\left(S_{\mathrm{I}}\right) \\
\quad \text { (N) } \\
\quad \text { (iii) }\end{array}$ & $\begin{array}{l}\text { Error (\%) in (iii) } \\
\text { based on (ii) } \\
\text { (iv) }\end{array}$ & $\begin{array}{c}\text { 3D model } \\
\text { designations in } S_{\mathrm{II}} / S_{\mathrm{I}} \\
(\mathrm{v})\end{array}$ & $\begin{array}{l}Q_{\mathrm{u} .}\left(S_{\mathrm{II}} /\right. \\
\left.S_{\mathrm{I}}\right)(\mathrm{N}) \\
\quad(\mathrm{vi})\end{array}$ & $\begin{array}{l}\text { Qu.anlyl.. }\left(S_{\text {II }} /\right. \\
\left.S_{\mathrm{I}}\right)(\mathrm{N}) \\
\quad(\mathrm{vii})\end{array}$ & $\begin{array}{c}\text { Error (\%) in (vii) } \\
\text { based on (vi) } \\
\text { (viii) }\end{array}$ \\
\hline $3 \mathrm{D}: 72-0.33-5-\left(S_{\mathrm{I}}\right)$ & 170.15 & 155.67 & +08.51 & $\begin{array}{l}\text { 3D:72-0.33-5- } \\
\left(0.58 S_{\mathrm{II}} / 0.42 S_{\mathrm{I}}\right)\end{array}$ & 219.37 & 198.94 & +09.31 \\
\hline 3D:72-0.38-3- $\left(S_{\mathrm{I}}\right)$ & 36.93 & 40.00 & -08.32 & $\begin{array}{l}\text { 3D:72-0.38-3- } \\
\left(0.18 S_{\mathrm{II}} / 0.82 S_{\mathrm{I}}\right)\end{array}$ & 38.91 & 42.40 & -08.97 \\
\hline 3D:72-0.38-4- $\left(S_{\mathrm{I}}\right)$ & 70.76 & 66.95 & +05.39 & $\begin{array}{l}3 \mathrm{D}: 72-0.38-4- \\
\left(0.38 S_{\mathrm{II}} / 0.62 S_{\mathrm{I}}\right)\end{array}$ & 84.14 & 78.70 & +06.46 \\
\hline 3D:72-0.38-5- $\left(S_{\mathrm{I}}\right)$ & 98.94 & 99.40 & -00.46 & $\begin{array}{l}3 \mathrm{D}: 72-0.38-5- \\
\left(0.51 S_{\text {II }} / 0.49 S_{\mathrm{I}}\right)\end{array}$ & 132.12 & 118.74 & +10.12 \\
\hline $3 \mathrm{D}: 72-0.46-3-\left(S_{\mathrm{I}}\right)$ & 19.65 & 22.88 & -16.46 & $3 \mathrm{D}: 72-0.46-3-\left(S_{\mathrm{I}}\right)$ & 19.65 & 22.88 & -16.46 \\
\hline 3D:72-0.46-4- $\left(S_{\mathrm{I}}\right)$ & 33.60 & 36.01 & -07.18 & $\begin{array}{l}3 \mathrm{D}: 72-0.46-4- \\
\left(0.25 S_{\mathrm{II}} / 0.75 S_{\mathrm{I}}\right)\end{array}$ & 37.57 & 39.48 & -05.08 \\
\hline $3 \mathrm{D}: 72-0.46-5-\left(S_{\mathrm{I}}\right)$ & 51.16 & 52.70 & -03.01 & $\begin{array}{l}3 \mathrm{D}: 72-0.46-5- \\
\left(0.40 S_{\mathrm{II}} / 0.60 S_{\mathrm{I}}\right)\end{array}$ & 63.76 & 60.88 & +04.52 \\
\hline
\end{tabular}

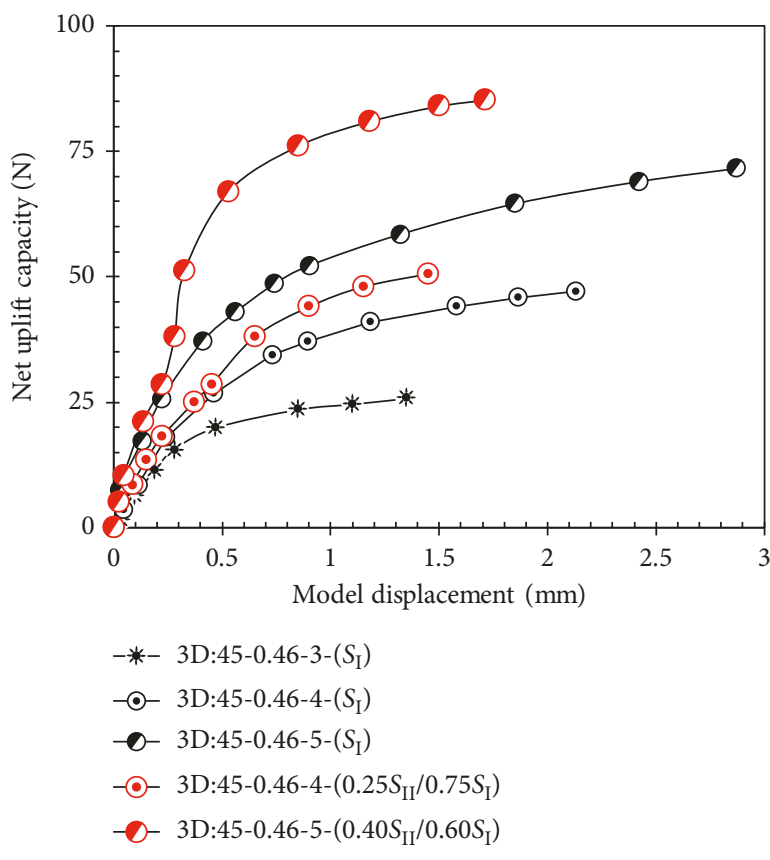

(a)

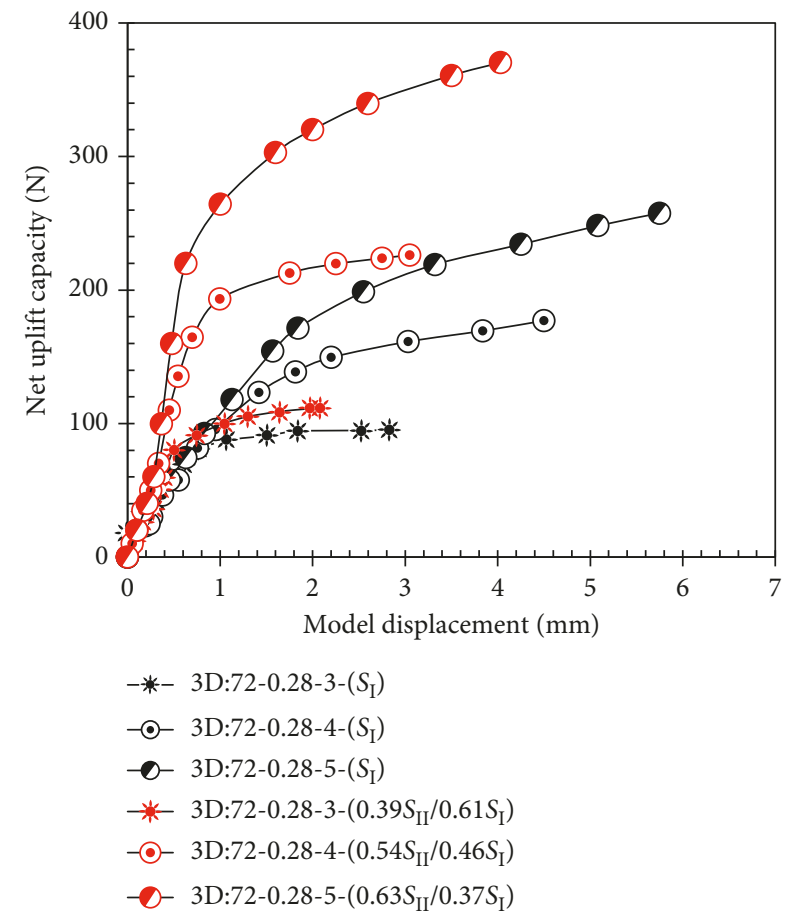

(b)

Figure 4: Comparison of net uplift capacity vs. model displacement (a) for model 3D:45-0.46 and (b) for model 3D:72-0.28, both in homogeneous $\left(S_{\mathrm{I}}\right)$ and layered $\left(S_{\mathrm{II}} / S_{\mathrm{I}}\right)$ sand deposits at $L / D_{\mathrm{b}}=3,4$, and 5 .

physical modelling. Dickin and Leung [3] reported the variation in uplift behaviour of anchors having bell angle within a range of 22 to $72^{\circ}$ in centrifugal modelling test and noticed that, when bell angle was $72^{\circ}$, there was a rapid decrease in uplift capacity in comparison to those found for $62^{\circ}$ belled anchor. In case of each model, $Q_{\mathrm{u}}\left(S_{\mathrm{II}} / S_{\mathrm{I}}\right)$ is relatively higher than $Q_{\mathrm{u}}\left(S_{\mathrm{I}}\right)$, as more tensile load necessitates for developing and lifting larger breakout wedge in $S_{\mathrm{II}} / S_{\mathrm{I}}$.

\section{Observations on Nonlinear Failure Surfaces}

Before installation of 2D panels inside the testing tank, due to symmetricity about vertical axis, a vertical centre-line is marked along the thickness of each model. This centre line is detectable from outside of plaxi-glass. In this study, applied forces are acting along the vertical plane of $2 \mathrm{D}$ panels.

Figures $5(\mathrm{a})-5(\mathrm{c})$ show the typical pictorial failure surfaces on both the sides of 2D:45-0.46-4- $\left(S_{\mathrm{I}}\right), 2 \mathrm{D}: 63-0.33-5-$ $\left(S_{\mathrm{I}}\right)$, and 2D:72-0.46-4- $\left(S_{\mathrm{I}}\right)$, respectively. Figures 6(a)-6(c) represent the typical pictorial failure surfaces on both the sides of $2 \mathrm{D}: 45-0.28-3-\left(0.39 S_{\mathrm{II}} / 0.61 S_{\mathrm{I}}\right), 2 \mathrm{D}: 63-0.33-4-\left(0.47 S_{\mathrm{II}} /\right.$ $\left.0.53 S_{\mathrm{I}}\right)$, and $2 \mathrm{D}: 72-0.38-3-\left(0.18 S_{\mathrm{II}} / 0.82 S_{\mathrm{I}}\right)$, respectively. The midpoint of panel base is taken as origin $(0,0)$, and failure points are presented in co-ordinate system in semi-infinite sand mass. At the collapsed stage, at every $21 \mathrm{~mm}$ vertical interval, the corresponding horizontal distance between 


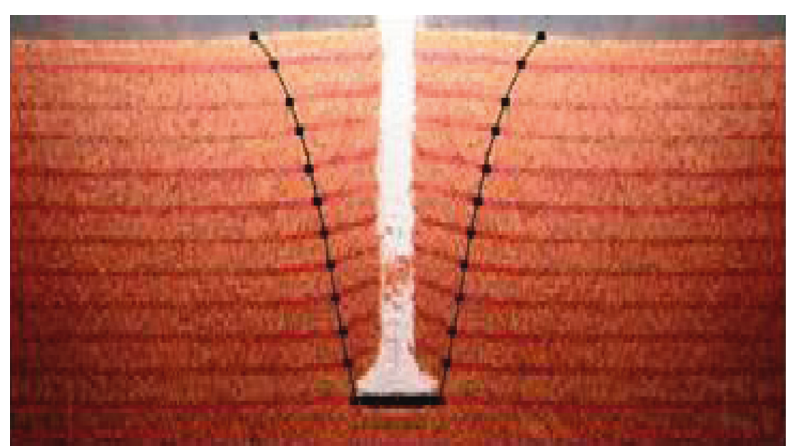

(a)

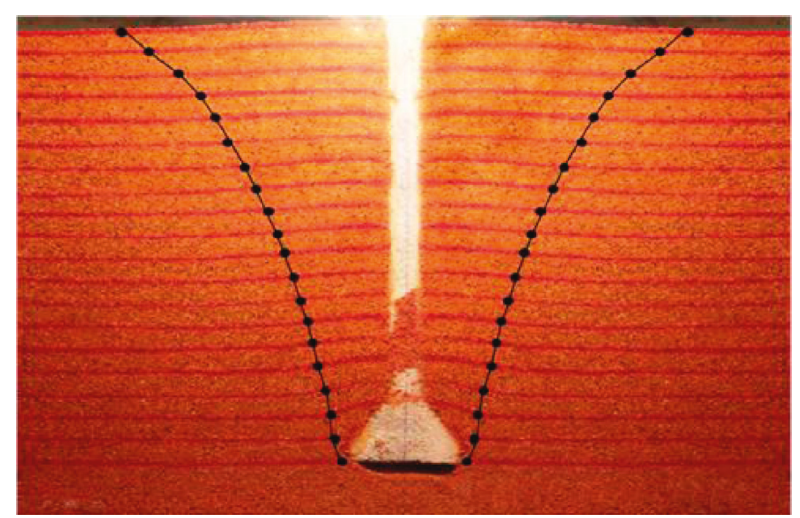

(b)

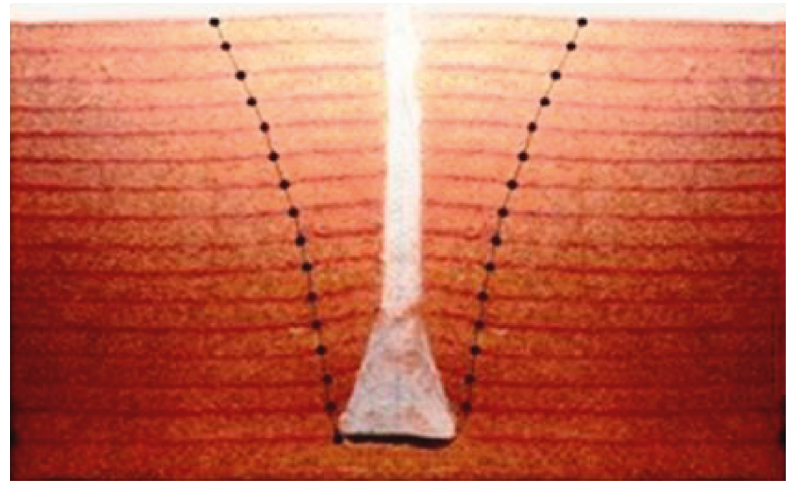

(c)

FIGURe 5: Pictorial view of nonlinear failure surfaces on both the sides of (a) panel 2D:45-0.46-4- $\left(S_{\mathrm{I}}\right)$, (b) panel 2D:63-0.33-5-( $\left.S_{\mathrm{I}}\right)$, and (c) panel 2D:72-0.33-4- $\left(S_{\mathrm{I}}\right)$.

centre line and deformed dyed sand layers of breakout wedge is measured.

In typical Figures $7-13$, plots of failure surfaces are presented to explore the comparison of the behaviour of failure surfaces and uplift capacities in $S_{\text {I }}$ and $S_{\text {II }} / S_{\text {I }}$ deposits in reference to embedment ratios, diameter ratios, and bell angles. In these plots, failure surface is symbolized by "FS." It is observed that, for all the 45 and $63^{\circ}$ anchors, $\beta_{\mathrm{a}}\left(S_{\mathrm{I}}\right)$ and $\beta_{\mathrm{a}}\left(S_{\mathrm{II}} / S_{\mathrm{I}}\right)$ values are very close, and these are within the range of 12.09 to $15.95^{\circ}$. For the $72^{\circ}$ anchors, almost all the $\beta_{\mathrm{a}}\left(S_{\mathrm{I}}\right)$ and $\beta_{\mathrm{a}}\left(S_{\mathrm{II}} / S_{\mathrm{I}}\right)$ values are within the range of 8.13 to $10.78^{\circ}$. The $\beta_{\mathrm{f}}\left(S_{\mathrm{I}}\right)$ and $\beta_{\mathrm{f}}\left(S_{\mathrm{II}} / S_{\mathrm{I}}\right)$ values for the 45 and $63^{\circ}$ anchors are within the range of 32.74 to $50.19^{\circ}$. For the $72^{\circ}$ anchors, all the $\beta_{\mathrm{f}}\left(S_{\mathrm{I}}\right)$ and $\beta_{\mathrm{f}}\left(S_{\mathrm{II}} / S_{\mathrm{I}}\right)$ values are within the range of 19.98 to $27.76^{\circ}$ and 24.62 to $34.22^{\circ}$, respectively. In general, for all models, the difference between the values of $\beta_{\mathrm{a}}\left(S_{\mathrm{I}}\right)$ and $\beta_{\mathrm{f}}\left(S_{\mathrm{I}}\right)$, and $\beta_{\mathrm{a}}\left(S_{\mathrm{II}} / S_{\mathrm{I}}\right)$ and $\beta_{\mathrm{f}}\left(S_{\mathrm{II}} / S_{\mathrm{I}}\right)$ are at least $10^{\circ}$, which supports the nonlinearity of the failure surfaces.

\section{Analysis of Failure Surfaces Based on Horizontal Slice Method}

The horizontal failure points obtained from both the sides of $2 \mathrm{D}$ panels can be identically replicated around the $3 \mathrm{D}$ model anchors as a three-dimensional axisymmetric solid body of breakout sand. From the known coordinates of failure points, a number of horizontal slices are found having $21 \mathrm{~mm}(\Delta \mathrm{z})$ thickness. Each slice of breakout sand is acting as a truncated cone in the axisymmetric model, and elemental forces acting on the slice wedge are presented by the free body diagram, as shown in Figures 14 and 15 for $S_{\text {I }}$ and $S_{\text {II }} / S_{\text {I }}$ deposits, respectively. All the mathematical terms and expressions used to establish the method of plastic analysis is explained in Sections 8.1 and 8.2.

8.1. Analysis of Breakout Wedge in Homogeneous Sand Deposit $\left(S_{I}\right)$. Similar procedure is followed to analyze net ultimate uplift capacity in layered buried sand $\left(S_{\mathrm{II}} / S_{\mathrm{I}}\right)$ and presented elaborately in next Section 8.2.

Analytical gross ultimate uplift capacity for whole wedge is found by summing up gross uplift capacities for $n$ number of slices:

$$
Q_{\text {g.anlyl. }}\left(S_{I}\right)=\sum_{j=1}^{m} Q_{\text {j.g.anlyl. }}\left(S_{I}\right) \text {, }
$$

and analytical net ultimate uplift capacity is

$$
Q_{\text {u.anlyl. }}\left(S_{\mathrm{I}}\right)=Q_{\text {g.anlyl. }}\left(S_{\mathrm{I}}\right)-W_{\text {anlyl. }}\left(S_{\mathrm{I}}\right),
$$

where $m=$ total numbers of slices in the wedge; $j=$ any slice within the failure wedge (value: 1 to $m$ ); $Q_{\text {j.g.anlyl. }}\left(S_{I}\right)=$ gross ultimate uplift capacity of $j^{\text {th }}$ wedge in $S_{I}$ deposit; $Q_{\text {g.anlyl. }}\left(S_{\mathrm{I}}\right)=$ gross ultimate uplift capacity of wedge in $S_{\mathrm{I}}$ deposit; $Q_{\text {u.anlyl. }}\left(S_{\mathrm{I}}\right)=$ net ultimate uplift capacity of wedge in $S_{\text {I }}$ deposit; and $W_{\text {anlyl. }}\left(S_{\mathrm{I}}\right)=$ weight of sand equal to the same 


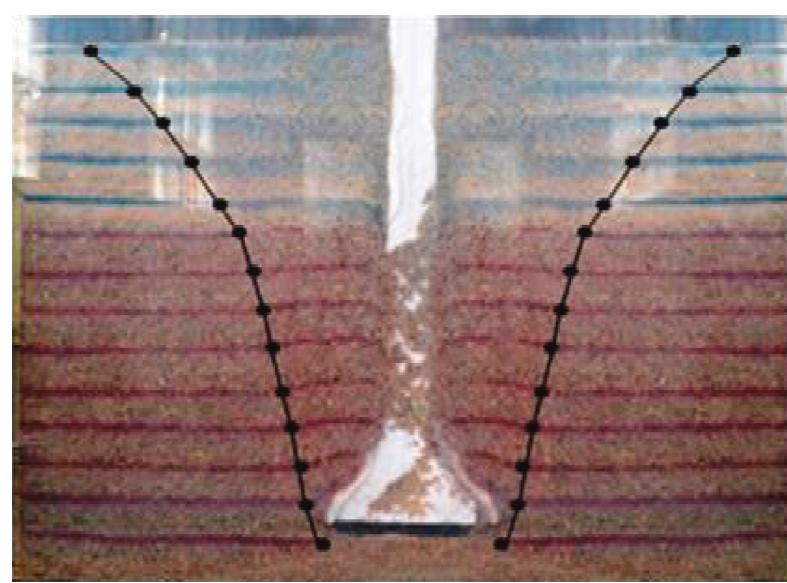

(a)

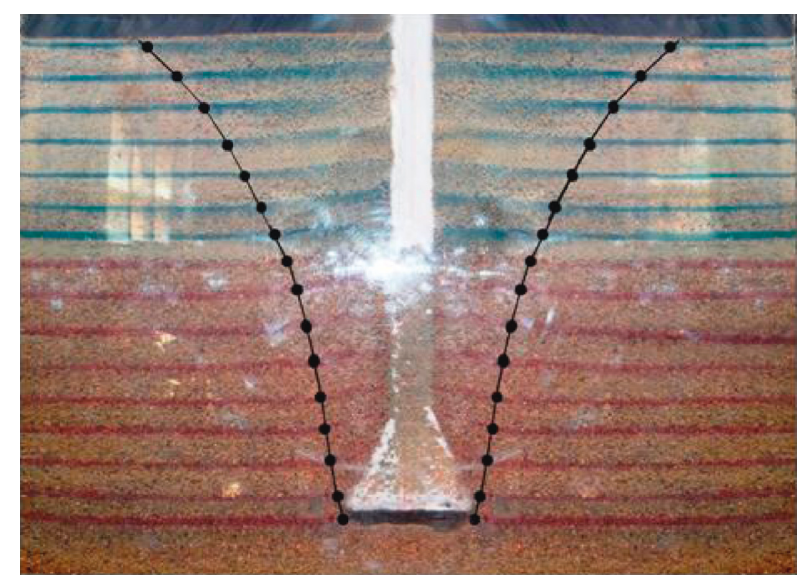

(b)

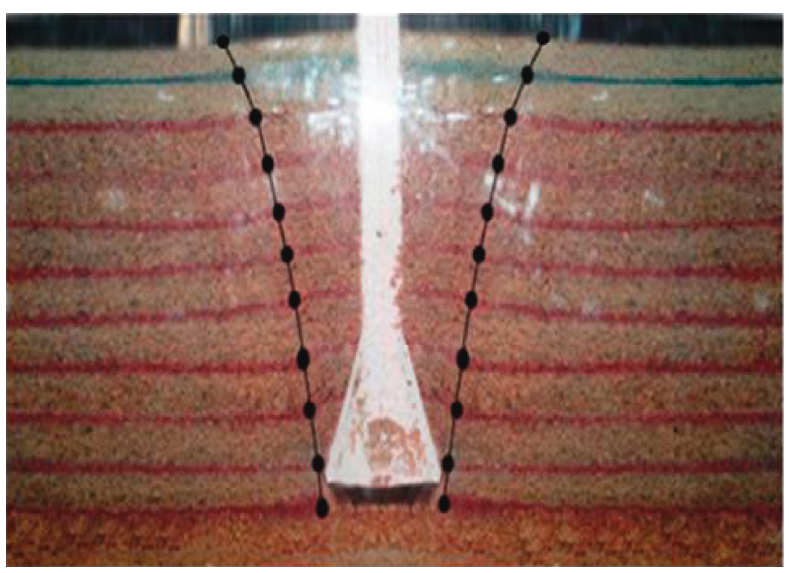

(c)

FIGURE 6: Pictorial view of nonlinear failure surfaces on both the sides of (a) panel 2D:45-0.28-3- $\left(0.39 S_{\text {II }} / 0.61 S_{\text {I }}\right)$, (b) panel 2D:63-0.33-4$\left(0.47 S_{\text {II }} / 0.53 S_{\text {I }}\right)$, and (c) panel $2 \mathrm{D}: 72-0.38-3-\left(0.18 S_{\text {II }} / 0.82 S_{\text {I }}\right)$.

volume of the respective anchor model inside the breakout wedge in $S_{\mathrm{I}}$ deposit.

8.2. Analysis of Breakout Wedge in Layered Sand Deposit $\left(S_{I I} /\right.$ $S_{I}$ ). The interference of $d$ was ignored by Dickin et al. [2,26] on failure mechanism of plate and semicylindrical belled piles, so the same is followed in this study also. Moreover, Dickin and Leung [3] presented that artificially roughened belled shaft contribute to only $10 \%$ hike in uplift capacity.

Soil reaction on failure plane of $j^{\text {th }}$ slice:

$$
\begin{aligned}
\Delta F_{j}=\Delta R_{j} \Delta L_{j}= & {\left[\gamma_{\mathrm{I}}\left\{\left(y_{j}+\Delta y\right)-y_{j}\right\}\right.} \\
& \left.\cdot\left\{k_{0} \cos \beta_{j}+\sin \beta_{j}\right\} \frac{\Delta y}{\cos \beta_{j}}\right] .
\end{aligned}
$$

Soil reaction on failure plane of $i^{\text {th }}$ slice:

$$
\begin{aligned}
\Delta F_{i}=\Delta R_{i} \Delta L_{i}= & {\left[\gamma_{\mathrm{II}}\left\{\left(y_{i}+\Delta y\right)-y_{i}\right\}\right.} \\
& \left.\cdot\left\{k_{0} \cos \beta_{i}+\sin \beta_{i}\right\} \frac{\Delta y}{\cos \beta_{i}}\right] .
\end{aligned}
$$

At the collapsed stage, in state of limit equilibrium of soil, Mohr-Coulomb failure criteria can be considered. In accordance with Chattopadhyay and Pise [26], the vertical component of downward acting resultant mobilized shear resistance for $j^{\text {th }}$ and $i^{\text {th }}$ slice surface is calculated as follows:

$$
\begin{aligned}
\Delta T_{v j}= & {\left[2 \gamma_{\mathrm{I}} \pi \Delta y\left(r_{j}+\frac{\Delta r_{j}}{2}\right)\left\{\left(y_{j}+\Delta y\right)-y_{j}\right\}\right.} \\
& \left.\cdot\left\{k_{0} \cos \beta_{j}+\sin \beta_{j}\right\} \tan \phi\right], \\
\Delta T_{v i}= & {\left[2 \gamma_{\mathrm{II}} \pi \Delta y\left(r_{i}+\frac{\Delta r_{i}}{2}\right)\left\{\left(y_{i}+\Delta y\right)-y_{i}\right\}\right.} \\
& \left.\cdot\left\{k_{0} \cos \beta_{i}+\sin \beta_{i}\right\} \tan \phi\right] .
\end{aligned}
$$

Resultant surcharge intensity for $j^{\text {th }}$ slice:

$$
=\left[\pi\left\{\left(q_{r j}+\Delta q_{r j}\right)\left(r_{j}+\Delta r_{j}\right)^{2}-\left(q_{r j} r_{j}^{2}\right)\right\}\right] .
$$

Resultant surcharge intensity for $i^{\text {th }}$ slice:

$$
=\left[\pi\left\{\left(q_{r i}+\Delta q_{r i}\right)\left(r_{i}+\Delta r_{i}\right)^{2}-\left(q_{r i} r_{i}^{2}\right)\right\}\right] .
$$




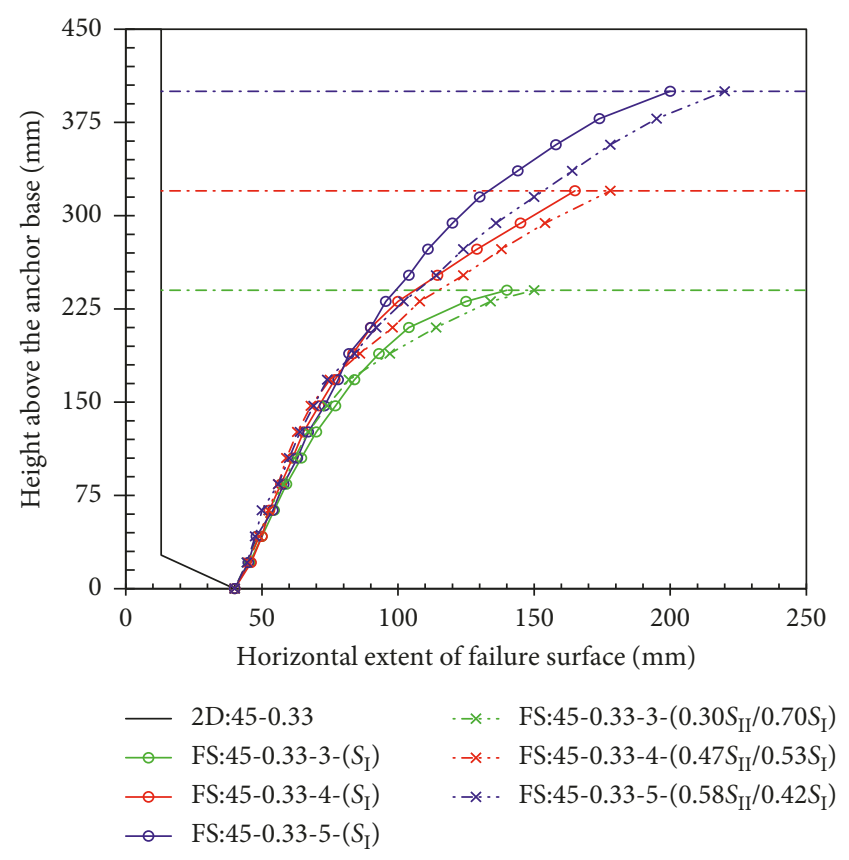

Figure 7: Comparison of FS:45-0.33-3- $\left(S_{\mathrm{I}}\right)$ and FS:45-0.33-3$\left(0.30 S_{\text {II }} / 0.70 S_{\text {I }}\right), \quad F S: 45-0.33-4-\left(S_{I}\right)$ and FS:45-0.33-4- $\left(0.47 S_{\text {II }} /\right.$ $\left.0.53 S_{\mathrm{I}}\right)$, and FS:45-0.33-5- $\left(S_{\mathrm{I}}\right)$ and FS:45-0.33-5-(0.58S $\left.\mathrm{II} / 0.42 S_{\mathrm{I}}\right)$.

Self-weight of the $j^{\text {th }}$ slice:

$$
=\left[\pi \gamma_{\mathrm{I}} \frac{\Delta y}{3}\left\{r_{j}^{2}++\left(r_{j}+\Delta r_{j}\right)^{2}+r_{j}\left(r_{j}+\Delta r_{j}\right)\right\}\right] \text {. }
$$

Self-weight of the $i^{\text {th }}$ slice:

$$
=\left[\pi \gamma_{\mathrm{II}} \frac{\Delta y}{3}\left\{r_{i}^{2}++\left(r_{i}+\Delta r_{i}\right)^{2}+r_{i}\left(r_{i}+\Delta r_{i}\right)\right\}\right] \text {. }
$$

Considering vertical equilibrium for all elementary forces of $j^{\text {th }}$ and $i^{\text {th }}$ slice, gross ultimate uplift capacity is

$$
\begin{aligned}
Q_{\text {j.g.anly }(}\left(\frac{S_{\mathrm{II}}}{S_{\mathrm{I}}}\right)= & {\left[2 \gamma_{\mathrm{I}} \pi \Delta y\left(r_{j}+\frac{\Delta r_{j}}{2}\right)\left\{\left(y_{j}+\Delta y\right)-y_{j}\right\}\right.} \\
& \left.\cdot\left\{k_{0} \cos \beta_{j}+\sin \beta_{j}\right\} \tan \phi\right] \\
& +\left[\pi\left\{\left(q_{r j}+\Delta q_{r j}\right)\left(r_{j}+\Delta r_{j}\right)^{2}-\left(q_{r j} r_{j}^{2}\right)\right\}\right] \\
& +\left[\pi \gamma_{\mathrm{I}} \frac{\Delta y}{3}\left\{r_{j}^{2}+\left(r_{j}+\Delta r_{j}\right)^{2}+r_{j}\left(r_{j}+\Delta r_{j}\right)\right\}\right] \\
Q_{\text {i.g.anly }}\left(\frac{S_{\mathrm{II}}}{S_{\mathrm{I}}}\right)= & {\left[2 \gamma_{\mathrm{II}} \pi \Delta y\left(r_{i}+\frac{\Delta r_{i}}{2}\right)\left\{\left(y_{i}+\Delta y\right)-y_{i}\right\}\right.} \\
& \left.\cdot\left\{k_{0} \cos \beta_{i}+\sin \beta_{i}\right\} \tan \phi\right] \\
& +\left[\pi\left\{\left(q_{r i}+\Delta q_{r i}\right)\left(r_{i}+\Delta r_{i}\right)^{2}-\left(q_{r i} r_{i}^{2}\right)\right\}\right] \\
& +\left[\pi \gamma_{\mathrm{II}} \frac{\Delta y}{3}\left\{r_{i}^{2}+\left(r_{i}+\Delta r_{i}\right)^{2}+r_{i}\left(r_{i}+\Delta r_{i}\right)\right\}\right] .
\end{aligned}
$$

Analytical gross ultimate uplift capacity $\left(Q_{\text {g.anlyl. }}\left(S_{\mathrm{II}} / S_{\mathrm{I}}\right)\right)$ for whole wedge may be computed by summing up gross uplift capacities for total $m$ number of slices in lower as well as upper layer:

$$
Q_{\text {g.anlyl }}\left(\frac{S_{\text {II }}}{S_{\text {I }}}\right)=\sum_{j=1}^{5} Q_{\text {j.g.anlyl }}\left(\frac{S_{\text {II }}}{S_{\text {I }}}\right)+\sum_{i=6}^{m} Q_{\text {i.g.anlyl }}\left(\frac{S_{\text {II }}}{S_{\text {I }}}\right) .
$$

Analytical net ultimate uplift capacity:

$$
Q_{\text {u.anlyl }}\left(\frac{S_{\text {II }}}{S_{\text {I }}}\right)=Q_{\text {g.anlyl }}\left(\frac{S_{\text {II }}}{S_{\text {I }}}\right)-W_{\text {anlyl }}\left(\frac{S_{\text {II }}}{S_{\text {I }}}\right),
$$

where $i=$ any slice within the failure wedge in top layer (value: 6 to $m) ; j=$ any slice within the failure wedge in bottom layer (value: 1 to 5 ); $m=$ total numbers of slices in breakout wedge; $Q_{r j+\Delta r j}=q \pi\left(r_{j}+\Delta r_{j}\right)^{2}$, surcharge load acting downward in $j^{\text {th }}$ slice; $Q Q_{\mathrm{rj}}=q \pi r_{j}^{2}$, surcharge load acting upward in $j^{\text {th }}$ slice; $Q_{r i+\Delta r i}=q \pi\left(r_{\mathrm{i}}+\Delta r_{i}\right)^{2}$, acting downward in $i^{\text {th }}$ slice; $Q Q_{\mathrm{ri}}=q \pi r_{j}^{2}$, acting upward in $i^{\text {th }}$ slice; $r_{\mathrm{i}}+\Delta \mathrm{r}_{\mathrm{i}}=$ larger radius of $i^{\text {th }}$ slice at the height of $y_{\mathrm{i}}+\Delta \mathrm{y} ; r_{\mathrm{i}}=$ smaller radius of $i^{\text {th }}$ slice; $r_{j}+\Delta r_{j}=$ larger radius of $j^{\text {th }}$ slice at the height of $y_{j}+\Delta y$; $r_{\mathrm{j}}=$ smaller radius of $j^{\text {th }}$ slice at height of $z_{\mathrm{j}}$ from anchor base; $\beta_{\mathrm{i}}=$ failure angle made with vertical by elemental $i^{\text {th }}$ slice; $\beta_{\mathrm{j}}=$ failure angle made with vertical by elemental $j^{\text {th }}$ slice; $\gamma_{\mathrm{II}}\left(y_{i}+\Delta y\right)=$ vertical pressure from $i^{\text {th }}$ slice acting downward; $\gamma_{\mathrm{I}}\left(y_{\mathrm{j}}+\Delta \mathrm{y}\right)=$ vertical pressure from $j^{\text {th }}$ slice acting downward; $\gamma_{\mathrm{II}} \mathrm{y}_{\mathrm{i}}=$ vertical reaction within $i^{\text {th }}$ slice acting upward; $\gamma_{\mathrm{I}} \mathrm{y}_{\mathrm{j}}=$ vertical reaction within ${ }^{\text {th }}$ slice acting upward; and $k_{0}=$ $(1-\sin \phi)$, used by Chattopadhyay and Pise [26].

\section{Discussions}

Based on failure surface study, the analytical data of net ultimate uplift capacity are found out for both homogeneous $\left(Q_{\text {u.anlyl. }}\left(S_{\mathrm{I}}\right)\right)$ and layered $\left(Q_{\text {u.anlyl. }}\left(S_{\mathrm{II}} / S_{\mathrm{I}}\right)\right)$ buried sand, and results are summarized in Table 4 (column (iii) and (vii)). On the basis of these data comparison of $Q_{\mathrm{u} \text {.anlyl. }}\left(S_{\mathrm{I}}\right)$ and $Q_{\text {u.anlyl. }}\left(S_{\mathrm{II}} / S_{\mathrm{I}}\right)$ in reference to embedment ratios, diameter ratios and bell angles are discussed herein. The variation in the values of maximum extent of failure in both the types of sand deposits has also been discussed in this section.

9.1. Comparison of Nonlinear Failure Surface around 2D Panels and Analytical Uplift Capacities of 3D Belled Anchor in Homogeneous and Layered Sand in reference to Embedment Ratios, Diameter Ratios, and Bell Angles. From the mentioned Figures $7-13$, it is observed that all the curves of failure surface are similar in pattern. The migration of curves started from the edge of anchor base and terminated in sandsurface. At anchor base and sand-surface, the values of horizontal distance of breakout points are minimum and maximum, respectively. The influence of overburden pressure and confinement of sand is maximum near to anchor base and minimum towards the sand-surface; hence, radial expansion of failure points near anchor base is minimum, gradually extensive in horizontal direction, and ultimately maximum at sand-surface $\left(r_{\max }\left(S_{\mathrm{I}}\right)\right.$ in $S_{\mathrm{I}}$ deposit and $r_{\max }\left(S_{\mathrm{II}} / S_{\mathrm{I}}\right)$ in $S_{\mathrm{II}} / S_{\mathrm{I}}$ deposit. Higher the confining pressure 
effects on lesser dilation of sand, subsequently lesser sliding and more interlocking.

The typical Figures 7-9 present that at higher embedment depth, near to the anchor base, failure points are relatively closer to each other, but the failure points towards the sand-surfaces have propensity to move more in horizontal direction, and thus $r_{\max }\left(S_{\mathrm{I}}\right)$ or $r_{\max }\left(S_{\mathrm{II}} / S_{\mathrm{I}}\right)$ values are larger in deep embedment depth compared to those wedges formed due to shallow embedment depth. Hence, larger volumes of wedges are generated for more embedment depth in comparison to those wedges generated due to smaller embedment depth in both the types of sand deposits. It has been noticed that, in $S_{\mathrm{II}} / S_{\mathrm{I}}$ deposit, in upper layer, comparatively wider zone of failure is developed than those observed in $S_{\text {I }}$ deposit. Matsuo et al. [24, 34] presented the pattern of failure surfaces in homogeneous sand deposit from the experimental study, Kumar [22] in collapse mechanism and velocity hydrograph, and Sakai and Tanaka [23] in shear bend propagation for layered sand and presented that linear failure surfaces in denser overlying sand extended horizontally more than underlying lesser dense sand. The typical Figures 7-9 reflect that, in FS:45-0.33-3$\left(0.30 S_{\text {II }} / 0.70 S_{\mathrm{I}}\right)$, FS: $72-0.38-3-\left(0.18 S_{\mathrm{II}} / 0.82 S_{\mathrm{I}}\right)$, and FS:63$0.46-4-\left(0.25 S_{\mathrm{II}} / 0.75 S_{\mathrm{I}}\right)$, there is a little hike in expansion of wedge than FS:45-0.33-3- $\left(S_{\mathrm{I}}\right)$, FS:72-0.38-3- $\left(S_{\mathrm{I}}\right)$, and FS:630.46-4- $\left(S_{\mathrm{I}}\right)$, respectively. In case of Figure 7, in FS:45-0.33-4$\left(0.47 S_{\text {II }} / 0.53 S_{\text {I }}\right)$ and FS:45-0.33-5- $\left(0.58 S_{\text {II }} / 0.42 S_{\text {I }}\right)$, the lateral expansion of wedge is higher in upper layer of sand than in FS:45-0.33-4- $\left(S_{\mathrm{I}}\right)$ and FS:45-0.33-5- $\left(S_{\mathrm{I}}\right)$, respectively. The same trend is also observed for FS:72-0.38-4- $\left(0.38 S_{\mathrm{II}} / 0.62 S_{\mathrm{I}}\right)$ and FS:72-0.38-5-(0.51S $\left.S_{\mathrm{II}} / 0.49 S_{\mathrm{I}}\right)$ (in Figure 8 ) and FS:63$0.46-5-\left(0.40 S_{\text {II }} / 0.60 S_{\text {I }}\right)$ (in Figure 9$)$ resulting in larger volume of wedges with higher values of $r_{\text {max. }}\left(S_{\mathrm{II}} / S_{\mathrm{I}}\right)$ than $r_{\text {max. }}\left(S_{\mathrm{I}}\right)$. As a result, more volume of sand is contained inside, providing higher dead-weight of breakout sand and exposing more lateral surface area to develop frictional shear (as $\gamma$ and $\phi$ values are higher for top layer than bottom layer). Data analysis from Table 4 (column (iii) and (vii)) reveals that, for 3D:63-0.28-3-(0.39S $\left.S_{\mathrm{II}} / 0.61 S_{\mathrm{I}}\right), 3 \mathrm{D}$ : 63-0.28-4- $\left(0.54 S_{\text {II }} / 0.46 S_{\text {I }}\right)$, and 3D:63-0.28-5-(0.63S 1 $\left.0.37 S_{\mathrm{I}}\right), Q_{\text {u.anlyl. }}\left(S_{\mathrm{II}} / S_{\mathrm{I}}\right)$ values are $128.56,247.51$, and $447.44 \mathrm{~N}$, respectively, whereas in the same model, $Q_{\text {u.anlyl. }}\left(S_{\mathrm{I}}\right)$ values $106.51,199.90$, and $321.46 \mathrm{~N}$ at $L / D_{\mathrm{b}}=3$, 4 , and 5 , respectively.

The typical graphical illustration of horizontal extent of failure points vs. embedment ratios for panels possessing $T_{\mathrm{s}} l$ $T_{\mathrm{b}}$ of $0.28,0.33,0.38$, and, 0.46 and each panel belonging to $\beta$ of $45^{\circ}$, at $L / T_{\mathrm{b}}$ of 5 are presented in Figures $10(\mathrm{a})$ and $10(\mathrm{~b})$ for both homogeneous and layered sand deposits. From the Figure 9, it is observed that volume of wedge inside the FS: 45-0.28-5- $\left(S_{\mathrm{I}}\right), \mathrm{FS}: 45-0.33-5-\left(S_{\mathrm{I}}\right), \mathrm{FS}: 45-0.38-5-\left(S_{\mathrm{I}}\right)$, and FS: 45-0.46-5- $\left(S_{\mathrm{I}}\right)$ are in the descending order, so among these four wedges, $Q_{\mathrm{u}}: 45-0.46-5-\left(S_{\mathrm{I}}\right)$ is minimum and $Q_{\mathrm{u}}: 45-0.28$ $5-\left(S_{\mathrm{I}}\right)$ is maximum. Similarly in Figure 9, it is noticed that volume of wedge inside the FS: $45-0.28-5-\left(0.63 S_{\text {II }} / 0.37 S_{\mathrm{I}}\right), \mathrm{FS}$ : $45-0.33-5-\left(0.58 S_{\text {II }} / 0.42 S_{\text {I }}\right)$, FS: $45-0.38-5-\left(0.51 S_{\text {II }} / 0.49 S_{\text {I }}\right)$, and FS:45-0.46-5- $\left(0.40 S_{\text {II }} / 0.60 S_{\mathrm{I}}\right)$ is in descending order; hence, among these four wedges $Q_{\mathrm{u}}: 45-0.46-5-\left(0.40 S_{\mathrm{II}} / 0.60 S_{\mathrm{I}}\right)$ is minimum and $Q_{\mathrm{u}}: 45-0.28-5-\left(0.63 S_{\mathrm{II}} / 0.37 S_{\mathrm{I}}\right)$ is maximum.

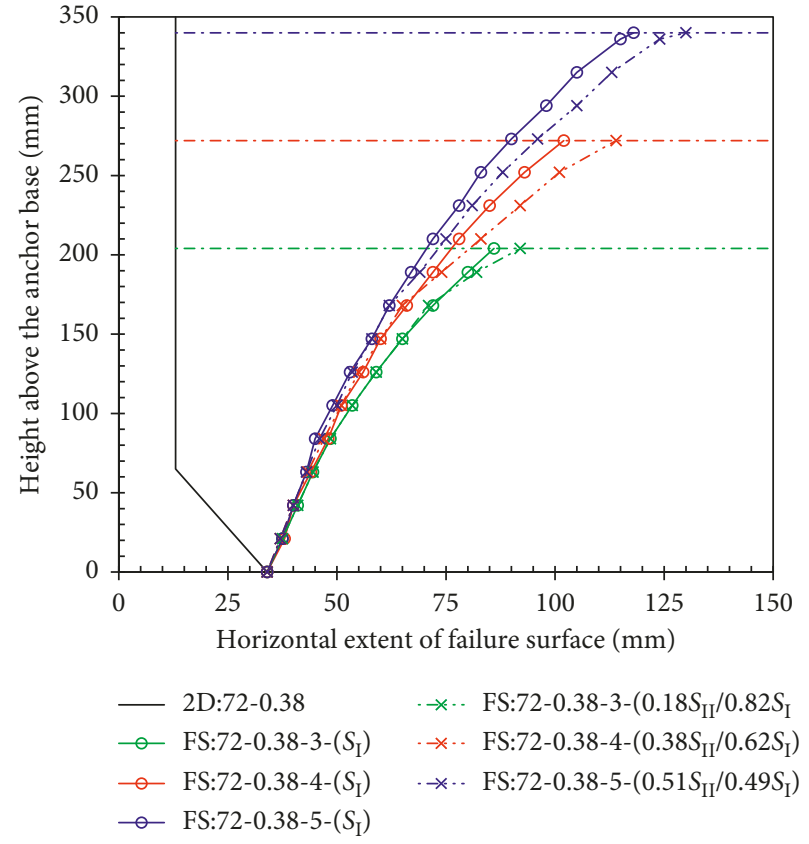

FIgURE 8: Comparison of FS:72-0.38-3- $\left(S_{\mathrm{I}}\right)$ and FS:72-0.38-3$\left(0.18 S_{\text {II }} / 0.82 S_{\text {I }}\right)$, FS:72-0.38-4- $\left(S_{\mathrm{I}}\right)$ and FS:72-0.38-4- $\left(0.38 S_{\text {II }} /\right.$ $\left.0.62 S_{\mathrm{I}}\right)$, and FS:72-0.38-5- $\left(S_{\mathrm{I}}\right)$ and FS:72-0.38-5-(0.51 $\left.S_{\mathrm{II}} / 0.49 S_{\mathrm{I}}\right)$.

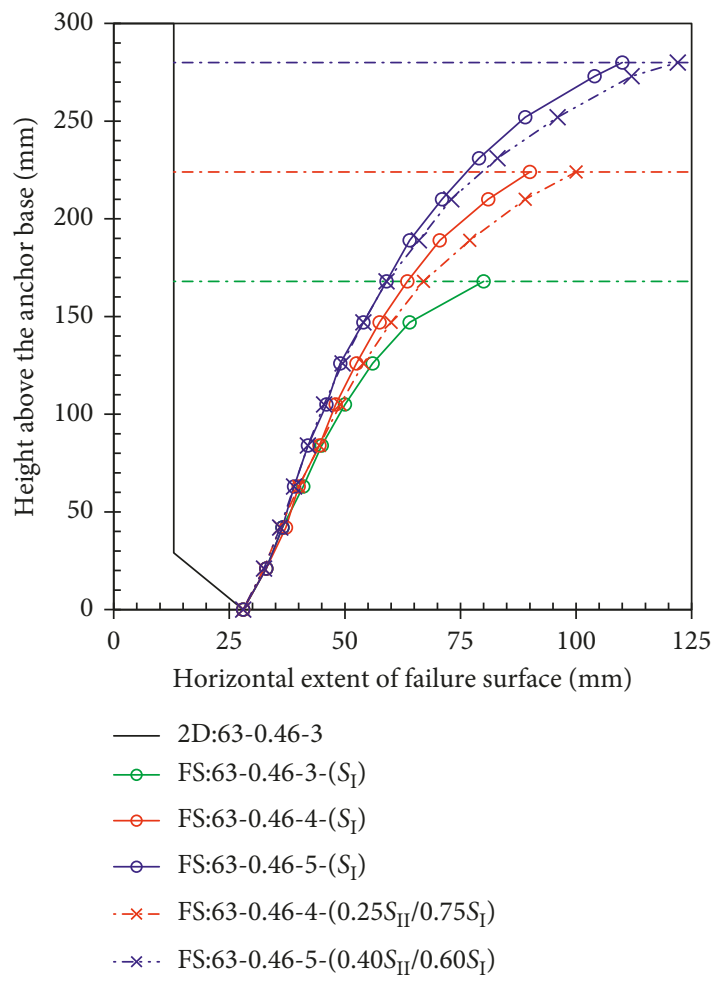

Figure 9: Failure surface around panel 2D:63-0.46-3- $\left(S_{\mathrm{I}}\right)$, in comparison to FS:63-0.46-4- $\left(S_{\mathrm{I}}\right)$ and FS:63-0.46-4- $\left(0.25 S_{\mathrm{II}} / 0.75 S_{\mathrm{I}}\right)$ and FS:63-0.46-5-( $\left.S_{\mathrm{I}}\right)$ and FS:63-0.46-5-(0.40S $\left.S_{\mathrm{II}} / 0.60 S_{\mathrm{I}}\right)$.

The abovementioned failure surfaces as developed in $S_{\mathrm{I}}$ and $S_{\text {II }} / S_{\text {I }}$ around their respective panels are presented in Figures 11(a)-11(d). These figures reveal that the integrated volume of wedge as well as dead weight of sand inside the 


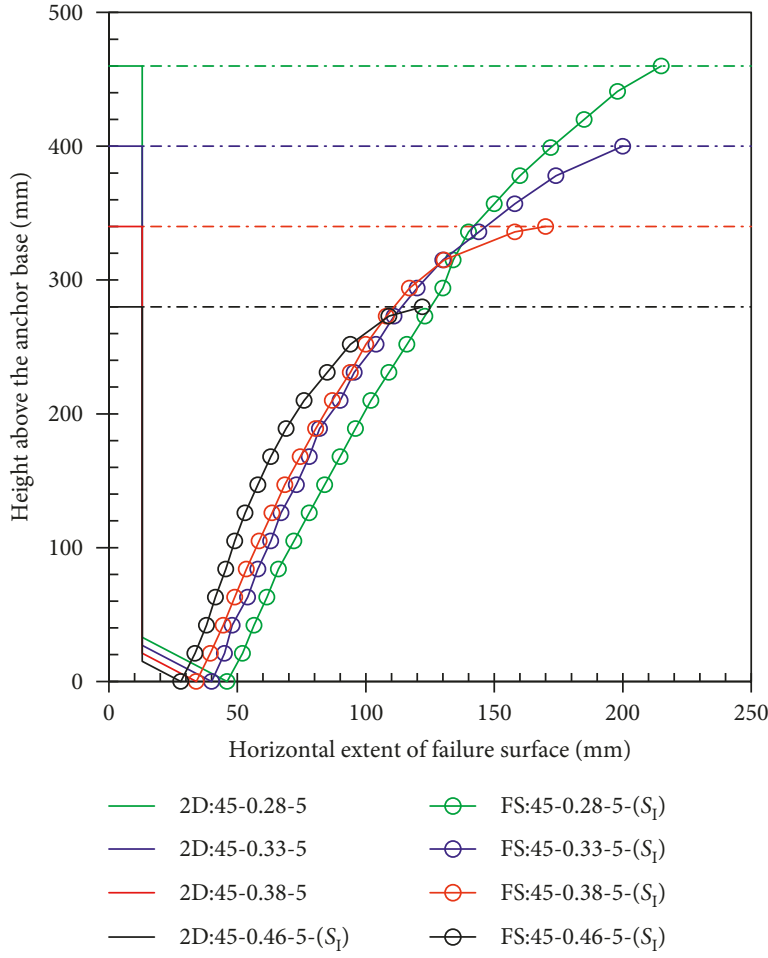

(a)

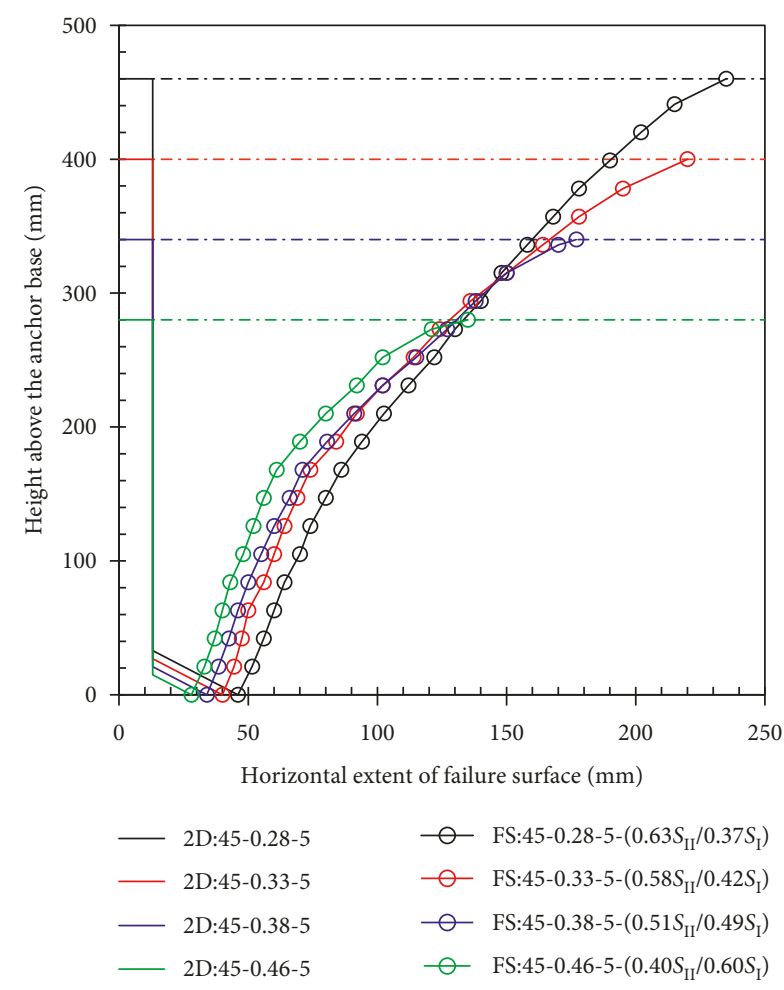

(b)

Figure 10: Height above the anchor base vs. horizontal extent of failure surface besides (a) panels having $a=45^{\circ}, L / T_{\mathrm{b}}=5$, and $T_{\mathrm{s}} / T_{\mathrm{b}}=0.28$, $0.33,0.38$, and 0.46 in homogeneous sand deposit $\left(S_{\mathrm{I}}\right)$ and (b) panels having $a=45^{\circ}$ and $L / T_{\mathrm{b}}=0.28,0.33,0.38$, and 0.46 in layered sand deposit $\left(S_{\mathrm{II}} / S_{\mathrm{I}}\right)$.

wedge and frictional area is higher in $S_{\text {II }} / S_{\text {I }}$ compared to $S_{\text {I }}$. Data analysis from Table 4 (column (iii) and (vii)) shows that the values of $Q_{\mathrm{u}}: 63-0.28-4-\left(S_{\mathrm{I}}\right), Q_{\mathrm{u}}: 63-0.33-4-\left(S_{\mathrm{I}}\right), Q_{\mathrm{u}}: 63-$ $0.38-4-\left(S_{\mathrm{I}}\right)$, and $Q_{\mathrm{u}}: 63-0.46-4-\left(S_{\mathrm{I}}\right)$ are $199.90,136.42,79.26$, and $41.42 \mathrm{~N}$, respectively, and for same models, the values of $Q_{\mathrm{u}}: 63-0.28-4-\left(0.54 S_{\mathrm{II}} / 0.46 S_{\mathrm{I}}\right), Q_{\mathrm{u}}: 63-0.33-4-\left(0.47 S_{\mathrm{II}} / 0.53 S_{\mathrm{I}}\right)$, $Q_{\mathrm{u}}: 63-0.38-4-\left(0.38 S_{\mathrm{II}} / 0.62 S_{\mathrm{I}}\right)$, and $Q_{\mathrm{u}}: 63-0.46-4-\left(0.25 S_{\mathrm{II}} /\right.$ $0.75 S_{\text {I }}$ ) are $247.51,167.42,100.80$, and $48.71 \mathrm{~N}$, respectively.

The typical graphical illustration of failure surfaces around panels having different values of $\beta$ for $2 \mathrm{D}$ panels at $L / T_{\mathrm{b}}=4, T_{\mathrm{s}} / T_{\mathrm{b}}$ of 0.33 and $2 \mathrm{D}$ panels at $L / T_{\mathrm{b}}=5, T_{\mathrm{s}} / T_{\mathrm{b}}$ of 0.28 is represented in Figures 12 and 13 in homogeneous and layered sand deposits, respectively. In general, it is observed that the failure surfaces for 45 and $63^{\circ}$ anchors are very close to each other than $72^{\circ}$ anchors in both $S_{\text {I }}$ and $S_{\text {II }} /$ $S_{\text {I }}$ deposits. Larger bell angle stands for steeper tapered bell base; so the base of sand column contains sand of comparatively lesser stability as well as potential to mobility than that of vertically standing sand column above the tapered portion of bell base possessing lesser bell angle. In case of $72^{\circ}$ belled anchor, the sand close to anchor base possesses noticeably lesser potential to mobility, and obviously lesser sand dilatancy may hinder the radial movement of wedge near about anchor base as well as further radial extension of wedge upward up to sand surface. Due to this similar phenomenon in both $S_{\text {I }}$ and $S_{\text {II }} /$ $S_{\text {I }}$, lesser volume of wedge is generated for $72^{\circ}$ belled anchor and yields smaller dead-weight of breakout wedge as well as shear strength mobilization at collapsed stage. Matsuo et al. $[24,34]$ reported the similar behaviour of failure surfaces in sand for different belled angles. In Figure 12, it is observed that FS:45-0.33-5- $\left(0.58 S_{\mathrm{II}} / 0.42 S_{\mathrm{I}}\right), \quad \mathrm{FS}: 63-0.33-5-\left(0.58 S_{\mathrm{II}} /\right.$ $\left.0.42 S_{\mathrm{I}}\right)$, and FS:72-0.33-5- $\left(0.58 S_{\mathrm{II}} / 0.42 S_{\mathrm{I}}\right)$ are comparatively extensive in nature than FS:45-0.33-5- $\left(S_{I}\right)$, FS:630.33-5- $\left(S_{\text {I }}\right)$, and FS:72-0.33-5- $\left(S_{\text {I }}\right)$. In Figure 13, similar type of observation can be made as FS:45-0.28-5-(0.63S $S_{\text {II }} /$ $\left.0.37 S_{\mathrm{I}}\right), \quad \mathrm{FS}: 63-0.33-5-\left(0.63 S_{\mathrm{II}} / 0.37 S_{\mathrm{I}}\right)$, and FS:72-0.33-5$\left(0.63 S_{\text {II }} / 0.37 S_{\mathrm{I}}\right)$ are comparatively extensive in nature than FS:45-0.25-5- $\left(S_{\mathrm{I}}\right)$, FS:63-0.28-5- $\left(S_{\mathrm{I}}\right)$, and FS:72-0.28-5- $\left(S_{\mathrm{I}}\right)$. Data analysis from Table 4 (column (iii) and (vii)) presents that $Q_{\mathrm{u}}\left(S_{\mathrm{I}}\right)$ values are $147.90,117.97$, and $99.40 \mathrm{~N}$ for 3D: 45-0.38-5- $\left(S_{\mathrm{I}}\right)$, 3D:63-0.38-5- $\left(S_{\mathrm{I}}\right)$, and 3D:72-0.38-5- $\left(S_{\mathrm{I}}\right)$, respectively, and for the same models 3D:45-0.38-5$\left(0.51 S_{\mathrm{II}} / 0.49 S_{\mathrm{I}}\right), 3 \mathrm{D}: 63-0.38-5-\left(0.51 S_{\mathrm{II}} / 0.49 S_{\mathrm{I}}\right)$, and $3 \mathrm{D}: 72-$ $0.38-5-\left(0.51 S_{\text {II }} / 0.49 S_{\mathrm{I}}\right) Q_{\mathrm{u}}\left(S_{\mathrm{II}} / S_{\mathrm{I}}\right)$ values are $188.64,166.85$, and $118.74 \mathrm{~N}$, respectively.

9.2. Comparison of $r_{\max }\left(S_{I}\right)$ and $r_{\max }\left(S_{I I} / S_{I}\right)$ Values of Failure Surface at Sand Surface in Homogeneous $\left(S_{I}\right)$ and Layered $\left(S_{I I}\right)$ $\left.S_{I}\right)$ Sand Deposits. The $r_{\max }\left(S_{\mathrm{I}}\right)$ and $r_{\max }\left(S_{\mathrm{II}} / S_{\mathrm{I}}\right)$ values are increased with higher $L / T_{\mathrm{b}}$ irrespective of $T_{\mathrm{s}} / T_{\mathrm{b}}, \beta$, and types of sand deposits (i.e., $S_{\mathrm{I}}$ and $\left.S_{\mathrm{II}} / S_{\mathrm{I}}\right)$, but the values of $r_{\max }\left(S_{\mathrm{II}} /\right.$ $S_{\mathrm{I}}$ ) are higher than $r_{\max }\left(S_{\mathrm{I}}\right)$, as observed from Figures 7-9. 


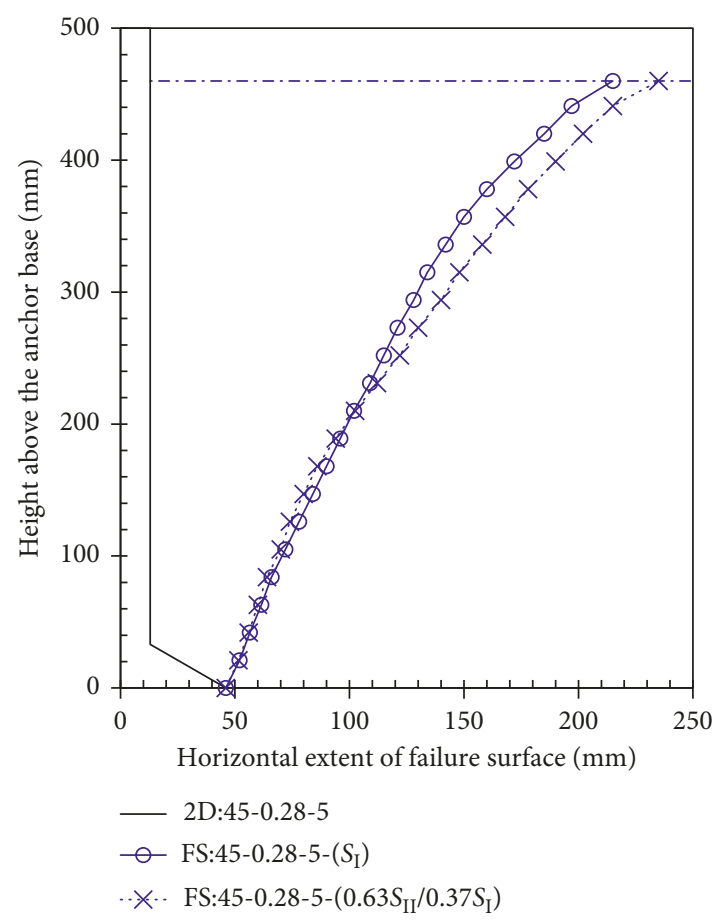

(a)

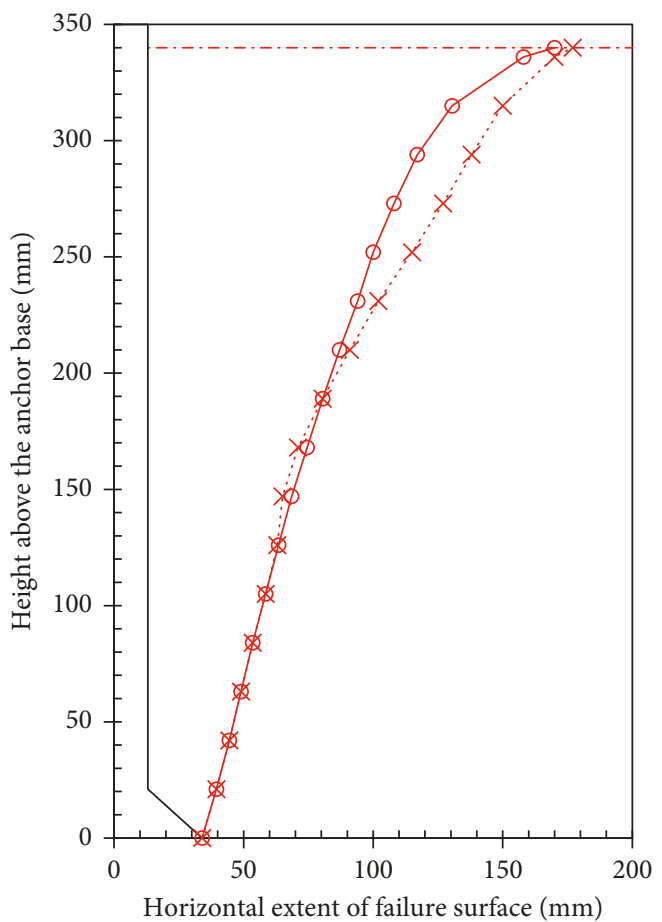

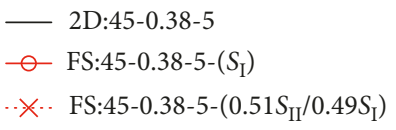

(c)

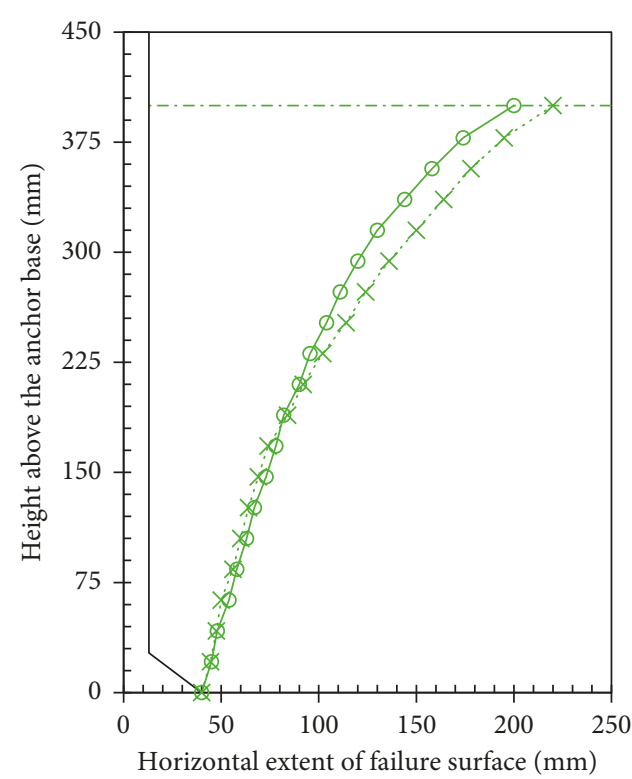

- 2D:45-0.28-5

$\multimap$ FS:45-0.28-5-( $\left(S_{\mathrm{I}}\right)$

× FS:45-0.28-5- $\left(0.58 S_{\text {II }} / 0.42 S_{\mathrm{I}}\right)$

(b)

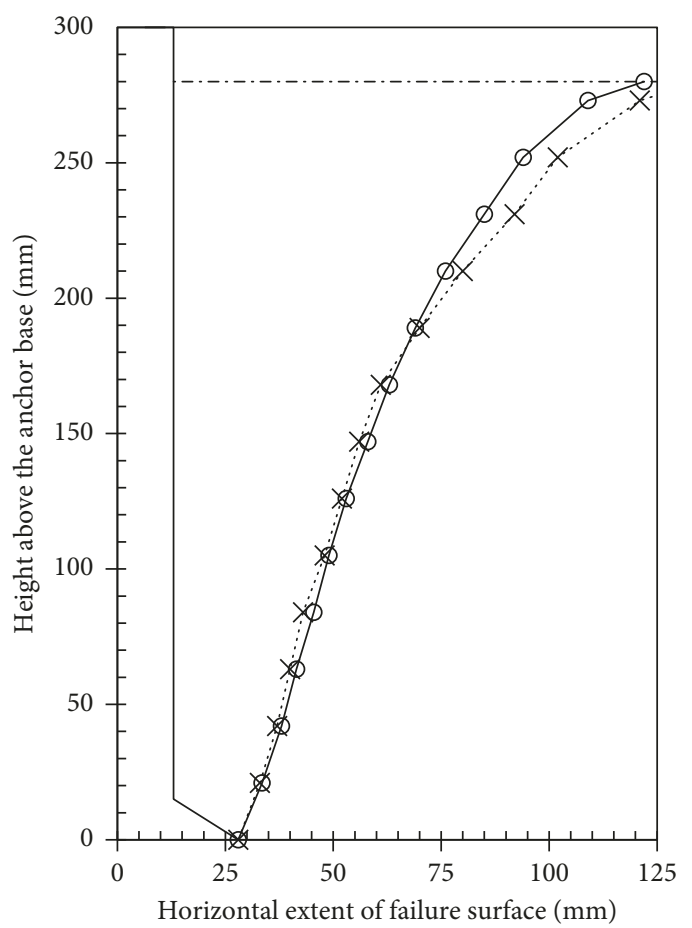

— 2D:45-0.46-5

○- FS:45-0.46-5- $\left(S_{\mathrm{I}}\right)$

.. FS:45-0.46-5- $\left(0.40 S_{\text {II }} / 0.60 S_{\text {I }}\right)$

(d)

Figure 11: Comparison of (a) FS:45-0.28-5-( $\left.S_{\mathrm{I}}\right)$ and FS:45-0.28-5- $\left(0.63 S_{\text {II }} / 0.37 S_{\mathrm{I}}\right)$, (b) FS:45-0.33-5- $\left(S_{\mathrm{I}}\right)$ and FS:45-0.33-5- $\left(0.58 S_{\mathrm{II}} / 0.42 S_{\mathrm{I}}\right)$, (c) FS:45-0.38-5- $\left(S_{\mathrm{I}}\right)$ and FS:45-0.38-5- $\left(0.51 S_{\text {II }} / 0.49 S_{\mathrm{I}}\right)$, and $(\mathrm{d}) \mathrm{FS}: 45-0.46-5-\left(S_{\mathrm{I}}\right)$ and FS:45-0.46-5- $\left(0.40 S_{\text {II }} / 0.60 S_{\mathrm{I}}\right)$. 


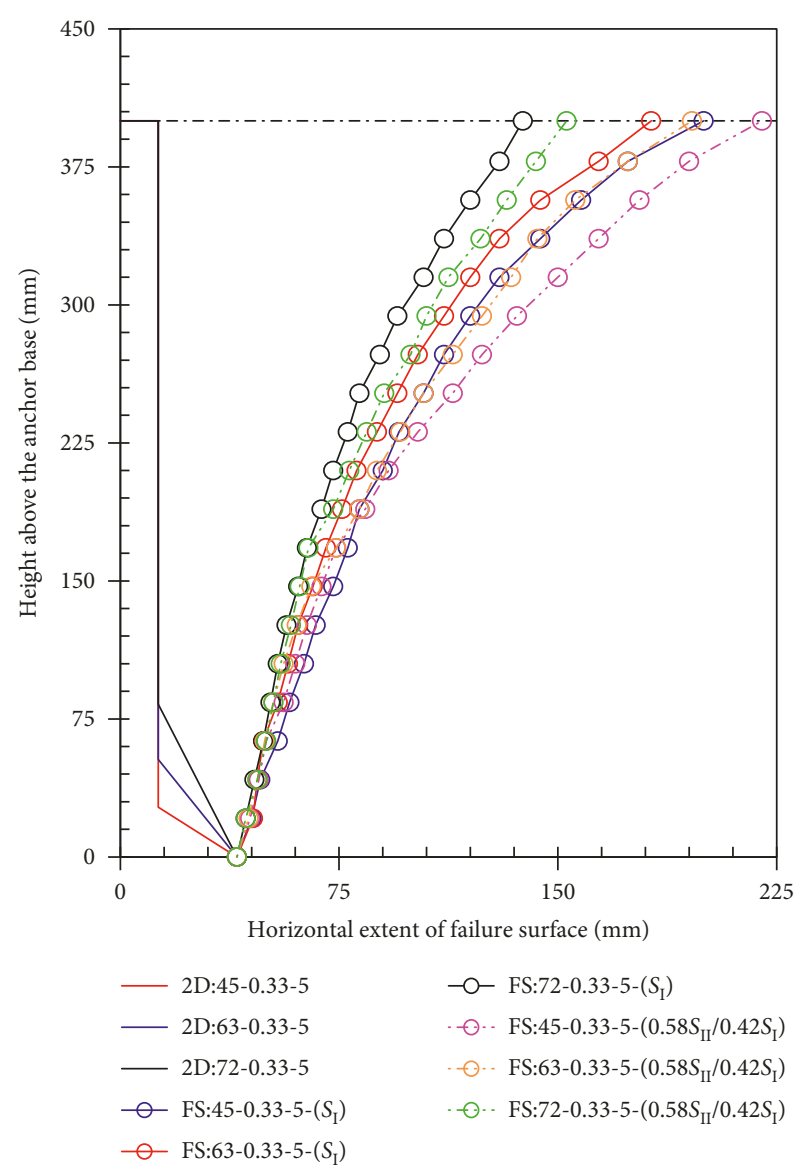

Figure 12: Comparison of FS:45-0.33-5- $\left(S_{\mathrm{I}}\right)$ and FS:45-0.33-5$\left(0.58 S_{\mathrm{II}} / 0.42 S_{\mathrm{I}}\right), \quad \mathrm{FS}: 463-0.33-5-\left(S_{\mathrm{I}}\right)$ and FS:63-0.33-5- $\left(0.58 S_{\mathrm{II}} /\right.$ $\left.0.42 S_{\mathrm{I}}\right)$, and FS:72-0.33-5-( $\left.S_{\mathrm{I}}\right)$ and FS:72-0.33-5- $\left(0.58 S_{\mathrm{II}} / 0.42 S_{\mathrm{I}}\right)$.

For FS:72-0.33-3- $\left(S_{\mathrm{I}}\right)$, FS:72-0.33-4- $\left(S_{\mathrm{I}}\right)$, and FS:72-0.33-5$\left(S_{\mathrm{I}}\right)$, the values of $r_{\max }\left(S_{\mathrm{I}}\right)$ are 100,124 , and $138 \mathrm{~mm}$, respectively, and for FS:72-0.33-3- $\left(0.30 S_{\mathrm{II}} / 0.70 S_{\mathrm{I}}\right)$, FS:7-0.33$4-\left(0.47 S_{\text {II }} / 0.53 S_{\text {I }}\right)$, and FS:72-0.33-5- $\left(0.58 S_{\text {II }} / 0.42 S_{\text {I }}\right)$, the values of $r_{\max }\left(S_{\mathrm{II}} / S_{\mathrm{I}}\right)$ are 109,130 , and $153 \mathrm{~mm}$, respectively. Deb et al. $[34,36]$ reported that, as the values of embedment ratio increases, lateral heave at sand surface gradually increases in homogeneous buried sand.

The $r_{\max }\left(S_{\mathrm{I}}\right)$ and $r_{\max }\left(S_{\mathrm{II}} / S_{\mathrm{I}}\right)$ values are progressively increased with lesser $T_{\mathrm{s}} / T_{\mathrm{b}}$, regardless $L / T_{\mathrm{b}}, \beta, S_{\mathrm{I}}$, and $S_{\mathrm{II}} /$ $S_{\text {I }}$ deposits, but the values of $r_{\max }\left(S_{\mathrm{II}} / S_{\mathrm{I}}\right)$ are higher than $r_{\max }\left(S_{\mathrm{I}}\right)$, as noticed from Figures 10 and 11. For FS:450.28-4- $\left(S_{\mathrm{I}}\right)$, FS:45-0.33-4- $\left(S_{\mathrm{I}}\right), \mathrm{FS}: 45-0.38-4-\left(S_{\mathrm{I}}\right)$, and FS: 45-0.46-4- $\left(S_{\mathrm{I}}\right)$, the values of $r_{\max }\left(S_{\mathrm{I}}\right)$ are $150,140,100$, and $82 \mathrm{~mm}$, respectively, and FS:45-0.28-4- $\left(0.54 S_{\mathrm{II}} /\right.$ $\left.0.46 S_{\mathrm{I}}\right)$, FS: $45-0.33-4-\left(0.47 S_{\mathrm{II}} / 0.53 S_{\mathrm{I}}\right)$, FS: $45-0.38-4-$ $\left(0.3 S_{\mathrm{II}} / 0.62 S_{\mathrm{I}}\right)$, and FS:45-0.46-4- $\left(0.25 S_{\mathrm{II}} / 0.75 S_{\mathrm{I}}\right)$, the values of $r_{\max }\left(S_{\mathrm{II}} / S_{\mathrm{I}}\right)$ are $198,178,158$, and $109 \mathrm{~mm}$, respectively.

The $r_{\max }\left(S_{\mathrm{I}}\right)$ and $r_{\max }\left(S_{\mathrm{II}} / S_{\mathrm{I}}\right)$ values at sand surface are gradually decreased with higher values of $\beta$ despite of $L / T_{\mathrm{b}}$, $T_{\mathrm{s}} / T_{\mathrm{b}}, S_{\mathrm{I}}$, and $S_{\mathrm{II}} / S_{\mathrm{I}}$ deposit, but the values of $r_{\max }\left(S_{\mathrm{II}} / S_{\mathrm{I}}\right)$ are higher than $r_{\max }\left(S_{\mathrm{I}}\right)\left(S_{\mathrm{I}}\right)$, as observed from Figures 12 and 13. For FS:45-0.33-4- $\left(S_{\mathrm{I}}\right)$, FS:63-0.33-4- $\left(S_{\mathrm{I}}\right)$, and FS:72-0.33-5$\left(S_{\mathrm{I}}\right)$, the values of $r_{\max }\left(S_{\mathrm{I}}\right)$ are 165,152 , and $124 \mathrm{~mm}$,

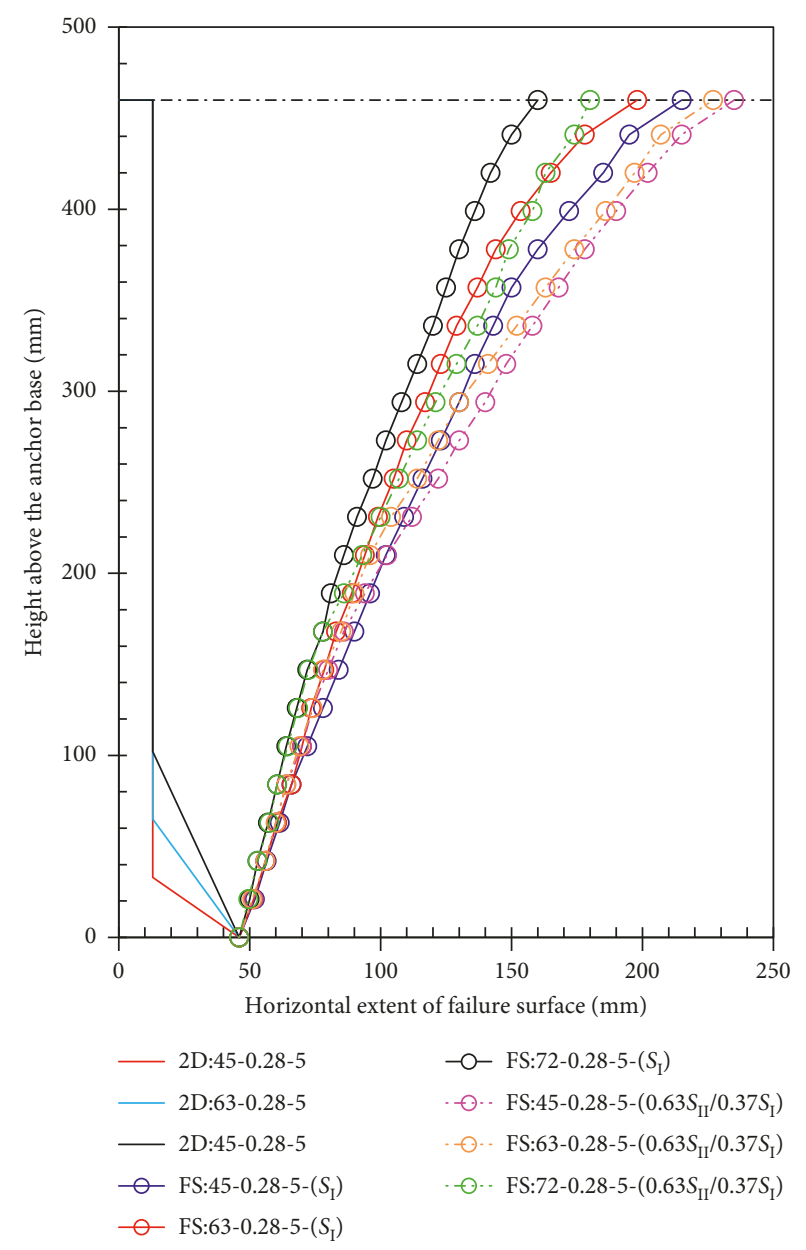

FIgURE 13: Comparison of FS:45-0.28-5- $\left(S_{\mathrm{I}}\right)$ and FS:45-0.28-5$\left(0.63 S_{\text {II }} / 0.37 S_{\mathrm{I}}\right)$, FS:63-0.28-5- $\left(S_{\mathrm{I}}\right)$ and FS:63-0.28-5- $\left(0.63 S_{\mathrm{II}} /\right.$ $\left.0.37 S_{\mathrm{I}}\right)$, and FS:72-0.28-5- $\left(S_{\mathrm{I}}\right)$ and FS:72-0.28-5- $\left(0.63 S_{\mathrm{II}} / 0.37 S_{\mathrm{I}}\right)$.

respectively, and for FS:45-0.33-4- $\left(0.47 S_{\text {II }} / 0.53 S_{\text {I }}\right)$, FS:63$0.33-4-\left(0.47 S_{\text {II }} / 0.53 S_{\text {I }}\right)$, and FS: $72-0.33-4-\left(0.47 S_{\text {II }} / 0.53 S_{\text {I }}\right)$, the values of $r_{\max }\left(S_{\mathrm{II}} / S_{\mathrm{I}}\right)$ are 178,170 , and $130 \mathrm{~mm}$, respectively. Deb and Pal [34] have made similar observation on the variation in horizontal extent of failure points at sand surface for variation in $L / T_{\mathrm{b}}$ and $\beta$.

\section{Breakout Factor}

Net ultimate uplift capacities $\left(Q_{\mathrm{u}}\left(S_{\mathrm{I}}\right)\right.$ and $\left.Q_{\mathrm{u}}\left(S_{\mathrm{I}} / S_{\mathrm{II}}\right)\right)$ are presented as breakout factor, nondimensionalized by density $\left(\gamma_{\mathrm{I}}\right.$ or both $\gamma_{\mathrm{I}}$ and $\left.\gamma_{\mathrm{II}}\right)$, embedment depth ( $L$ or both $L_{\mathrm{I}}$ and $\left.L_{\mathrm{II}}\right)$, and belled base area $\left(A_{\mathrm{b}}\right)$. The breakout factors ignore the size effect. For similar anchor characteristics, breakout factors are similar, rather for small-scale or full-scale models. For homogeneous sand deposit, breakout factors $\left(N_{\text {u.obs. }}\left(S_{\mathrm{I}}\right)\right)$ are calculated as follows:

$$
N_{\text {u. }\left(\text { obs. } S_{\mathrm{I}}\right)}=\frac{\mathrm{Q}_{\mathrm{u}}\left(S_{\mathrm{I}}\right)}{\gamma A_{\mathrm{b}} L} .
$$

For layered sand deposit, breakout factors (Nu.obs.(SI/ SII)) are calculated as 


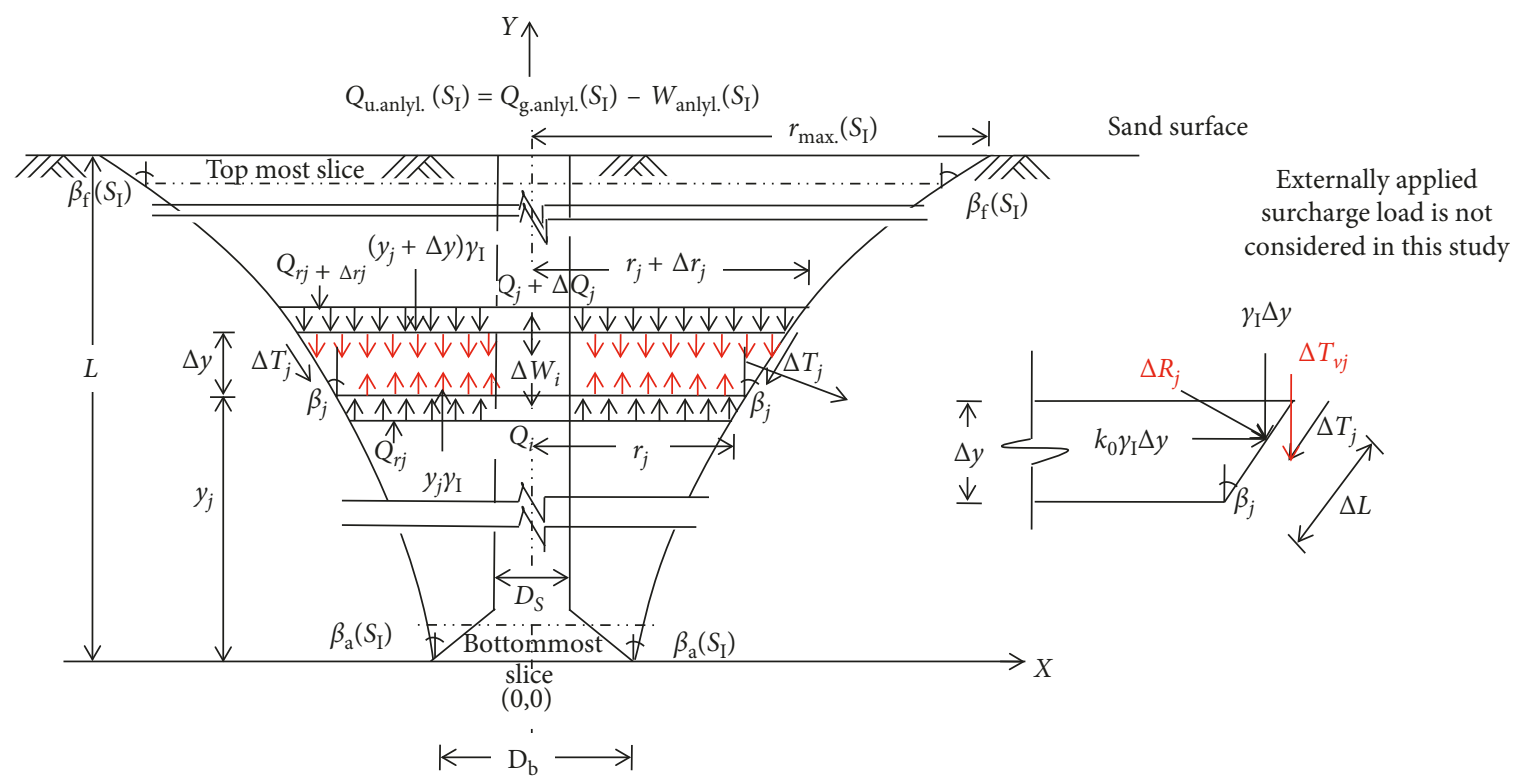

FIGURE 14: Free body diagram of a three-dimensional elemental slice wedge as per the horizontal slice method, in homogeneous sand deposit $\left(S_{\mathrm{I}}\right)$.

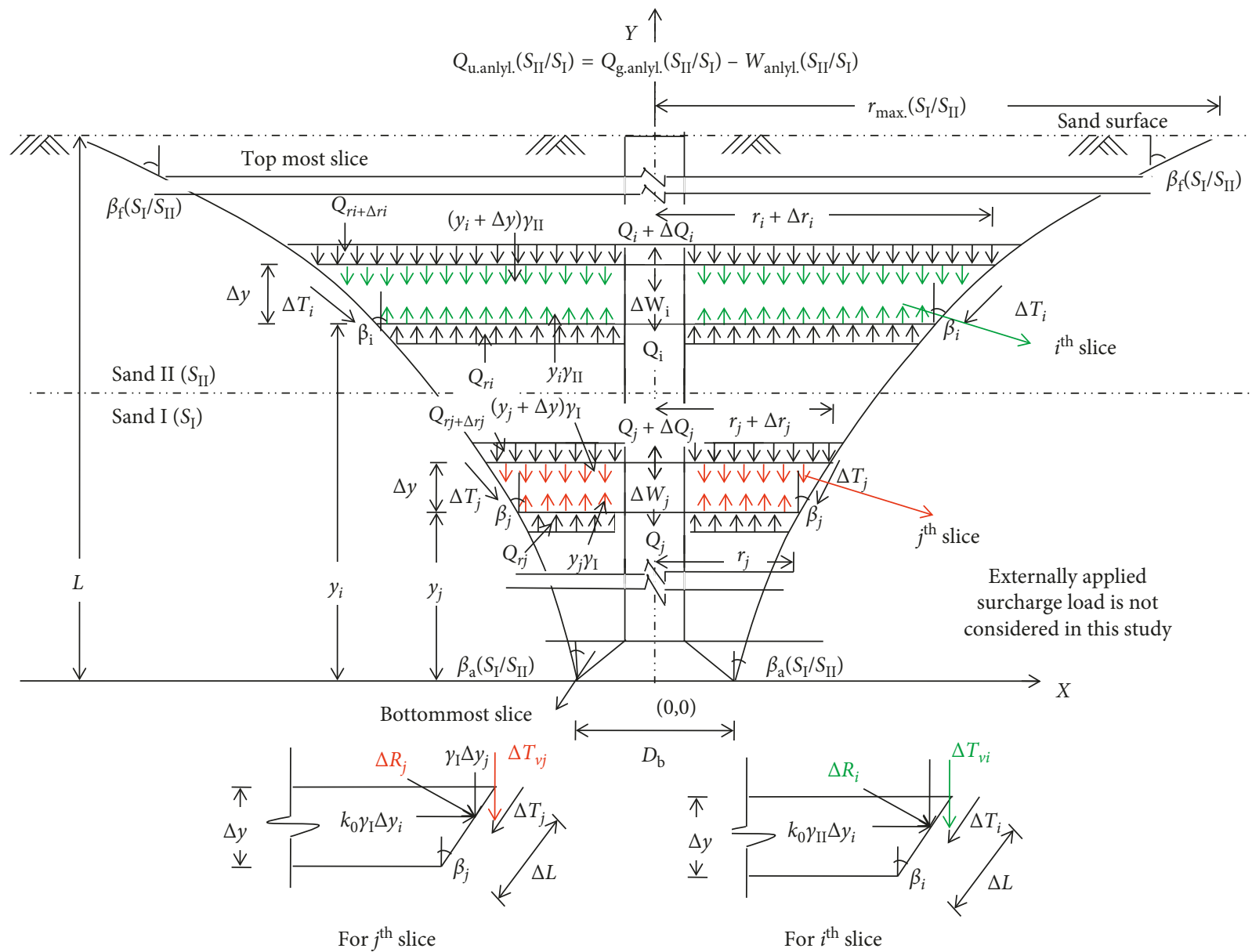

FIGURE 15: Free body diagram of a three-dimensional elemental slice wedge as per the horizontal slice method, in layered sand deposit $\left(S_{\text {II }} /\right.$ $S_{\text {I). }}$. 


$$
N_{\text {u. }\left(\text { obs. }\left(S_{\text {II }} / S_{\mathrm{I}}\right)\right)}=\frac{Q_{\mathrm{u}}\left(S_{\mathrm{II}} / S_{\mathrm{I}}\right)}{A_{\mathrm{b}}\left(\gamma_{\mathrm{II}} L_{\mathrm{II}}+\gamma_{\mathrm{I}} L_{\mathrm{I}}\right)} .
$$

To develop the regression models with observed breakout factors (i.e., $N_{\text {u.(obs.SI) }}$ ) and $N_{\text {u. (obs.SI/SII) }}$ ) for $45^{\circ}, 63^{\circ}$ and $72^{\circ}$ belled anchors, these are identified as $N_{\text {u. (obs. } 45^{\circ} \text { ), }}$ $N_{\text {u. }\left(\text { obs. } .3^{\circ}\right)}$, and $N_{\left.\text {u. (obs. } 72^{\circ}\right)}$, respectively. Similarly, for all the $45^{\circ}, 63^{\circ}$, and $72^{\circ}$ belled anchors, the breakout factors are identified as $N_{\text {u. }\left(\text { obs } 445^{\circ}, 63^{\circ}, 72^{\circ}\right) \text {. }}$.

\section{Multiple Linear Regression Models}

11.1. Significance of Multiple Regression Coefficients as a Whole Multiple Regression Coefficient and Partial Multiple Regression Coefficients. The multiple linear regression is a predictive analysis to explain the relationship between one dependent parameter and two or more independent parameters, and the judgment of regression equations can be done through estimation of $R^{2}, R_{\text {adj }}^{2}$, and $E_{\mathrm{s}}$ (as explained by Draper and Smith [37]). The significance of multiple regression coefficients as a whole and in part separately can be evaluated through ' $F$ ' test and " $t$ " test, respectively. This study is made for the level of significance $(\alpha)$ of requisite hypothesis $=0.05$.

The "F" test can evaluate all multiple coefficients, simultaneously, whereas " $t$ " test that can evaluate only one regression coefficient at a time. These two tests imply the probability of acceptance of the assumed model to predict data. In accordance with the null hypothesis, there is no statistical significance among the variables, i.e., $H_{0}$ : $\xi_{1}=\xi_{2}=\ldots=\xi_{p}=0$. According to the alternative hypothesis $\left(H_{\mathrm{a}}\right)$, at least one of the values of $\xi$ is nonzero.

The decision rule for " $F$ " test is

$$
\begin{array}{r}
\text { reject } H_{0} \text {, if } F_{\text {cal }}>F_{(1-\alpha, p-1, n-p)} \text {, } \\
\text { accept } H_{0} \text {, if } F_{\text {cal }} \leq F_{(1-\alpha, p-1, n-p)} \text {, }
\end{array}
$$

where $F_{(1-\alpha, p-1, n-p)}$ is chosen from the $F$ table for the level of significance $\alpha=0.05$.

If the null hypothesis is not accepted in case of " $F$ " test, then " $t$ " test should be performed to assess the contribution of each independent variables to explain the dependent variable. From the " $t$ " statistics, if any regression coefficient is defined as insignificant, then a new regression model should be proposed by eliminating the previous data in the set of independent variables.

The decision rule for " $t$ " test is

$$
\begin{array}{r}
\text { reject } \mathrm{H}_{0} \text {, if } \mathrm{t}_{\text {cal }}>t_{(1-\alpha / 2, n-p)} \text { or } t_{\text {cal }}<-t_{(1-\alpha / 2, n-p)}, \\
\text { accept } \mathrm{H}_{0} \text {, if }-t_{(1-\alpha / 2, n-p)} \leq t_{\text {cal }} \leq t_{(1-\alpha / 2, n-p)},
\end{array}
$$

where $t_{(1-\alpha / 2, n-p)}$ is chosen from the $t$ table for the level of significance $\alpha=0.05$.

11.2. Possible Multiple Regression Models Proposed by Using the Values of $N_{u .\left(o b s .45^{\circ}\right)}, \quad N_{u .\left(o b s .63^{\circ}\right)}, \quad N_{u .\left(o b s .72^{\circ}\right)}$, and

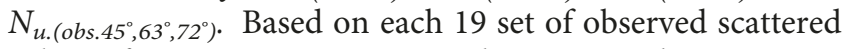
values of $N_{\text {u. }\left(\text { obs. } 45^{\circ}\right),} N_{\left.\text {u. (obs. } 63^{\circ}\right)}$, and $N_{\text {u. }\left(\text { obs. } .72^{\circ}\right)}$, the regression models (18), (19), and (20) have been established to predict

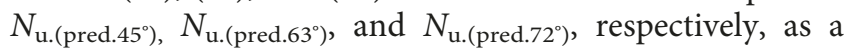
function of $L / D_{\mathrm{b}}, D_{\mathrm{s}} / D_{\mathrm{b}}$, and $i$ :

$$
\begin{aligned}
& N_{\mathrm{u}\left(\text { pred. } 45^{\circ}\right)}=3.54+1.67\left(\frac{L}{D_{\mathrm{b}}}\right)-4.19\left(\frac{D_{\mathrm{s}}}{D_{\mathrm{b}}}\right)-2.96(a), \\
& N_{\mathrm{u} .\left(\text { pred. } 63^{\circ}\right)}=3.87+1.48\left(\frac{L}{D_{\mathrm{b}}}\right)-4.61\left(\frac{D_{\mathrm{s}}}{D_{\mathrm{b}}}\right)-2.97(a),
\end{aligned}
$$

$$
N_{\mathrm{u} .(\text { pred.72 })}=2.75+1.17\left(\frac{L}{D_{\mathrm{b}}}\right)-2.70\left(\frac{D_{\mathrm{s}}}{D_{\mathrm{b}}}\right)-2.26(a) .
$$

The use of 63 sets of scattered data of $N_{\text {u. }\left(\text { obs. } 45^{\circ}, 63^{\circ}, 72^{\circ}\right)}$ has

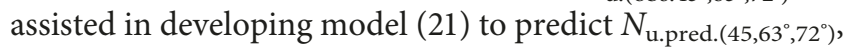
where $L / D_{\mathrm{b}}, D_{\mathrm{s}} / D_{\mathrm{b}}, \beta$, and $i$ are the independent variables:

$$
\begin{aligned}
N_{\text {u.pred. }\left(45^{\circ}, 63^{\circ}, 72^{\circ}\right)} & =6.79+1.43 \frac{L}{D_{\mathrm{b}}}-3.12 \frac{D_{\mathrm{s}}}{D_{\mathrm{b}}} \\
& -0.06(\beta)-2.71(a) .
\end{aligned}
$$

These models (18), (19), and (20) are developed to predict breakout factors for $45^{\circ}, 63^{\circ}$, and $72^{\circ}$ anchors, respectively, and each model is valid for the values of $L / D_{\mathrm{b}}$ and $D_{\mathrm{s}} / D_{\mathrm{b}}$ within the ranges of 3 to 5 and 0.28 to 0.46 , respectively; the values of $a$ is 1 in homogeneous sand deposit and within the ranges of 0.37 to 0.82 when $S_{\mathrm{I}}\left(\gamma_{\mathrm{I}}=15.60 \mathrm{kN} / \mathrm{m}^{3}\right)$ is underlying. In the model (21), the additional parameter $\beta$ lies within the ranges of 45 to $72^{\circ}$.

In the model (18), the values of $R^{2}, R_{\mathrm{adj}}^{2}$, and $E_{\mathrm{s}}$ have been found out, and these are $0.961,0.953$, and 0.392 , respectively. The values of $R^{2}, R_{\text {adj }}^{2}$, and $E_{\mathrm{s}}$ are calculated as $0.968,0.961$, and 0.339 , respectively for model (19). In the model (20), the values of $R^{2}, R_{\text {adj }}^{2}$, and $E_{\mathrm{s}}$ are $0.961,0.952$, and 0.262 , respectively. The values of $R^{2}, R_{\text {adj }}^{2}$, and $E_{\mathrm{s}}$ are $0.934,0.929$, and 0.458 , respectively, in model (21). The calculated value of $F_{\mathrm{cal}\left(45^{\circ}\right),} F_{\mathrm{cal}\left(63^{\circ}\right)}$, and $F_{\mathrm{cal}\left(72^{\circ}\right)}$ are $123.57,150.38$, and 115.57 ,

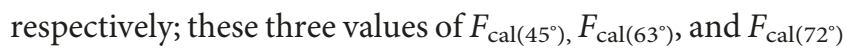
are greater than tabulated $F_{(0.95,2,54)}=3.168$. The calculated value of $F_{\text {cal }\left(45^{\circ}, 63^{\circ}, 72^{\circ}\right)}=203.85$, and this is greater than tabulated $F_{(0.95,3,248)}=2.631$. The independent variables, coefficients, standard error, and $t$ statistics of all the parameters and values of $t_{\text {critical }}$ for models (18) to (21) have been presented in Table 5 .

The models (18) to (21) of the present study may be followed for full-scale models of identical anchor characteristics as used in this study. This particular study may be directly used for the densities, values of $L / D_{\mathrm{b}}, D_{\mathrm{s}} / D_{\mathrm{b}}$, and $\beta$ and $a$ as used in this study. Due to the paucity of data in the relevant literature, these equations cannot be verified with previous data in homogeneous as well as layered sand deposits. These multiple regression equations are verified by other data of the present study, which are not used for development of these correlations. These equations may be 
TABLE 5: Independent variables, coefficients, standard error, $t_{\text {statistics, }}$ and $t_{\text {critical }}$ of all the parameters from models (18) to (21).

\begin{tabular}{|c|c|c|c|c|}
\hline Parameters & Coefficients & Standard error & $t$ statistics & $t_{\text {critical }}=t_{(0.975,54)}$ \\
\hline \multicolumn{5}{|c|}{ In accordance with model (18) } \\
\hline$L / D_{\mathrm{b}}$ & +1.67 & 0.11 & 14.54 & \multirow{3}{*}{2.01} \\
\hline$D_{\mathrm{s}} / D_{\mathrm{b}}$ & -4.19 & 1.43 & 2.93 & \\
\hline $\mathrm{a}$ & -2.96 & 0.41 & 7.13 & \\
\hline \multicolumn{5}{|c|}{ In accordance with model (19) } \\
\hline$L / D_{\mathrm{b}}$ & +1.48 & 0.10 & 14.62 & \multirow[t]{3}{*}{2.01} \\
\hline$D_{\mathrm{s}} / D_{\mathrm{b}}$ & -4.61 & 1.21 & 3.80 & \\
\hline $\mathrm{a}$ & -2.97 & 0.36 & 8.16 & \\
\hline \multicolumn{5}{|c|}{ In accordance with model (20) } \\
\hline$L / D_{\mathrm{b}}$ & +1.17 & 0.08 & 15.27 & \multirow[t]{3}{*}{2.01} \\
\hline$D_{\mathrm{s}} / D_{\mathrm{b}}$ & -2.70 & 1.00 & 2.69 & \\
\hline $\mathrm{a}$ & -2.26 & 0.29 & 7.84 & \\
\hline Parameters & Coefficients & Standard error & $t$ statistics & $t_{\text {critical }}=t_{(0.975,248)}$ \\
\hline \multicolumn{5}{|c|}{ In accordance with model (21) } \\
\hline$L / D_{\mathrm{b}}$ & +1.43 & 0.74 & 19.47 & \multirow[t]{4}{*}{1.979} \\
\hline$D_{\mathrm{s}} / D_{\mathrm{b}}$ & -3.62 & 0.94 & 3.85 & \\
\hline$\beta$ & -0.06 & 0.01 & 11.23 & \\
\hline $\mathrm{a}$ & -2.71 & 0.26 & 10.27 & \\
\hline
\end{tabular}

checked before application due to a wide range of prevailing variations in-field soil properties.

\section{Validation of Experimental Results}

The values of $Q_{\mathrm{u}}\left(S_{\mathrm{I}}\right), Q_{\mathrm{u} \text {.anlyl. }}\left(S_{\mathrm{I}}\right)$, and predicted errors (\%) on $Q_{\text {u.anlyl. }}\left(S_{\mathrm{I}}\right)$ are presented in Table 4 column (ii), (iii), and (iv), respectively. The values of $Q_{\mathrm{u}}\left(S_{\mathrm{I}}\right)$ and $Q_{\mathrm{u} \text {.anlyl. }}\left(S_{\mathrm{I}}\right)$ are compared and errors in $94.45 \%$ data are within the range of +08.51 to $-10.70 \%$. The values of $Q_{\mathrm{u}}\left(S_{\mathrm{II}} /\right.$ $\left.S_{\mathrm{I}}\right), Q_{\text {u.anlyl. }}\left(S_{\mathrm{II}} / S_{\mathrm{I}}\right)$ as well as predicted errors (\%) on $\left.Q_{\text {u.anlyl. }}\left(S_{\mathrm{II}} / S_{\mathrm{I}}\right)\right)$ are presented in Table 4 column (vi), (vii), and (viii), respectively. The results of $Q_{\mathrm{u}}\left(S_{\mathrm{II}} / S_{\mathrm{I}}\right)$ and $Q_{\text {u.anlyl. }}\left(S_{\mathrm{II}} / S_{\mathrm{I}}\right)$ are compared, and errors in all the data are within the range of +10.47 to $-10.72 \%$. In absence of field test data on uplift resistance, an ideal knowledge regarding soil profile, simulation of strata in laboratory, and failure study on both the sides of 2D panels may be helpful for the practicing engineers to rationally predict the most probable failure pattern and to evaluate net uplift capacity by execution of horizontal slice method in failure surface.

Table 6 presents that the errors are within the ranges of +3.72 to $-14.11 \%$ to predict $N_{\left.\text {u.(pred. } 45^{\circ}\right)}$ based on $N_{\text {u. }\left(\text { obs. } 45^{\circ}\right) \text {, }}$ +8.35 to $-11.87 \%$ to predict $N_{\left.\text {u.(pred.63 } 63^{\circ}\right)}$ based on $N_{\text {u. (obs.63 }}{ }^{\circ}$ ), +6.77 to $-4.75 \%$ to predict $N_{\text {u. }\left(\text { pred. } .72^{\circ}\right)}$ based on $N_{\left.\text {u. (obs. } 72^{\circ}\right) \text {, }}$ and -10.45 to $+16.01 \%$ to predict $N_{\mathrm{u} .\left(\text { pred. } 45^{\circ}, 63^{\circ}, 72^{\circ}\right)}$ based on $N_{\text {u. }\left(\text { obs. } 45^{\circ}, 63^{\circ}, 72^{\circ}\right)}$ in accordance with the models (18), (19), (20), and (21), respectively.

\section{Practical Applications}

Two different types of sands are used in this study, because the existing buried soil (in low lying areas) and newly filled material may not be identical by geotechnical properties. In fact, the homogeneity of soil in whole depth of foundation and frictional soil in huge quantity may not prevail in the construction site. For anchors, soil having high density and frictional angle is useful as filling material. For this study, it may be assumed that the foundation soil is either dry cohesionless single-layered soil or layered soil (denser sand overlying comparatively lesser dense sand). It may also be assumed that usually ground water table is adequately below the anchor base or has been lowered down below the anchor base for a short time during the construction period. Wenbai et al. [38] described the installation and uplift capacity of belled pile in drought loess having $w$ calcium gluing property. Chae et al. [39] reported the field test on belled pile in weathered sand stone of Abu Dhabi. Experimental studies on the numbers of $2 \mathrm{D}$ panels and $3 \mathrm{D}$ models are conducted in laboratories in sand only. It should be checked and modify accordingly when different soil profiles of wide range of variation will be encountered at site. So, prior to direct implementation, these equations, and analytical method, it should be checked as per site soil conditions.

Experimental investigations on the model anchors are performed in laboratory in the sand only. In future, in a similar type of problem by formation of regression models for any other set of sand densities, $L / D_{\mathrm{b}}, D_{\mathrm{s}} / D_{\mathrm{b}}, \beta$, and $a$, it is possible to find out the predicted $N_{\mathrm{u}}$. The present regression models should be checked and revised accordingly when different soil profiles of a wide range of geotechnical properties will be encountered in construction field.

\section{Concluding Remarks}

Based on experimental results, analytical study, and discussions, following concluding remarks may be highlighted.

14.1. Uplift Capacities of $3 D$ Models in Homogeneous $\left(S_{I}\right)$ and Layered $\left(S_{I I} / S_{I}\right)$ Sand Deposits

(i) The uplift capacities of belled anchors in layered sand $\left(Q_{\mathrm{u}}\left(S_{\mathrm{II}} / S_{\mathrm{I}}\right)\right)$ are higher than homogeneous sand $\left(Q_{\mathrm{u}}\left(S_{\mathrm{I}}\right)\right)$ deposit. The model 3D:45-0.33-3$\left(0.30 S_{\text {II }} / 0.7 S_{\mathrm{I}}\right), 3 \mathrm{D}: 45-0.38-3-\left(0.18 S_{\text {II }} / 0.82 S_{\mathrm{I}}\right), 3 \mathrm{D}$ : 45-0.46-4- $\left(0.25 S_{\text {II }} / 0.75 S_{\text {I }}\right), \quad 3 \mathrm{D}: 63-0.33-3-\left(0.30 S_{\text {II }} /\right.$ 
TABLE 6: Comparison of the observed breakout factor and predicted breakout factor by using models (18) to (21).

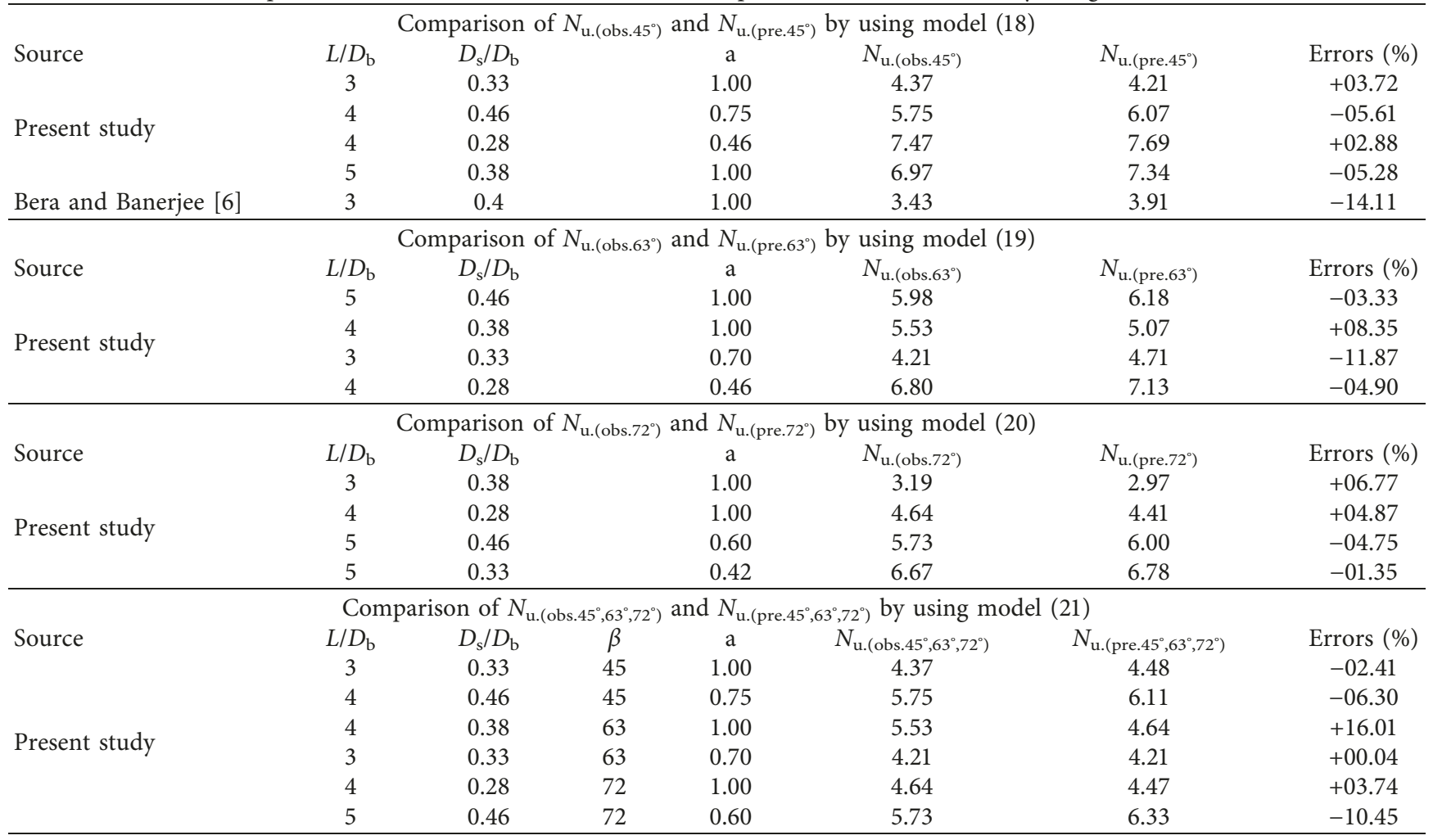

$\left.0.70 S_{\mathrm{I}}\right), 3 \mathrm{D}: 63-0.38-3-\left(0.18 S_{\mathrm{II}} / 0.82 S_{\mathrm{I}}\right), 3 \mathrm{D}: 63-0.46-$ $4-\left(0.25 S_{\text {II }} / 0.75 S_{\mathrm{I}}\right), \quad 3 \mathrm{D}: 7-0.33-3-\left(0.30 S_{\mathrm{II}} / 0.70 S_{\mathrm{I}}\right)$, $3 \mathrm{D}: 72-0.38-3-\left(0.18 S_{\mathrm{II}} / 0.82 S_{\mathrm{I}}\right)$, and $3 \mathrm{D}: 672-0.46-4-$ $\left(0.25 S_{\mathrm{II}} / 0.75 S_{\mathrm{I}}\right)$ are found to be less effective to gain higher $\left.Q_{\mathrm{u}}\left(S_{\mathrm{II}} / S_{\mathrm{I}}\right)\right)$ compared to $Q_{\mathrm{u}}\left(S_{\mathrm{I}}\right)$ in homogeneous sand deposit.

(ii) Uplift capacities of belled anchors are gradually higher for deeper embedment in both homogeneous $\left(S_{\mathrm{I}}\right)$ and layered $\left(S_{\mathrm{II}} / S_{\mathrm{I}}\right)$ sand deposits. With increase in the values of $L / D_{\mathrm{b}}$, the rate of increase in uplift capacities of belled anchors in layered sand $\left(Q_{\mathrm{u}}\left(S_{\mathrm{II}} / S_{\mathrm{I}}\right)\right)$ is comparatively higher than $Q_{\mathrm{u}}\left(S_{\mathrm{I}}\right)$ for the same model, regardless the particular values of $D_{\mathrm{s}} / D_{\mathrm{b}}$ and $\beta$.

(iii) Uplift capacities of belled anchors are gradually higher for lesser diameter ratios in both homogeneous $\left(S_{\mathrm{I}}\right)$ and layered $\left(S_{\mathrm{II}} / S_{\mathrm{I}}\right)$ sand deposits. With decrease in the values of $D_{\mathrm{s}} / D_{\mathrm{b}}$ from 0.46 to 0.28 , the increase in $Q_{\mathrm{u}}\left(S_{\mathrm{II}} / S_{\mathrm{I}}\right)$ is comparatively higher than $Q_{\mathrm{u}}\left(S_{\mathrm{I}}\right)$ for the same model, irrespective of particular values of $L / D_{\mathrm{b}}$ and $\beta$.

(iv) The 45 and $63^{\circ}$ belled anchors are more efficient uplift-protective structures than $72^{\circ}$ anchors capacities in both types of sand deposits. For the change of $\beta$ value from 63 to $72^{\circ}, Q_{\mathrm{u}}\left(S_{\mathrm{I}}\right)$ and $Q_{\mathrm{u}}\left(S_{\mathrm{II}} /\right.$ $S_{\mathrm{I}}$ ) are decreased at higher rate than those rates of decrement as observed for the change in $\beta$ value from 45 to $63^{\circ}$. The increase in $Q_{\mathrm{u}}\left(S_{\mathrm{II}} / S_{\mathrm{I}}\right)$ is comparatively higher than $Q_{\mathrm{u}}\left(S_{\mathrm{I}}\right)$ for the same model, irrespective of particular values of $L / D_{\mathrm{b}}$ and $D_{\mathrm{s}} / D_{\mathrm{b}}$.

14.2. Nonlinear Failure Surfaces around 2D Panels in Homogeneous $\left(S_{I}\right)$ and Layered $\left(S_{I I} / S_{I}\right)$ Sand Deposits and Analytical Approach

(i) All the nonlinear failure curves are similar in pattern; they are formed from edge of anchor base and terminated at sand-surface irrespective of type of sand deposits, values of embedment ratios, thickness ratios, and bell angles.

(ii) The nonlinear failure surfaces of belled anchors in layered sand are larger than homogeneous sand deposit. The models FS:45-0.33-3- $\left(0.30 S_{\text {II }} / 0.70 S_{\text {I }}\right)$, FS:45-0.38-3-(0.18S 1 II $\left./ 0.82 S_{\text {I }}\right)$, FS:45-0.46-4- $\left(0.25 S_{\text {II }} /\right.$ $\left.0.75 S_{\mathrm{I}}\right), \quad \mathrm{FS}: 63-0.33-3-\left(0.3 S_{\mathrm{II}} / 0.7 S_{\mathrm{I}}\right), \quad \mathrm{FS}: 63-0.38-3-$ $\left(0.18 S_{\text {II }} / 0.82 S_{\mathrm{I}}\right), \quad$ FS: $63-0.46-4-\left(0.25 S_{\text {II }} / 0.75 S_{\mathrm{I}}\right), \quad$ FS: 72-0.33-3- $\left(0.30 S_{\text {II }} / 0.70 S_{\text {I }}\right), \quad$ FS: $72-0.38-3-\left(0.18 S_{\text {II }} /\right.$ $\left.0.82 S_{\mathrm{I}}\right)$, and FS:672-0.46-4- $\left(0.25 S_{\mathrm{II}} / 0.75 S_{\mathrm{I}}\right)$ are found to be slightly wider than corresponding failure surfaces in homogeneous sand deposit.

(iii) At higher values of embedment ratio, larger volume of failure wedge is formed than those formed due to smaller embedment ratio in both the type of sand deposits, in models possessing certain value of thickness ratio (or diameter ratio) and bell angle. 
The values of $Q_{u \text {.anlyl. }}\left(S_{\mathrm{II}} / S_{\mathrm{I}}\right)$ are progressively larger for higher embedment ratios than $Q_{\text {u.anlyl. }}\left(S_{\mathrm{I}}\right)$ values for the same model in reference of embedment ratios.

(iv) With larger values of thickness ratio (or diameter ratio), smaller volume of breakout wedge is generated in both the type of sand deposits, in models having certain value of embedment ratio and bell angle. The values of $Q_{u \text {.anlyl. }}\left(S_{\mathrm{II}} / S_{\mathrm{I}}\right)$ are higher than $Q_{u \text {.anlyl. }}\left(S_{\mathrm{I}}\right)$ values for the same model in reference of thickness ratios (or diameter ratios).

(v) For anchor having steeper bell, angle volume of breakout wedge is gradually reduced and for $72^{\circ}$ belled anchor of the reduction rate is higher in both the types of sand deposits, in models belonging to certain value of embedment ratio and thickness ratio (or diameter ratio). The values of $Q_{\text {u.anlyl. }}\left(S_{\mathrm{II}} / S_{\mathrm{I}}\right)$ are higher than $Q_{\mathrm{u} \text {.anlyl. }}\left(S_{\mathrm{I}}\right)$ values for the same model in reference of bell angles.

(vi) The $r_{\max }\left(S_{\mathrm{I}}\right)$ and $r_{\max }\left(S_{\mathrm{II}} / S_{\mathrm{I}}\right)$ values show increasing trend when the failure surfaces are developed for higher values of embedment ratio, lesser thickness ratio, and bell angle of $2 \mathrm{D}$ panels in both the types of sand deposits. But $r_{\max }\left(S_{\mathrm{II}} / S_{\mathrm{I}}\right)$ values are comparatively higher than $r_{\max }\left(S_{\mathrm{I}}\right)$ in reference of embedment ratios, thickness ratios (or diameter ratios), and bell angles.

(vii) Out of 36 analytical data in homogeneous sand, $94.45 \%$ data are within the range of +08.51 to $-10.70 \%$ and all 33 analytical data in layered sand are within the range of +10.47 to $-10.72 \%$, with respect to the experimental uplift capacities.

(viii) Four numbers of multiple regression models have been developed by $N_{\text {u. }\left(\text { obs. } 45^{\circ}\right)}, N_{\text {u. }\left(\text { obs. } 63^{\circ}\right)}, N_{\text {u. }\left(\text { obs. } 72^{\circ}\right)}$,

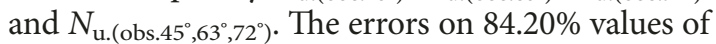

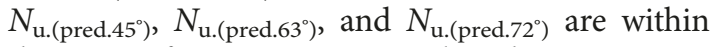
the range of +08.35 to $-10.45 \%$ based on $N_{\mathrm{u} .\left(\mathrm{obs} .45^{\circ}\right)}$, $N_{\text {u. }\left(\text { obs. } 63^{\circ}\right)}, N_{\text {u.obs. }\left(72^{\circ}\right) \text {, and }} N_{\text {u. }\left(\text { obs. } .45^{\circ}, 63^{\circ}, 72^{\circ}\right) \text {. }}$ Breakout factors eliminate the size effect, so the newly developed multiple linear regression models are appropriate for actual engineering to compare with prototype tests within the proposed limitation of values of variable parameters.

\section{Notations}

$a:$

$D_{\mathrm{b}}$ :

$D_{\mathrm{s}}$ :

$D_{\mathrm{s}} / D_{\mathrm{b}}:$

$E_{\mathrm{s}}$ :

Portions of embedment depth of anchor in the lower layer Base diameter of 3D belled anchor Shaft diameter of 3D belled anchor

Diameter ratio of $3 \mathrm{D}$ belled anchor

Estimated standard error of
$L:$ regression statistics
$F_{\mathrm{cal}\left(45^{\circ}\right)}, F_{\mathrm{cal}\left(63^{\circ}\right)}, F_{\mathrm{cal}\left(72^{\circ}\right)}$,

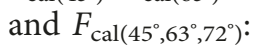

$L / D_{\mathrm{b}}$ :

$L / T_{\mathrm{b}}$ :

$n:$

$N_{\left.\text {u.(obs. } 45^{\circ}\right),} N_{\text {u. }\left(\text { obs. } 63^{\circ}\right)}$,

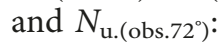

$N_{\text {u. }\left(\text { pre. } 45^{\circ}\right)}, N_{\text {u. }\left(\text { pre. } 63^{\circ}\right)}$, and $N_{\mathrm{u} .(\text { pre. }} 72^{\circ}$ ):

$N_{\text {u. }\left(\text { pre. } .5^{\circ}, 63^{\circ}, 72^{\circ}\right) \text { : }}$

$N_{\text {u.obs. }\left(45^{\circ}, 63^{\circ}, 72^{\circ}\right) \text { : }}$

$p:$

$Q_{\mathrm{g}}\left(S_{\mathrm{I}}\right):$

$Q_{\mathrm{g}}\left(S_{\mathrm{II}} / S_{\mathrm{I}}\right):$

$Q_{\text {g.anlyl. }}\left(S_{\mathrm{I}}\right)$ :

$Q_{\text {g.anlyl. }}\left(S_{\mathrm{II}} / S_{\mathrm{I}}\right)$ :

$R^{2}:$

$R_{\text {adj }}^{2}$ :

$r_{\text {max. }}\left(S_{I}\right):$

$r_{\max .}\left(S_{\mathrm{II}} / S_{\mathrm{I}}\right):$

$T_{\mathrm{b}}$ :

$T_{\mathrm{s}}$ :

$T_{\mathrm{s}} / T_{\mathrm{b}}$ :

Calculated values of $F$ statistics in regression model prepared by

$N_{\text {u. }\left(\text { obs. } 45^{\circ}\right)}, N_{\left.\text {u. (obs. } 63^{\circ}\right)}$ and

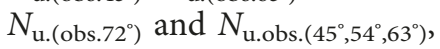
respectively

Embedment depth of belled anchor

Embedment ratio in 3D belled anchor

Embedment ratio in $2 \mathrm{D}$ panel anchor

Total number of observations in all groups

Observed values of breakout factor for $45^{\circ}, 63^{\circ}$, and $72^{\circ}$ anchors, respectively

Predicted values of breakout factor for $45^{\circ}, 63^{\circ}$, and $72^{\circ}$ anchors, respectively

Predicted values of breakout factor for $45^{\circ}, 63^{\circ}$, and $72^{\circ}$ anchors Observed values of breakout factor for $45^{\circ}, 63^{\circ}$, and $72^{\circ}$ anchors Number of independent groups Gross ultimate uplift capacity of 3D models installed in $S_{\text {I }}$ from experimental observation Gross ultimate uplift capacity of $3 \mathrm{D}$ models installed in $S_{\mathrm{II}} / S_{\mathrm{I}}$ from experimental observation Analytical gross ultimate uplift capacity of 3D models installed in $S_{\text {I }}$ deposit

Analytical gross ultimate uplift capacity of $3 \mathrm{D}$ models installed in $S_{\text {II }} / S_{\text {I }}$ deposit

Coefficient of determination

Adjusted multiple coefficients of determination

Maximum horizontal extent of failure point at sand surface of $S_{\text {I }}$ deposit

Maximum horizontal extent of failure point at sand surface of $S_{\text {II }} /$ $S_{\text {I }}$ deposit

Bell thickness in 2D panel anchor Shaft thickness in 2D panel anchor Thickness ratio in 2D panel anchor

USCS:

$W_{\text {anlyl. }}\left(S_{\mathrm{I}}\right)$ :

$W_{\text {anlyl. }}\left(S_{\mathrm{II}} / S_{\mathrm{I}}\right):$
Unified soil classification system Weight of sand equal to the volume of belled anchor inside the wedge of $S_{\text {I }}$

Weight of sand equal to the volume of belled anchor inside the wedge of $S_{\mathrm{II}} / S_{\mathrm{I}}$ 


$\begin{array}{ll}W_{\mathrm{M}}: & \text { Self-weight of } 3 \mathrm{D} \text { model } \\ \beta: & \text { Bell angle of anchor } \\ \beta_{\mathrm{a}}\left(S_{\mathrm{I}}\right): & \begin{array}{l}\text { Initial failure angle with vertical in } \\ \text { bottom most slice in } S_{\mathrm{I}} \text { deposit }\end{array} \\ \beta_{\mathrm{a}}\left(S_{\mathrm{II}} / S_{\mathrm{I}}\right): & \begin{array}{l}\text { Initial failure angle with vertical in } \\ \text { bottom most slice in } S_{\mathrm{II}} / S_{\mathrm{I}} \text { deposit }\end{array} \\ \beta_{\mathrm{f}}\left(S_{\mathrm{I}}\right): & \text { Final angle of failure with vertical } \\ \beta_{\mathrm{f}}\left(S_{\mathrm{II}} / S_{\mathrm{I}}\right): & \text { in top most slice in } S_{\mathrm{I}} \text { deposit } \\ \xi_{1}, \xi_{2}, \ldots, \xi_{p}: & \text { Final angle of failure with vertical } \\ & \text { in top most slice in } S_{\mathrm{II}} / S_{\mathrm{I}} \text { deposit } \\ & \text { Regression coefficients. }\end{array}$

\section{Data Availability}

The data used to support the findings of this study are available from the corresponding author upon request.

\section{Disclosure}

The authors are solely involved in the manuscript writing, editing, approval, or decision to publish.

\section{Conflicts of Interest}

The authors declare that there are no conflicts of interest.

\section{Acknowledgments}

The authors are grateful to the Department of Civil Engineering, National Institute of Technology, Agartala, for providing all necessary facilities for this investigation. The research work presented here was supported by the Institute Fellowship to the first author from the Ministry of Human Resource and Development, Government of India. The experimental setup and models are fabricated from the financial assistantship of the Departmental Promotional Fund of Civil Engineering Department.

\section{References}

[1] R. B. Peck, W. E. Hanson, and T. H. Thornburn, Foundation Engineering, John Wiley and Sons, Inc., New York, NY, USA, 2nd edition, 1974.

[2] E. A. Dickin and C. F. Leung, "Performance of piles with enlarged bases subject to uplift forces," Canadian Geotechnical Journal, vol. 27, no. 5, pp. 546-556, 1990.

[3] E. A. Dickin and C. F. Leung, "The influence of foundation geometry on the uplift behaviour of piles with enlarged bases," Canadian Geotechnical Journal, vol. 29, no. 3, pp. 498-505, 1992.

[4] S. K. Pal, "Uplift capacity of shallow and deep belled anchors tied geofabric strips," M.Tech. dissertation, IIT Kharagpur, West Bengal, India, 1992.

[5] A. Ghosh and A. K. Bera, "Effect of geotextile ties on uplift capacity of anchors embedded in sand," Geotechnical and Geological Engineering, vol. 28, no. 5, pp. 567-577, 2010.

[6] A. K. Bera and U. Banerjee, "Uplift capacity of model bell shaped anchor embedded in sand," International Journal of Geotechnical Engineering, vol. 7, no. 1, pp. 84-90, 2013.

[7] A. K. Bera, "Parametric study on uplift capacity of anchor with tie in sand," KSCE Journal of Civil Engineering, vol. 18, no. 4, pp. 1028-1035, 2014.
[8] R. Nazir, H. Moayedi, A. Pratikso, and M. Mosallanezhad, "The uplift load capacity of an enlarged base pier embedded in dry sand," Saudi Society for Geosciences, vol. 8, no. 9, pp. 7285-7296, 2014.

[9] J. I. Adams and H. S. RadhXakrishna, "Uplift resistance of augured footings in fissured clay," Canadian Geotechnical Journal, vol. 8, no. 3, pp. 452-462, 1971.

[10] N. F. Ismael and T. W. Klym, "Behavior of rigid piers in layered cohesive soils," Journal of Geotechnical Engineering, vol. 104, pp. 1061-1074, 1978.

[11] G. G. Meyerhof and J. I. Adams, "The ultimate uplift capacity of foundation," Canadian Geotechnical Journal, vol. 5, no. 4, pp. 225-244, 1968.

[12] A. Balla, "The resistance to breaking-out of mushroom foundations for pylons," in Proceedings of the 5th International Conference on Soil Mechanics and Foundation Engineering, vol. 1, pp. 569-576, Paris, France, July 1961.

[13] S. P. Clemence and C. J. Veesaert, "Dynamic uplift resistance of anchors in sand," in Proceedings of the International Conference on Soil-Structure Interaction, pp. 389-397, Roorkee, India, January 1977.

[14] R. K. Rowe and E. H. Davis, "The behaviour of anchor plates in sand," Géotechnique, vol. 32, no. 1, pp. 25-41, 1982.

[15] E. J. Murray and J. D. Geddes, "Uplift of anchor plates in sand," Journal of Geotechnical Engineering, vol. 113, no. 3, pp. 202-215, 1987.

[16] N. R. Krishnaswamy and S. P. Parashar, "Uplift behaviour of plate anchors with geosynthetics," Geotextiles and Geomembranes, vol. 13, no. 2, pp. 67-89, 1994.

[17] E. A. Dickin and M. Laman, "Uplift response of strip anchors in cohesionless soil," Advances in engineering software, vol. 38, no. 8-9, pp. 618-625, 2007.

[18] L. Vanitha, N. R. Patra, and S. Chandra, "Uplift capacity of pile group anchors," Geotechnical and Geological Engineering, vol. 25, no. 3, pp. 339-347, 2007.

[19] S. Mittal and S. Mukherjee, "Vertical uplift capacity of a group of helical screw anchors in sand," Indian Geotechnical Journal, vol. 43, no. 3, pp. 238-250, 2013.

[20] E. R. Sujatha and R. Balamuruga, "Pullout behavoiur of circular plate anchor in sand: a small scale investigation," Asian Journal of Applied Sciences, vol. 7, no. 6, pp. 424-432, 2014.

[21] A. Bouazza and T. W. Finlay, "Uplift capacity of plate anchors buried in a two-layered sand," Géotechnique, vol. 40, no. 2, pp. 293-297, 1990.

[22] J. Kumar, "Uplift resistance of strip and circular anchors in a two layered sand," Soils and Foundations, vol. 43, no. 1, pp. 101-107, 2003.

[23] T. Sakai and T. Tanaka, "Experimental and numerical study of uplift behaviour of shallow circular anchor in two layered sand," Journal of Geotechnical and Geoenvironmental Engineering, vol. 133, no. 4, pp. 469-477, 1985.

[24] M. Matsuo, "Study on the uplift resistance of footing (I)," Soils and Foundations, vol. 7, no. 4, pp. 1-37, 1967.

[25] K. S. S. Rao and J. Kumar, "Vertical uplift capacity of horizontal anchors," Journal of Geotechnical Engineering, vol. 120, no. 7, pp. 1134-1147, 1994.

[26] B. C. Chottapadhyay and P. J. Pise, "Breakout resistance of horizontal anchors in sand," Japanese Society of Soil Mechanics and Foundation Engineering, vol. 26, no. 4, pp. 16-26, 1986.

[27] H. S. Saeedy, "Stability of circular vertical earth anchors," Canadian Geotechnical Journal, vol. 24, no. 3, pp. 452-456, 1987. 
[28] B. Sutherlanhd, W. Flnlay, and M. O. Fadl, "Uplift capacity of embedded anchors in sand," in Proceedings of the $3 \mathrm{rd}$ International Conference on the Behaviour of Offshore Structures, vol. 2, pp. 451-463, Cambridge, MA, USA, 1889.

[29] P. A. Vermeer and W. Sutjiadi, "The uplift resistance of shallow embedded anchors," in Proceedings of the 11th International Conference on Soil Mechanics and Foundation Engineering, vol. 4, pp. 1635-1638, San Francisco, CA, USA, 1985.

[30] A. Ghaly, A. Hanna, and M. Hanna, "Uplift behavior of screw anchors in sand. I: dry sand," Journal of Geotechnical Engineering, vol. 117, no. 5, pp. 773-793, 1991.

[31] S. Saran, G. Ranjan, and A. S. Nene, "Soil anchors and constitutive laws," Journal of Geotechnical Engineering, vol. 112, no. 12, pp. 1084-1100, 1986.

[32] K. Ilamparuthi and K. Muthukrishnaiah, "Anchors in sand bed: delineation of rupture surface," Ocean Engineering, vol. 26, no. 12, pp. 1249-1273, 1999.

[33] K. Ilamparuthi, E. A. Dickin, and K. Muthukrisnaiah, "Experimental investigation of the uplift behaviour of circular plate anchors embedded in sand," Canadian Geotechnical Journal, vol. 39, no. 3, pp. 648-664, 2002.

[34] T. Deb and S. K. Pal, "Study on the uplift behaviour and failure pattern of single belled anchor with $3 \mathrm{D}$ and $2 \mathrm{D}$ models in cohesionless soil bed," Iranian Journal of Science and Technology Transaction in Civil Engineering, 2018.

[35] W. Stewart, "Uplift capacity of circular plate anchors in layered soil," Canadian Geotechnical Journal, vol. 22, no. 4, pp. 589-592, 1985.

[36] K. Ilamparuthi and E. A. Dickin, "Predictions of the uplift response of model belled piles in geogrid-cell-reinforced sand," Geotextiles and Geomembranes, vol. 19, no. 2, pp. 89-109, 2001.

[37] N. R. Draper and H. Smith, Applied Regression Analysis, John Wiley and Sons, New York, NY, USA, 1998.

[38] L. Wenbai, Z. Jian, and M. T. Mohr, "Uplift bearing tests and calculations of belled piles in loess of arid regions," in Proceedings of Fifth International Conference on Case Histories in Geotechnical Engineering, pp. 13-17, New York, NY, USA, April 2004.

[39] D. Chae, W. Cho, and Y. H. Na, "Uplift capacity of belled pile in weathered sandstones," International Society of Offshore and Polar Engineers, vol. 22, no. 4, pp. 297-305, 2012. 


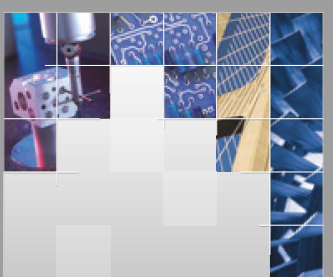

\section{Enfincering}
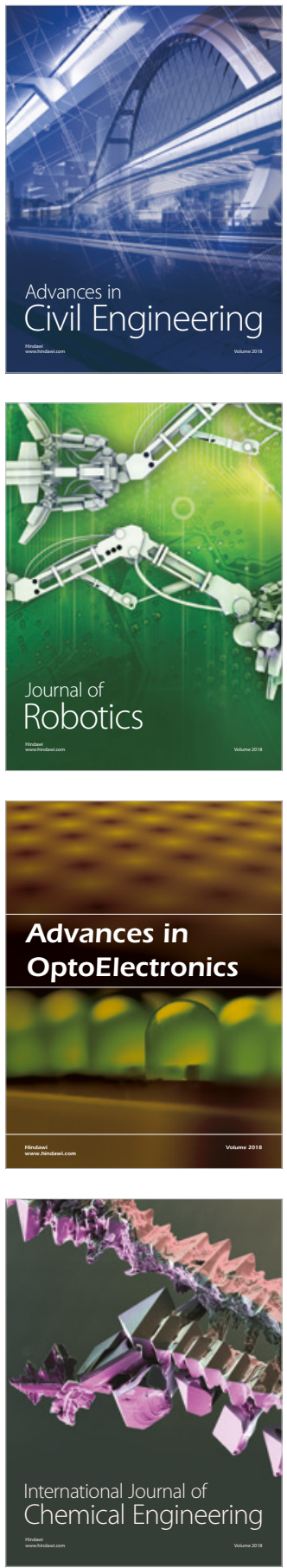

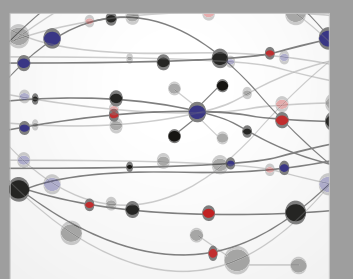

\section{Rotating \\ Machinery}

The Scientific World Journal

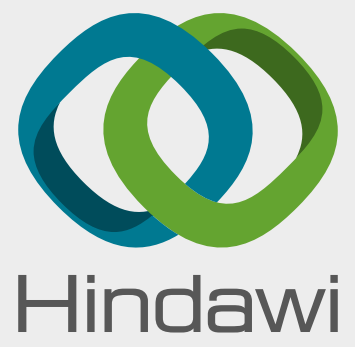

Submit your manuscripts at

www.hindawi.com
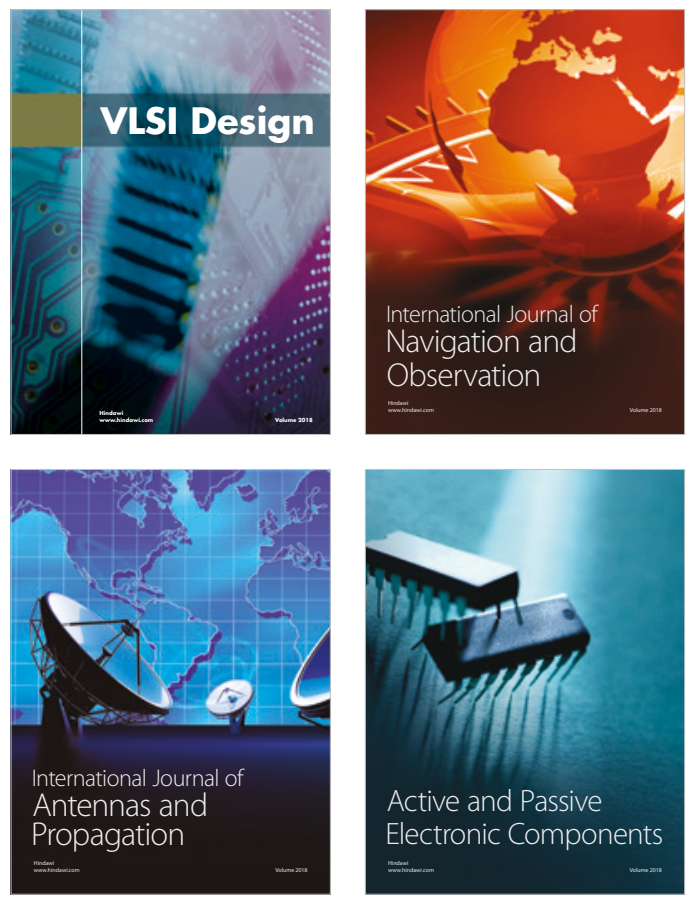
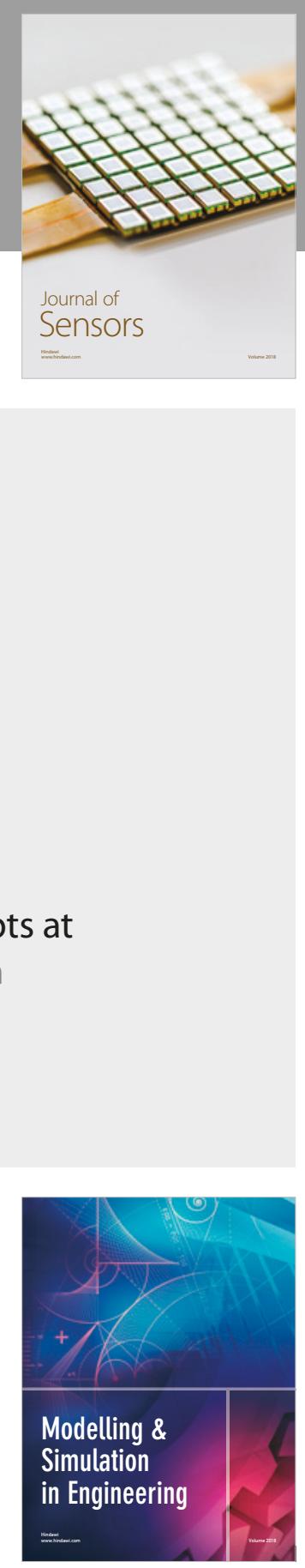

\section{Advances \\ Multimedia}
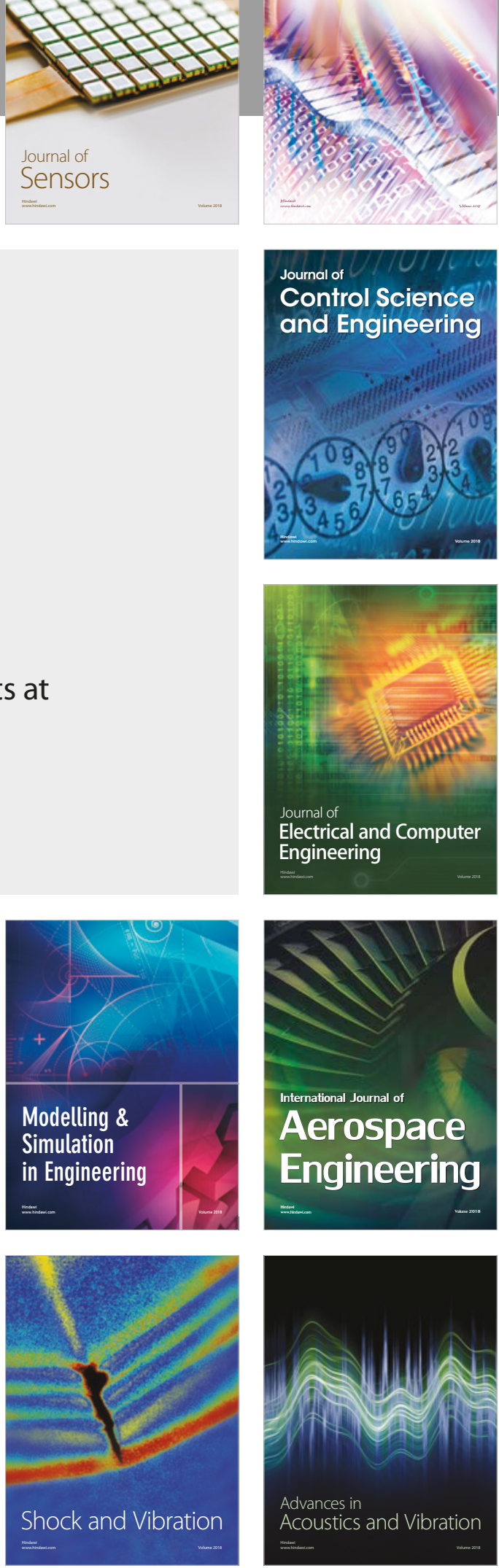